\author{
Universidade de São Paulo \\ Instituto de Física de São Carlos
}

Fernando Wellysson de Alencar Sobreira

\title{
Correlações fortes em nanoplasmônica
}

São Carlos

2016 

Fernando Wellysson de Alencar Sobreira

\section{Correlações fortes em nanoplasmônica}

Tese apresentada ao Programa de Pósgraduação em Física do Instituto de Física de São Carlos da Universidade de São Paulo, para obtenção do título de Doutor em Ciências.

Área de Concentração: Física Básica

Orientador: Prof. Dr. Euclydes Marega Jr.

Co-orientador: Prof. Dr. Rodrigo Gonçalves Pereira

\section{Versão Corrigida}

(Versão original disponível na Unidade que aloja o Programa)

\section{São Carlos}


AUTORIZO A REPRODUÇÃO E DIVULGAÇÃO TOTAL OU PARCIAL DESTE TRABALHO, POR QUALQÜER MEIO CONVENCIONAL OU ELETRÔNICO PARA FINS DE ESTUDO E PESQUISA, DESDE QUE CITADA A FONTE.

Ficha catalográfica revisada pelo Serviço de Biblioteca e Informação do IFSC, com os dados fornecidos pelo(a) autor(a)

Sobreira, Fernando Wellysson de Alencar

Correlações fortes em nanoplasmônica / Fernando Wellysson de Alencar Sobreira; orientador Euclydes Marega Júnior; co-orientador Rodrigo Gonçalves Pereira - versão corrigida -- São Carlos, 2016. $150 \mathrm{p}$.

Tese (Doutorado - Programa de Pós-Graduação em Física Básica) -- Instituto de Física de São Carlos, Universidade de São Paulo, 2016.

1. Plasmônica. 2. Correlações fortes. 3. Pontos quânticos. I. Marega Júnior, Euclydes, orient. II. Pereira, Rodrigo Gonçalves, co-orient. III. Título. 
$\grave{A}$ minha querida

Maria Luiza. 



\section{AGRADECIMENTOS}

Foi com o apoio do Prof. Dr. Euclydes Marega Jr. que tive a certeza de que a carreira na Física seria o meu caminho. Através das Olimpíadas de Física, onde conheci seu trabalho e caráter que me encontrei. A minha estada em São Carlos foi sem dúvida mais fácil pela sua presença constante. Após longas discussões, aqui está o sinal de meu maior agradecimento, a conclusão desse trabalho que não seria possível sem a sua orientação.

Outro apoio importante e sem dúvida imprescindível foi a co-orientação do Prof. Dr. Rodrigo Gonçalves Pereira. Essa pessoa que me fez acreditar ainda mais que a ciência no nosso país está em boas mãos, e com o qual eu aprendi tanto que sempre que penso em alguma coisa faço a reflexão: O que o Rodrigo ia pensar se falasse isso?

Reconheço ainda o apoio dado pelos técnicos de laboratório: Carlos Alberto e Haroldo Arakaki. Além da Neusa que fez parecer mais suave o trabalho de colocar esta tese no padrão incansavelmente variável da biblioteca e do Ítalo que sempre foi muito solicito em todo o meu doutorado.

Aos meus colegas de grupo: Otávio, Fábio, Victor, Sérgio e Rafael.

Também não posso esquecer dos professores com os quais eu trabalhei nas monitorias, Prof. Dr. Miled Hassan Youssef Moussa e Prof. Dr. Frederico Borges de Brito, pelos quais guardo profunda admiração.

Eu quero deixar um agradecimento para a minha família, em especial aos meus irmãos: Fernanda, Fernando e Wesley. Um agradecimento também à Silvana pelo apoio durante a tese: obrigado pelas coxinhas!

Minhas palavras não seriam suficientes para agradecer todo o apoio dado pela Maria Luiza e pela Ninoca, então deixo meu agradecimento na singela palavra: Obrigado.

Em todos esses anos de estudo as figuras que mais me incentivaram, desde sempre foram sem dúvidas: minha mãe e a tia Izete. Obrigado por tudo o que vocês fizeram por mim em todos esses anos. Amo vocês!

Retribuo aqui o apoio financeiro dado pelas agências de fomento: Conselho Nacional de Desenvolvimento Científico e Tecnológico (CNPq), à Fundação de Amparo à Pesquisa do Estado de São Paulo (FAPESP) e à Coordenação de Aperfeiçoamento de Pessoal de Nível Superior (CAPES). 

"O nordestino é bom por isso,

a gente nasce,

e se não morre até cinco anos de idade

cria um couro tão duro

que não tem nada que a gente não possa fazer."

Luis Inácio Lula da Silva

"De tanto ver triunfar as nulidades, de tanto ver prosperar a desonra, de tanto ver crescer a injustiça, de tanto ver agigantarem-se os poderes nas mãos dos maus, o homem chega a desanimar da virtude, a rir-se da honra, a ter vergonha de ser honesto."

Rui Barbosa

"Tatu não sobe em toco."

Ciro Gomes 



\section{RESUMO}

SOBREIRA, F.W.A. Correlações fortes em nanoplasmônica. 2016. 150 p. Tese (Doutorado em Ciências) - Instituto de Física de São Carlos, Universidade de São Paulo, São Carlos, 2016.

A plasmônica tem chamado atenção nos últimos anos como um candidato viável para substituir a indústria eletrônica, assim como interação dos plásmons com a matéria devido a suas propriedades exóticas. O confinamento destes plásmons de superfície em nanoestruturas metálicas fabricadas com técnicas de litografia óptica, eletrônica e de íons cada vez mais avançadas, abriu a possibilidade de desenvolver vários modelos de dispositivos ópticos que trabalham na região do visível. Além disso, o estudo da interação de plásmons poláritons de superfície com emissores quânticos nas proximidades de nanoestruturas metálicas permite manipular as propriedades tanto dos plásmons como dos emissores quânticos. Tanto a preparação como a análise de amostras em plasmônica necessitam de técnicas capazes de investigar sistemas em nanoescala. Neste trabalho, investigamos a interação de plásmon poláritons confinados numa superfície de ouro com átomos artificias, i.e. os emissores quânticos são pontos quânticos numa matriz de InAs/GaAs. Para isso, empregamos a análise da interação dos plásmons confinados numa grade metálica, com dimensões características abaixo do comprimento de onda da luz utilizada, assim como um sistema simples composto por uma fina camada de ouro capaz de confinar plásmons em duas dimensões. A análise da interação com os estados de energia dos éxcitons nos pontos quânticos foi feita empregando medidas de micro-fotoluminescência a 77K e medidas de tempo de vida. Nos sistemas compostos pelas grades metálicas, observamos que é possível manipular a relação do espectro de luminescência correspondente a cada estado de energia do éxciton. Já no sistema composto pelo filme metálico simples, foi possível modificar o tempo de vida do estado fundamental do éxciton apenas modificando o cap layer da camada de pontos quânticos.

Palavras-chave: Plasmônica. Correlações fortes. Pontos quânticos. 



\begin{abstract}
SOBREIRA, F.W.A. Strong correlations in nanoplasmonics. 2016. 150 p. Tese (Doutorado em Ciências) - Instituto de Física de São Carlos, Universidade de São Paulo, São Carlos, 2016.
\end{abstract}

Plasmonics has drawn attention in recent years as a viable candidate to replace the electronics industry, as well as the interaction of plasmons with matter due to its exotic properties. The confinement of these surface plasmons in metal nanostructures made of increasingly advanced optical, electronic and ionic lithography techniques, opened the possibility of developing various models of optical devices working in the visible spectrum. Moreover, the study of interaction of surface plasmon polaritons with quantum emitters nearby metallic nanostructures opens a path to manipulate the properties of both plasmons and the quantum emitters. Both the preparation and analysis of samples in plasmonics require techniques capable of investigating nanoscale systems. In this thesis, we investigate the interaction of plasmon polaritons confined to a golden metallic surface with artificial atoms, i.e. quantum emitters consisting of quantum dots in a matrix of InAs/GaAs. For this, we used the analysis of the interaction of plasmons confined in a metallic grating with characteristic dimensions below the wavelength of light used, as well as a simple system composed of a thin gold layer which can confine plasmons in two dimensions. The analysis of the interaction with the exciton energy states in quantum dots was made using micro-photoluminescence measurements at $77 \mathrm{~K}$ and lifetime measurements. In systems composed by metal gratings, we note that it is possible to manipulate the relationship of the corresponding luminescence spectrum for each exciton energy state. In the system composed of the simple metal film, it was possible to modify the ground state lifetime of the exciton only modifying the cap layer of the quantum dot layer.

Keywords: Plasmonics. Strong correlations. Quantum dots. 



\section{Lista de Figuras}

Figura 1 - Comparação entre as dimensões críticas e a velocidade de operação de dispositivos eletrônicos e seus proeminentes sucessores. . . . . . .

Figura 2 - Cálice de Licurgo. Um exemplo famoso de que a presença de SPPs (localizados) pode alterar drasticamente as propriedades ópticas de um meio. . . . . . . . . . . . . . . . . . . 30

Figura 3 - Intensidade da luz transmitida através de orifícios circulares fabricados sobre um filme de Ag como função do comprimento de onda da luz incidente. Na figura $a_{0}$ é o parâmetro de rede da grade. . . . 31

Figura 4 - Cadeia regular de QDs interagindo com SPPs num guia de onda cilíndrico.

Figura 5 - Grade metálica onde são suportados modos de SPPs capazes de interagir com QDs na matriz semicondutora. . . . . . . . . .

Figura 6 - Modelo de Drude para a constante dielétrica $\varepsilon_{\text {metal }}$ do Au e da Ag. Os valores experimentais obtidos por (1) estão indicados pelos pontos enquanto as linhas contínuas indicam um fitting para os dados considerando os melhores parâmetros que se adequam aos valores experimentais utilizando o modelo de Drude. . . . . . . . . . . 38

Figura 7 - Modelo de propagação de um SPP no guia plano. . . . . . . . . . 41

Figura 8 - Curva de dispersão dos SPPs na geometria plana, utilizando-se o ouro como metal e o GaAs como dielétrico, onde $\varepsilon_{d} \sim 13,1$. A frequência $\omega_{p}$ é a frequência de plasma do ouro. . . . . . . . . . . . 44

Figura 9 - Origem do cruzamento da dispersão da luz com os SPPs através do uso de um meio de acoplamento. . . . . . . . . . . . . . . . 46

Figura 10 - Geometrias de acoplamento da luz com um SPP através de um prisma. 47

Figura 11 - Acoplamento da luz com SPP através do método do casamento de

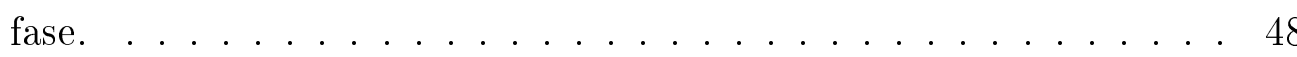

Figura 12 - Diagramas do modelo de SPPs adotado teoricamente e de um modelo experimental. . . . . . . . . . . . . . . . 51 
Figura 13 - Perfil do campo eletromagnético em nanofios metálicos com 100nm de raio e com energia correspondente a $1,1 \mathrm{eV}$. Somente a componente $B_{\phi}$ do campo magnético é não nula, indicando um modo transversal magnético puro. . . . . . . . . . . . . . 54

Figura 14 - Dispersão $\omega \times \beta$ para um fio metálico imerso em GaAs, para os valores calculados com a condição de contorno dada pela eq. (12) e pela quantização expressa na eq. (24). A linha horizontal indica a energia de um ponto quântico. Em ambos os casos foi utilizanddo um fio com 100nm de raio. . . . . . . . . . . . 56

Figura 15 - Perfil do campo eletromagnético para os modos excitados de um SPP num guia de ouro de 100nm de raio e com energia correspondente a $1,1 \mathrm{eV}$ envolto por GaAs. . . . . . . . . . . . 57

Figura 16 - Curva de dispersão para os modos fundamental e primeiros excitados para um nanofio metálico imerso em GaAs. As linhas indicam a dispersão de cada um dos modos. A linha horizontal indica a energia de um QD com 1, 1eV. A linha pontilhada em verde indica a dispersão linear da luz no semicondutor. . . . . . . . . . . 58

Figura 17 - Comparação entre o comprimento de propagação $L_{s p p}$ de um SPP num guia cilíndrico com 100nm de raio para fios de Au e Ag imersos em uma matriz de GaAs. . . . . . . . . . . . . . . . 61

Figura 18 - Comprimento de penetração $\delta$ do campo do SPP para uma interface plana entre metal/GaAs como função do vetor de propagação $\beta$. As curvas mostradas são correspondentes ao Au (vermelho) e à Ag (azul). 64

Figura 19 - Comprimento de penetração $\delta$ do campo do SPP para um guia cilíndrico metal/GaAs com 100nm de raio como função do vetor de propagação $\beta$. As curvas mostradas são correspondentes ao Au (azul) e à $\mathrm{Ag}$ (vermelho). . . . . . . . . . . . . . 65

Figura 20 - Dependência do comprimento de onda de ressonância de um LSPP como função de sua geometria 20(a) e de suas dimensões 20(b). . . . 65 
Figura 21 - Diagrama de funcionamento básico de um sistema de MBE indicando em (a) as câmaras de efusão que contêm os materiais a serem depositados no substrato semicondutor, bem como o RHEED utilizado para acompanhar o processo de deposição. Em (b) é mostrado o processo de deposição do material sobre o substrato indicando a formação de camadas atômicas bem definidas. . . . . . . . . . . 68

Figura 22 - Diagramas indicando os processos de excitação (a) e formação (b)

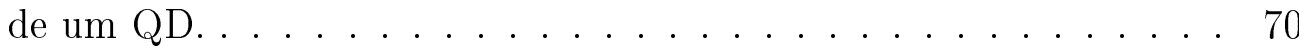

Figura 23 - Esquema indicando os poços quânticos utilizados para a modelagem de QDs crescidos pelo método do CEO. . . . . . . . . . . . 72

Figura 24 - Espectro normalizado dos níveis de energia dos QDs de InAs obtidos utilizando-se de espectroscopia de fotoluminescência. . . . . . . . . . 74

Figura 25 - Diagrama de um poço quântico de GaAs $/ \mathrm{Ga}_{1-x} \mathrm{Al}_{x} \mathrm{As}$ para exemplificar o procedimento de confinamento do elétron numa nanoestrutura quântica. . . . . . . . . . . . . . . . . 75

Figura 26 - Densidade de estados para um elétron confinado em diversas estruturas como função da dimensionalidade do sistema. . . . . . . . . . 76

Figura 27 - Diagrama esquemático da interação de uma cadeia de QD com SPPs suportados num nanofio metálico. A distância entre a cadeia e o nanofio é $r_{q d}$ e o parâmetro de rede da cadeia de QDs é $a_{l} . \ldots \ldots$

Figura 28 - Módulo do fator de acoplamento $\left|g_{\beta}\right|$ entre os QDs e os SPPs num nanofio metálico de ouro com raio de 100nm. No gráfico está indicada a distância do QD até a superfície do fio metálico bem como o valor da constante de acoplamento. No modelo, consideramos que há várias camadas de QDs na matriz semicondutora. . . . . . . . 81

Figura 29 - Fator de acoplamento $g$ para uma camada de J-aggregates com espessura $\mathcal{W}$ colocada a uma distância $s$ de um filme metálico. A densidade de nanopartículas da camada dopada é $n=10^{6} / \mu \mathrm{m}^{-3} \ldots$.

Figura 30 - Anti-cruzamento entre os níveis de energia dos SPPs confinados num plano metálico interagindo com J-aggregates. . . . . . . . . . . 85 
Figura 31 - Anti-cruzamento entre os níveis de energia dos SPPs confinados num nanofio metálico de $\mathrm{Au}$ interagindo com éxcitons numa cadeia com 1QD $/ \mu \mathrm{m}$. A amostra de QDs é composta por 5 camadas de cadeias umas sobre as outras. . . . . . . . . . . . . . 86

Figura 32 - Modelo de bandas plamônicas induzidas pela presença de um potencial artificial gerado por uma cadeia de átomos. O parâmetro de rede considerado é $a_{l}=150 \mathrm{~nm}$ e a distância entre a superfície do nanofio e a cadeia é $250 \mathrm{~nm}$. O fator de acoplamento considerado é 10 vezes maior que o fator para um QD simples. . . . . . . . . 89

Figura 33 - AFM de uma amostra típica de QDs auto-organizados. . . . . . . 96

Figura 34 - Diagrama esquemático indicando a deposição de um filmo fino sobre uma amostra (sample) através da evaporação de um metal sólido (evaporating source) contido num cadinho (crucible) de molibdênio ou tungstênio. . . . . . . . . . . . . . . . . 97

Figura 35 - Transmissão de luz através de filmes finos de Au depositados sobre uma superfície de vidro. As espessuras dos filmes estão mostradas

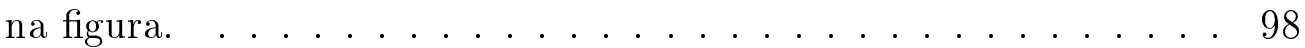

Figura 36 - Etapas da litografia por feixe de elétrons. (a) Deposição do photoresist. (b) Exposição do resist ao feixe de elétrons, alterando suas propriedades químicas. (c) Remoção da parte exposta do resist através de um ataque qúimico. (d) Deposição do metal. (e) Remoção dos excessos de resist e metal com um ataque químico mais violento (lift off $) \ldots \ldots \ldots \ldots \ldots \ldots$

Figura 37 - Diagrama esquemático de um sistema composto por dois feixes, eletrônico e de íons. . . . . . . . . . . . . . . . . . . 101

Figura 38 - Diagrama esquemático dos modos de funcionamento de um microscópio por feixe de íons. . . . . . . . . . . . . . . . . . . 102

Figura 39 - Penetração dos feixes de litografia em uma amostra cristalina e exemplo de um estrutura capaz de ser produzida num FIB. . . . . . 103 
Figura 40 - Conjunto de grades metálicas fabricadas com o feixe de íons sobre a superfície do $\mathrm{Au}$, com diferentes parâmetros de fabricação, a serem analisadas utilizando espectroscopia Raman para determinar os parâmetros ótimos de calibragem do sistema de fabricação. . . . . . 106

Figura 41 - Espectro de micro-Raman para amostras fabricadas usando o feixe de íons. As grades metálicas produzidas possuem diferentes parâmetros de fabrização. As medidas foram feitas utilizando o laser nos modos TE e TM. Os dados apresentados aqui são obtidos com a mesma polarização dos feixes de entrada e saída. . . . . . . . . . 108

Figura 42 - Espectro de micro-Raman para uma amostra de período 500nm e fendas de largura 50nm. As curvas indicam a resposta do sistema com feixes de entrada com polarização indicada por "In" e coleta da resposta na polarização indicada por "Out". . . . . . . . . . . . . 109

Figura 43 - Aumento do espectro de fotoluminescência de uma amostra de QDs na presença de um conjunto de nanoesferas metálicas de ouro. A amostra possui um cap layer (distância entre a camada de QDs e a interface com o ar) de 50nm. As medidas foram realizadas a 7K. . . 110

Figura 44 - Espectro de fotoluminescência, normalizado para a unidade, de uma amostra de pontos quânticos empilhados, como na fig. 5, sob uma grade metálica. A potência do laser utilizado é 90mW em todas. . . 111

Figura 45 - Modelo do conjunto de camadas com QDs que interage com a grade plasmônica. O objetivo de produzir uma amostra com várias camadas é aumentar a densidade de QDs e, por consequência, aumentar o fator de acoplamento. . . . . . . . . . . . . . . 114 
Figura 46 - Imagem de microscopia eletrônica de uma rede plasmônica fabricada utilizando FIB sobre um filme de ouro com 120nm de espessura depositado sobre uma superfície de GaAs. As posições numeradas de $P_{1-4}$ representam as posições onde o espectro de PL da amostra foi obtido. O foco do laser utilizado nas medidas estava sobre a superfície da amostra. A figura mostra ainda uma imagem de seção transversal do padrão fabricado. As fendas possuem 100nm de largura, $10 \mu \mathrm{m}$ de comprimento e estão espaçadas de 400nm. . . . . 115

Figura 47 - Sinal integrado de PL para a rede plasmônica para os lasers de 633nm (linha vermelha) e 785nm (linha azul pontilhada). O sinal máximo foi normalizado para ambos os lasers e foi atingido quando o foco dos mesmos estava entre $30 \mu \mathrm{m}$ e $40 \mu \mathrm{m}$ acima da superfície da $\operatorname{amostra}(z<0 \mu \mathrm{m})$, a posição $z=0 \mu \mathrm{m}$ corresponde ao foco do laser sobre a superfície da amostra. Os pontos experimentais estão conectados por segmentos de reta que servem como guia de olho. Veja a fig. 48 para o sinal de PL. . . . . . . . . . . 116

Figura 48 - Comparativo entre os sinais de PL para uma amostra de QDs abaixo de uma estrutura metálica fabricada em Au com 400nm de período e fendas com largura de 100nm. . . . . . . . . . . 117

Figura 49 - Simulação FDTD para a intensidade total do campo elétrico do SPP sobre a camada de QDs. Os resultados para a incidência do laser nas posições $P_{1}-P_{4}$, dadas na fig. 46 , estão mostradas nas figuras de (a) a (d), respectivamente. Na simulação, o laser de 785nm com perfil gaussiano, com modo TM, foi utilizado. A cintura do feixe utilizado é $2 \mu \mathrm{m}$, assim como no sistema experimental, e os perfis de intensidade foram tomados a 12nm abaixo da interface Au/GaAs. . 118 
Figura 50 - Sinal de PL normalizado para cada um dos pontos $P_{1-4}$ indicados na fig. 46. O laser com $785 \mathrm{~nm}$ de comprimento de onda é focalizado sobre a superfície da amostra em cada uma das posições com intensidade máxima de $530 \times 10^{3} \mathrm{~W} / \mathrm{cm}^{2}$ e polarização TM. A figura anexa mostra o espectro normalizado para a amostra de UQDs com intensidade mínima $\left(0,5 \times 10^{3} \mathrm{~W} / \mathrm{cm}^{2}\right)$ e máxima $\left(530 \times 10^{3} \mathrm{~W} / \mathrm{cm}^{2}\right)$ do feixe laser. . . . . . . . . . . . . . . . . 119

Figura 51 - Sinal de PL normalizado quando o laser de 633nm incide sobre a amostra de UQDs (linhas pontilhadas) ou quando é colocado na posição $P_{1}$ (linha contínua). No espectro são comparados os sinais obtidos quando a intensidade do feixe laser é máxima (high, $120 \times$ $10^{3} \mathrm{~W} / \mathrm{cm}^{2}$ ) e duas ordens de magnitude menor (low, $\left.1,2 \times 10^{3} \mathrm{~W} / \mathrm{cm}^{2}\right) .120$

Figura 52 - Shift de energia induzido pela interação do SPP com um emissor quântico como função da energia $(\omega)$ do emissor. O modelo utilizado é aquele mostrado na fig. 45. . . . . . . . . . . . . . . . 121

Figura 53 - Shift de energia do estado fundamental da amostra de SPPs como função da medida (indireta) de densidade de estados dos SPPs. . . . 122

Figura 54 - Esquema representando a montagem para a medida de fotoluminescência de QDs de InAs em GaAs cobertos (ou não) por um filme de Au de $6 \mathrm{~nm}$ de espessura. A figura ilustra a competição entre o decaimento radiativo e o decaimento em SPPs de um emissor quântico nas proximidades de um filme metálico. . . . . . . . . . . . 123

Figura 55 - Espectro de PL para a amostra com cap layer de 50nm de espessura, medida com potência do laser a $5 \mathrm{~mW}$. O espectro foi obtido no GaAs descoberto (linha preta) e na região coberta com o filme de Au (linha vermelha). O pico em $1,09 \mathrm{eV}$ corresponde ao estado fundamental e os outros aos estados excitados. 
Figura 56 - Medida de TRPL para a amostra com $d=30 \mathrm{~nm}$ de cap layer, a $1 \mathrm{~mW}$ de potência. As medidas são no GaAs descoberto (pontos em preto), sob a camada de Au (pontos em vermelho) e o IRF é mostrado em pontos na cor cinza. . . . . . . . . . . . . . 125

Figura 57 - Tempo de vida do estado fundamental dos QDs extraídos das curvas de TRPL para as amostras com $d=10$ a 50nm de cap layer como função da potência do laser. Os resultados são dados para as regiões sem (a) e com (b) o filme de Au. . . . . . . . . . . . 126

Figura 58 - (a) Fator de acoplamento do SPP como função da energia do QD e da espessura do cap layer. A linha vertical é um guia para o olho indicando a energia do QD em nosso experimento. (b) Razão entre o tempo de vida do estado fundamental do QD na região com $\mathrm{Au}$ e sem $\mathrm{Au}$. As linhas conectando os pontos experimentais foram colocadas como guia de olho. . . . . . . . . . . . 127

Figura 59 - Tempo de vida como função da temperatura medida para fótons coletados com energia de $1,1 \mathrm{eV}$, típico da recombinação do éxciton na amostra de QD com 10nm de cap layer, cujo espectro de PL está mostrado na fig. 24(a). . . . . . . . . . . . . . . 143

Figura 60 - Medidas de tempo de vida como função da temperatura para o estado fundamental dos éxcitons confinados num QD de InAs/GaAs, em torno de $1,1 \mathrm{eV}$. Cada figura indica um valor diferente de cap layer. O esquema experimental utilizado é o mesmo adotado para medidas de tempo de vida a baixas temperaturas e está indicado na fig. 54. . . . . . . . . . . . . . . . 145

Figura 61 - Diagrama da competição entre o potencial de dipolo e o potencial gerado pelos SPPs interagindo com os elétrons no QD. . . . . . 146

Figura 62 - Espectro de PL para uma camada de QDs a 50nm de distância de uma fenda simples fabricada num filme metálico. O comprimento $L$ da fenda está indicado. Os gráficos apresentados estão normalizados e deslocados verticalmente para facilitar a visualização. . . . . . . 150 


\section{Lista de Tabelas}

Tabela 1 - Parâmetros do modelo de Drude utilizados para interpolar as partes real e imaginária da constante dielétrica do Au e da Ag. . . . . . . . 39

Tabela 2 - Parâmetros de fabricação das grades metálicas apresentadas na fig. 40 utilizadas na análise de espectroscopia Raman. Algumas das grades não estão na figura. . . . . . . . . . . . . . 107 



\section{Lista de Abreviaturas}

SPP Plásmon poláriton de superfície

EOT Transmissão óptica extraordinária

QED Eletrodinâmica quântica

$Q D \quad$ ponto quântico

TE $\quad$ Modo transversal elétrico

TM Modo transversal magnético

SNOM Microscopia óptica de campo próximo

LSPP Plásmon de superfície localizado

MBE $\quad$ Epitaxia por feixes moleculares

RHEED Difração de elétrons altamente energéticos

CEO Crescimento sobre bordas clivadas

SK Método de crescimento de Stranski-Krastanov

PL Espectroscopia de Fotoluminescência

RWA Aproximação de ondas girantes

$Z B \quad$ Zona de Brillouin

AFM Microscopia de força atômica

FIB Feixe de íons

SEM Microscopia eletrônica de varredura

LDOS Densidade local de estados

FDTD Método das diferenças finitas no domínio do tempo

TRPL Fotoluminescência resolvida no tempo

IRF Resposta interna do sistema (de TRPL)

PMMA Polimetilmetacrilato

TO Transverse optic phonon

LO Longitudinal optic phonon 



\section{Lista de Símbolos}

$\varepsilon \quad$ Constante dielétrica

$\omega_{p} \quad$ Frequência de plasma

$\tau \quad$ Tempo de relaxação

$E_{i} \quad$ Componente $i$ do campo elétrico

$B_{i} \quad$ Componente $i$ do campo de indução magnética

$\mu \quad$ Permeabilidade magnética relativa

$\beta \quad$ Constante de propagação do SPP

$\vec{A} \quad$ Potencial vetor magnético

$t_{\beta}, m_{\beta}$ Termo cinético da energia do SPP

$v_{\beta} \quad$ Termo de potencial da energia do SPP

L Comprimento de propagação do SPP

$\delta \quad$ Comprimento de penetração do SPP

$\Delta, \omega_{q d}$ Energia (frequência) do QD

$g \quad$ Fator de acoplamento SPP-QD

$\Gamma \quad$ Taxa de decaimento

$\xi \quad$ Susceptibilidade dinâmica 



\section{Conteúdo}

$1 \quad$ Introdução $\ldots \ldots \ldots \ldots \ldots \ldots \ldots$

1.1 Uma ciência de longa data . . . . . . . . . . . . . . 30

$1.2 \quad$ Plasmônica clássica . . . . . . . . . . . . . . . . . 31

1.3 Plasmônica quântica . . . . . . . . . . . . . . . . . . . 32

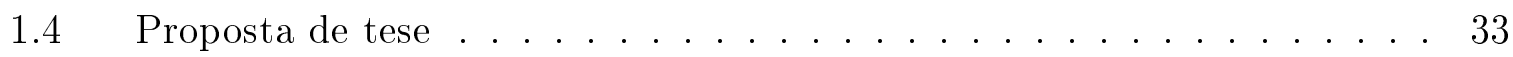

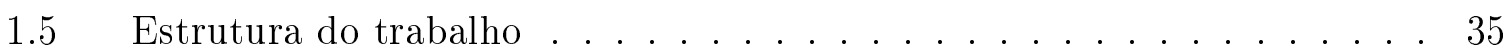

2 Plasmônica: do clássico ao quântico . . . . . . . . . . 37

2.1 Modelo do metal/dielétrico . . . . . . . . . . . . . . . 37

2.2 Plásmon Polaritons de Superfície . . . . . . . . . . . . . . . 40

2.3 Dispersão clássica num guia de ondas plano . . . . . . . . . . . . . . 41

2.4 Acoplamento de luz com SPPs . . . . . . . . . . . . . 45

2.4.1 Acoplamento via prismas . . . . . . . . . . . . . 45

2.4.2 Acoplamento via grades . . . . . . . . . . . . . . . 47

2.5 SPPs em um guia cilíndrico . . . . . . . . . . . . . 49

2.6 Modelo de quantização . . . . . . . . . . . . . . . 53

2.7 Modos excitados e aproximação unidimensional . . . . . . . . . . . 57

$2.8 \quad$ Decaimento dos SPPs . . . . . . . . . . . . . . 59

2.8.1 Efeito das colisões no metal . . . . . . . . . . . . . . . 59

2.8.2 Efeito das rugosidades no metal . . . . . . . . . . . . 61

2.8.3 Consequências no modelo de quantização . . . . . . . . . . . . . . 62

2.9 Plasmons de superfície localizados (LSPPs) . . . . . . . . . . 63

$3 \quad$ Emissores quânticos ..................... 67

$3.1 \quad$ Vidros dopados . . . . . . . . . . . . . . . 67

3.2 Pontos quânticos . . . . . . . . . . . . . . . 68

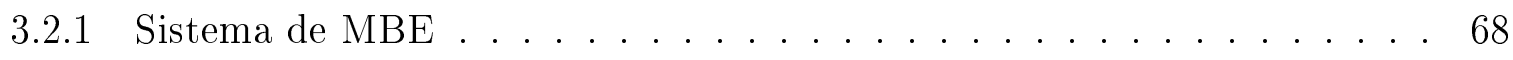

3.2.2 Crescimento de pontos quânticos . . . . . . . . . . . . 69

3.2.3 Propriedades do pontos quânticos . . . . . . . . . . . 73 
3.3 Modelo dos QDs ......................... 74

3.4 Hamiltoniano de interação . . . . . . . . . . . . . . . . . 77

3.4 .1 Fator de acoplamento ....................... 81

3.5 Estados do sistema interagente . . . . . . . . . . . . 83

$3.6 \quad$ Efeito Purcell . . . . . . . . . . . . . . . . 86

3.7 Bandas plasmônicas . . . . . . . . . . . . . . 88

3.8 Teoria de resposta linear . . . . . . . . . . . . . . . 90

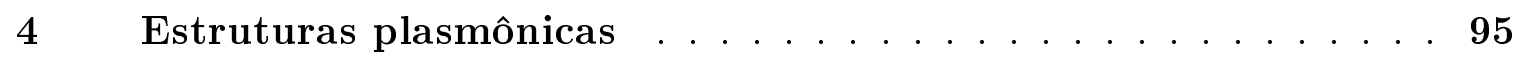

$4.1 \quad$ Preparação das amostras . . . . . . . . . . . . . 95

4.2 Evaporação de filmes finos . . . . . . . . . . . . . . . . 96

4.3 Técnicas de litografia . . . . . . . . . . . . . . . 99

4.3.1 Litografia por feixe de elétrons . . . . . . . . . . . . . . 99

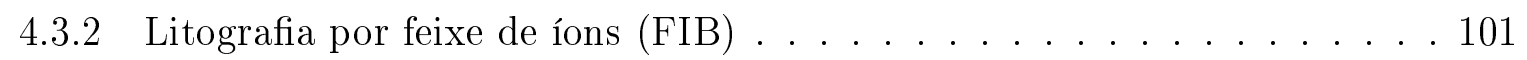

4.4 Amorfização local da amostra . . . . . . . . . . . . . 102

4.5 Deposição de materiais . . . . . . . . . . . . . . . 104

4.6 Caracterização das amostras . . . . . . . . . . . . . . 105

4.6.1 Espectroscopia Raman . . . . . . . . . . . . . . . . . 105

4.6.2 Presença de nanopartículas metálicas (acoplamento fraco) . . . . . . 109

4.6.3 Presença de grades metálicas . . . . . . . . . . . . . . . 110

5 Resultados experimentais em cavidades plasmônicas . . . . . 113

$5.1 \quad$ SPPs numa nanoestrutura metálica . . . . . . . . . . . . . 113

5.2 Modificação no tempo de vida . . . . . . . . . . . . . 122

6 Conclusão . . . . . . . . . . . . . . . . 129

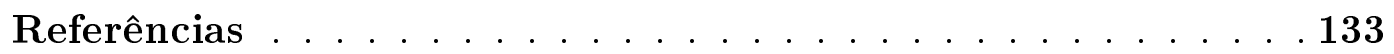

Apêndice A - Medidas de temperatura . . . . . . . . . . 143

Apêndice B - SPPs numa fenda metálica simples . . . . . . . 149 


\section{Introdução}

No fim da década de 90, o ramo da Plasmônica (2) surgiu como um novo ramo da Física capaz de prover soluções reais para sistemas fotônicos e eletrônicos (3), como a redução das dimensões de dispositivos fotônicos e aumento da velocidade de transmissão de dispositivos eletrônicos. Essa nova área baseia-se no estudo e nas aplicações dos Plásmon Poláritons de Superfície (SPP, "Surface Plasmon Polaritons"). (4, 5)

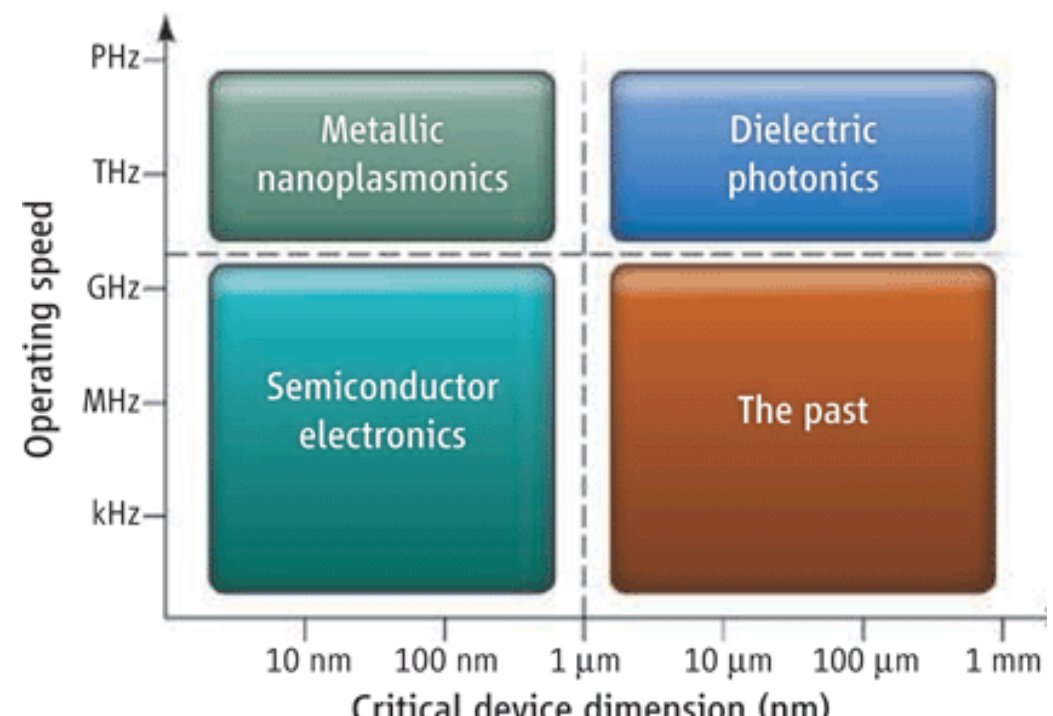

Figura 1 - Comparação entre as dimensões críticas e a velocidade de operação de dispositivos eletrônicos e seus proeminentes sucessores.

Fonte: BRONGERSMA; SHALAEV. (6)

Como pode ser visto na fig. 1, a eletrônica baseada em circuitos de semicondutores tem limitação na frequência de operação dos dispositivos, enquanto a área de fotônica, que utiliza luz, está limitada pelas dimensões físicas de seus dispositivos. A área de plasmônica, por sua vez, agrega o potencial da fotônica por ser capaz de produzir dispositivos que trabalham em regime óptico, além de ter o potencial para o desenvolvimento de dispositivos cada vez menores, já que trabalha abaixo do limite de difração da luz.

Em contraste aos Plásmons de Bulk (7) presentes num metal e resultado das oscilações de carga que se propagam através do mesmo (modos volumétricos), os SPPs consistem de densidades de carga eletrônicas acopladas à luz e capazes de se propagar na interface entre um metal e um dielétrico (modos superficiais). 


\subsection{Uma ciência de longa data}

Mesmo há muitos séculos, são empregadas nanopartículas metálicas na fabricação de peças de artesanato, como pode ser visto na fig. 2, onde o cálice de Licurgo (8) é uma peça capaz de mudar de coloração ao ser iluminada de diferentes posições. Esta peça data do século IV A.C. e é devida ao império romano. O mecanismo que dá a coloração à famosa peça é baseado na presença de nanopartículas metálicas de ouro e prata, numa proporção que até hoje permanece desconhecida. A fig. 2 indica a coloração da peça (esverdeada) sob iluminação ambiente à esquerda e quando é iluminada pelo seu interior à direita (avermelhada).

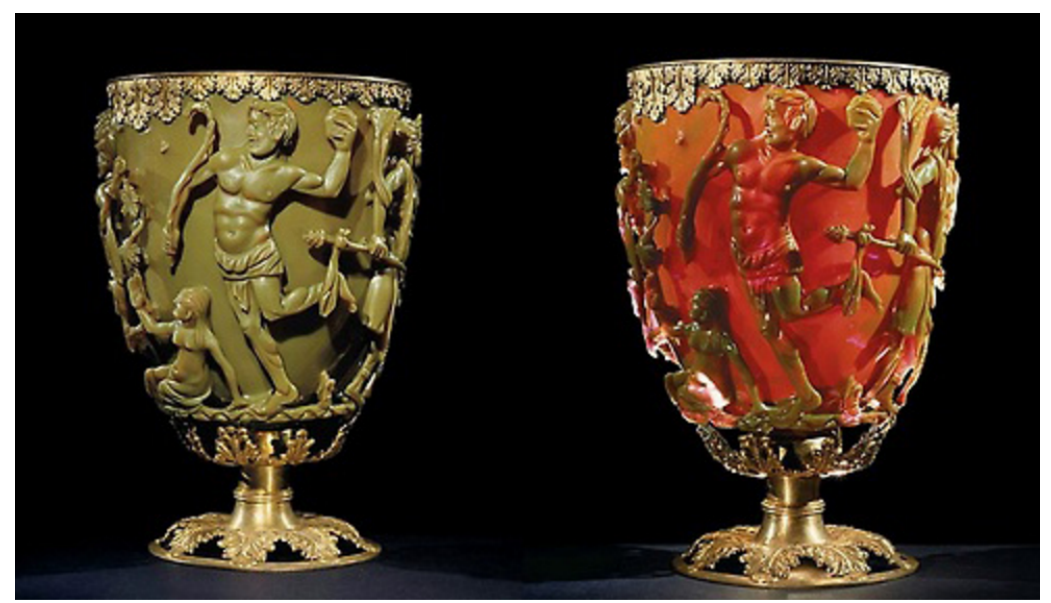

Figura 2 - Cálice de Licurgo. Um exemplo famoso de que a presença de SPPs (localizados) pode alterar drasticamente as propriedades ópticas de um meio.

Fonte: BARCHIESI. (8)

Além da utilização em peças de decoração, o estudo de ondas que se propagavam na interface entre dois meios foi inicialmente realizado em 1907 por J. Zenneck (9) e em 1909 por A. Sommerfeld. (10) Eles estudaram, entre outros, os efeitos de propagação de ondas eletromagnéticas para além do horizonte, com o objetivo de explicar a transmissão de ondas de rádio através da superfície da água. A solução para essa propagação, explicada parcialmente pela camada de Kennelli-Heaviside (a ionosfera), foi tida como uma das mais famosas controvérsias do século passado.

As ondas de Sommerfeld-Zenneck, ondas de superfície na região das ondas de rádio, enquanto o termo SPPs é utilizado para o regime óptico. No entanto, apesar da diferença entre as terminologias, a ideia por trás de ambas é a propagação de uma onda eletromagnética na interface entre um metal e um dielétrico. 


\subsection{Plasmônica clássica}

O divisor de águas sobre a investigação dessas densidades superficiais de carga ocorreu no fim da década de 90, devido a um trabalho publicado por Ebbesen. (11) Nesse trabalho, foi apresentada uma transmissão extraordinária de luz (EOT, "Extraordinary optical transmission") através de um conjunto de fendas circulares presentes num filme metálico de prata cujos diâmetros eram menores do que o comprimento de onda da luz incidente, conforme mostra a fig. 3. Esses resultados trouxeram novamente atenção às ondas de superfície capazes de se propagar na interface entre dois meios.

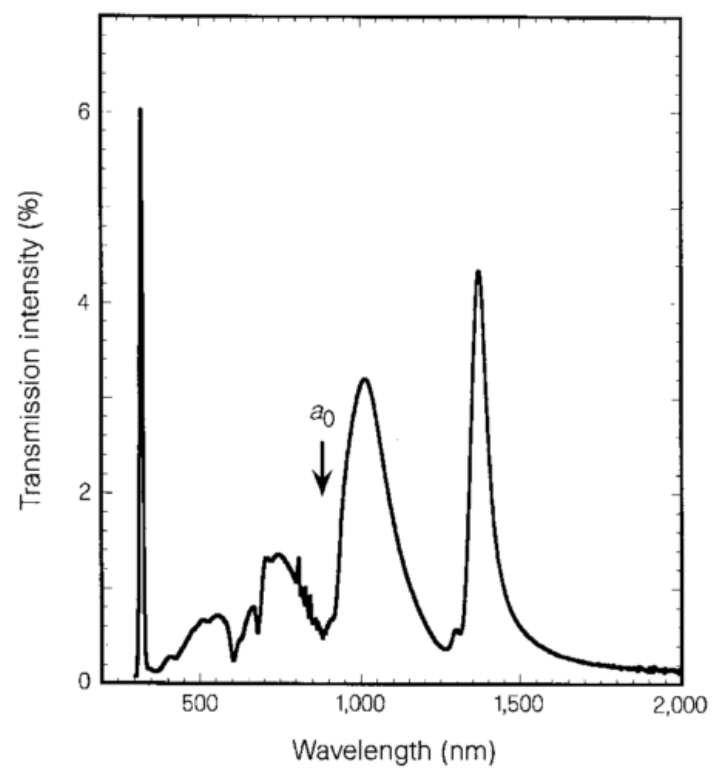

Figura 3 - Intensidade da luz transmitida através de orifícios circulares fabricados sobre um filme de Ag como função do comprimento de onda da luz incidente. Na figura $a_{0}$ é o parâmetro de rede da grade.

Fonte: EBBESEN et. al. (11)

Os resultados obtidos por Ebbesen não concordavam com as previsões teóricas de Bethe (12), baseadas na difração de luz por pequenas aberturas, que indicavam que a transmissão da luz deveria cair com a quarta potência do comprimento de onda da luz utilizada $\left(\lambda^{-4}\right)$. No modelo de Bethe não era levada em consideração a existência dos SPPs, que são a explicação para a existência da EOT.

Vale ressaltar que o termo "extraordinária" indica apenas que a transmissão é algumas ordens de grandeza superior àquela esperada por um modelo teórico que não leva em consideração a existência dos SPPs. No entanto, essa transmissão ainda é muito baixa quando comparada à intensidade da luz que seria obtida sem a presença de obstáculos. 
Com o objetivo de tornar a área de plasmônica um sucessor viável da indústria eletrônica e seguindo o mesmo caminho adotado por Ebbesen para explorar as características básicas dos SPPs no sentido de manipular propriedades fundamentais da interação com a matéria, vários trabalhos foram publicados para guiar a luz em dimensões abaixo do limite de difração $(13,14)$ ou mesmo produzir redes ópticas capazes de aprisionar átomos frios. (15)

Essas ideias, aliadas ao domínio de novas técnicas de litografia como aquelas baseadas em feixes de elétrons (16) ou de íons (17), capazes de fabricar estruturas em nanoescala, tornaram a atenção aos SPPs ainda mais intensa.

Nessa "segunda geração" do estudo dos SPPs, principalmente na última década, muito têm sido feito para explorar suas propriedades exóticas; como a capacidade de gerar dispositivos metamateriais (18) ou mesmo utilizando-se de suas propriedades quânticas, e assim aplicar os SPPs em modelos para comunicação quântica. (19)

\subsection{Plasmônica quântica}

Além de confinar a luz em regiões pequenas os SPPs têm, conforme será demonstrado, a propriedade de gerar altos campos eletromagnéticos, o que propõe sua utilização para modelar cavidades ópticas que podem interagir fortemente com a matéria em seu entorno.

Ainda mais recente é a atenção que tem se voltado para o estudo dos SPPs como excitações quantizadas sobre estruturas metálicas. $(19,20)$ Neste sentido, é possivel investigar a interação de SPPs com a matéria da mesma forma que tem sido feito com cavidades de microondas (21) e cavidades fotônicas. (22)

Já foi demonstrado utilizando eletrodinâmica quântica (QED, "Quantum Electrodynamics") que a interação entre fótons é possível mesmo no vácuo (23), apesar de ser um efeito muito pequeno e que deve ser observado somente em interações ocorrendo a altas energias. Por esse motivo, a ideia geral ao atacar esse tipo de problema é utilizar um meio material com não linearidades capazes de mediar a interação fóton-fóton.

Os estados de luz gerados pelos SPPs possuem grande acoplamento com a matéria, dessa maneira podem ser geradas fortes não linearidades, o que justifica sua abordagem como "fluidos quânticos de luz". Essa fase, bastante procurada em Física da matéria 
condensada (24-26), é caracterizada pelo fato de que a luz pode ser considerada como sendo composta por fótons "corpusculares", cuja interação seja grande o suficiente.

Ao contrário do que acontece em outros sistemas, e.g. cavidades de microondas, sistemas plasmônicos são capazes de suportar modos de luz em frequências ópticas (27), o que significa que a ordem de grandeza da energia dos "fótons" presentes no sistema é da mesma ordem de grandeza da transição energética do modo fundamental de elementos presentes na matéria. Isso sugere sua utilização, por exemplo, para explorar a Física dos modos de baixa excitação em sistemas atômicos.

Outra peculiridade dos sistemas plasmônicos é que eles são intrinsicamente sistemas abertos (por causa do decaimento radiativo e não radiativo dos SPPs) e devem, em sua maioria, ser tratados fora do equilíbrio (por causa do campo de excitação externo). Essa é uma diferença importante em relação aos sistemas tradicionais de matéria condensada.

Conforme tem sido estudado (29), a interação dos SPPs com éxcitons em estruturas semicondutoras é capaz de aumentar em ordens de grandeza a interação com a luz. Essa interação é responsável por efeitos como o controle da emissão espontânea em pontos quânticos (QDs, "Quantum dots") (30-32), conhecido como Efeito Purcell. (33)

Por esse motivo, acreditamos que a existência de um forte acoplamento entre os SPPs presentes em nanoestruturas metálicas e os éxcitons presentes em semicondutores põem a área de plasmônica como uma forte candidata para realizar estados da luz análogos a fases fortemente correlacionadas em matéria condensada.

\subsection{Proposta de tese}

A proposta geral desse trabalho foi investigar a viabilidade do estudo da plasmônica quântica, empregando pontos quânticos em semicondutores como elementos ativos e capazes de interagir com SPPs.

Durante o período do trabalho, os recursos técnicos existentes em nossos laboratórios de pesquisa foram ampliados e agora permitem a preparação e caracterização tanto de nanoestruturas semicondutoras como nanoestruturas plasmônicas, algumas das quais serão discutidas brevemente nos capítulos subsequentes. O estudo de sistemas fortemente 
interagentes na área de plasmônica representa um tema que se encontra tanto na fronteira teórica como experimental do que existe atualmente nessa área de pesquisa. Nossa motivação principal foi a de isolar as propriedades que poderiam ser obtidas experimentalmente em nossos laboratórios. Depois disso, vários testes foram realizados a fim de produzir e medir tais propriedades experimentalmente.

O trabalho foi dividido em duas frentes: uma teórica e outra experimental.

Do ponto de vista teórico, investigamos as propriedades dos modos de SPPs suportados por um nanofio metálico interagindo com um meio semicondutor que contem uma cadeia de pontos quânticos, conforme mostra a fig. 4. A ideia ao abordar este modelo foi a de retirar quais as assinaturas principais desse tipo de interação com o objetivo de posteriormente comparar com resultados experimentais obtidos de amostras produzidas em nossos sistemas experimentais.

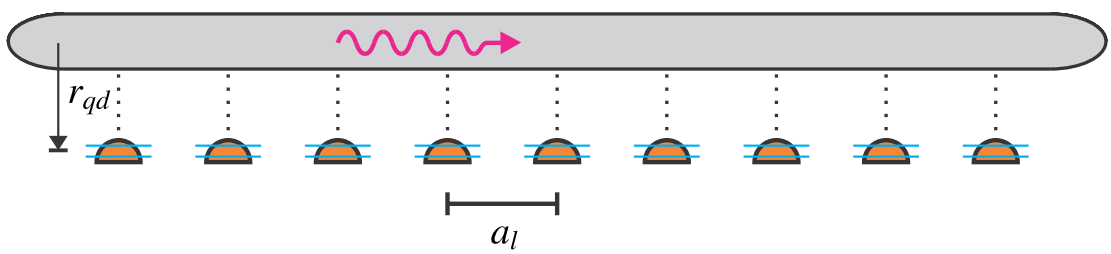

Figura 4 - Cadeia regular de QDs interagindo com SPPs num guia de onda cilíndrico. Fonte: Elaborada pelo autor.

Em paralelo a isso, um detalhado estudo experimental foi realizado, investigando quais as condições ótimas de fabricação de amostras semicondutoras para aplicação em nanoplasmônica. Muito foi feito no sentido de aprimorar o conhecimento das técnicas mais avançadas presentes em nossas facilidades, e.g. litografia por feixe de íons.

Nesse ponto, utilizamos várias técnicas de caracterização, e.g. (micro-)fotoluminescência, espectroscopia Raman, microscopia eletrônica e de força atômica, entre outras. Tudo isso para garantir que todo o trabalho fosse reprodutível. A utilização de várias técnicas serviu ainda como base para verificar a viabilidade das mesmas para caracterizar esse tipo de amostra, e.g. estruturas plasmônicas e propriedades dos QDs. Dessa forma, as análises obtidas poderão ser retormadas através de novas medidas em nossos sistemas e servirão de base para trabalhos posteriores.

O principal sistema experimental estudado nessa tese foi o de uma rede plasmônica capaz de interagir com uma (ou várias) camadas de pontos quânticos numa matriz semi- 
condutora, conforme mostra a fig. 5 .

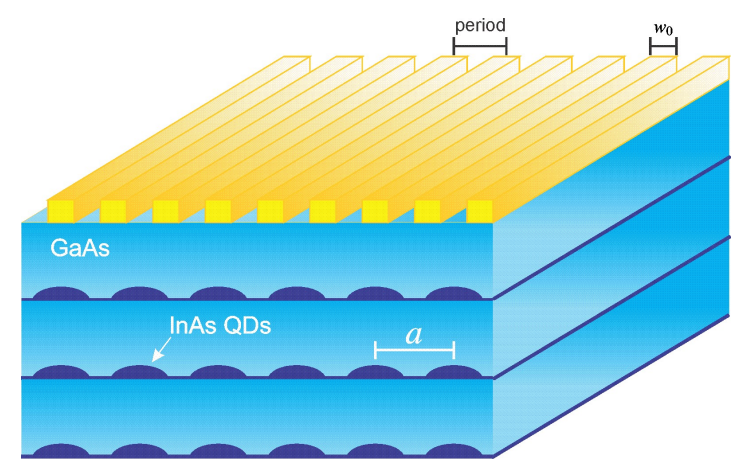

Figura 5 - Grade metálica onde são suportados modos de SPPs capazes de interagir com QDs na matriz semicondutora.

Fonte: Elaborada pelo autor.

\subsection{Estrutura do trabalho}

Iniciaremos o texto com uma descrição detalhada no capítulo 2 de como os SPPs se propagam numa interface metal-dielétrico. Quais os métodos de acoplamento dos SPPs com a interface. Neste capítulo, introduziremos os modelos de SPPs num guia plano e num guia cilíndrico unidimensional, i.e. onde os SPPs podem se progagar em uma direção. Será ainda discutido como obter um modelo de quantização canônica destes SPPs. Ainda é feita uma breve descrição dos modelos de decaimento dos SPPs assim como os efeitos de localização dos mesmos.

No capítulo 3 é discutido porque trabalhar com plasmônica na presença de meios com ganho, e é apresentado o conceito de ponto quântico (QD). Os métodos de crescimento e as principais propriedades dos pontos quânticos também serão introduzidos. O modelo de interação de SPPs com QDs, incluindo o fator de acoplamento característico destes sistemas é determinado. Ainda são obtidos resultados referentes à modificação do tempo de vida dos QDs na presença de SPPs, a geração de bandas plasmônicas em 1D e um modelo de condutividade baseado em teoria de resposta linear.

Com o objetivo de demonstrar os experimentos realizados durante o trabalho, no capítulo 4 é apresentado como as estruturas plasmônicas, redes metálicas, são fabricadas, e as principais técnicas utilizadas para a sua caracterização também são apresentadas.

No capítulo 5 são apresentados os principais resultados obtidos no desenvolvimento 
do trabalho, que incluem a verificação experimental de que a presença de estruturas que suportam SPPs induzem uma modificação no espectro de luminescência de um QD, além da alteração do tempo de vida dos estados dos QDs. As conclusões gerais são apresentadas no capítulo 6 junto com as perspectivas para trabalhos futuros nesta área. 


\section{Plasmônica: do clássico ao quântico}

Neste capítulo será dada uma descrição do modelo adotado para descrever as propriedades ópticas dos metais utilizados em nossos experimentos, bem como os modos de luz capazes de se propagar no metal. Também será apresentado o modelo de quantização utilizado para descrever as propriedades quânticas investigadas neste trabalho.

\subsection{Modelo do metal/dielétrico}

Em geral, a energia dos pontos quânticos utilizados em nossos experimentos é da ordem de 1,1 eV. Esses pontos quânticos serão descritos com maiores detalhes no capítulo 3. Por esse motivo, nosso objeto de estudo foram estruturas plasmônicas na qual a dispersão dos modos dos plásmons de superfície se encontram em torno dessa região, i.e. o espectro visível e infravermelho próximo da luz (regime óptico).

Conforme discutiremos logo a seguir, a dispersão dos plásmons de superfície é fortemente dependente da constante dielétrica do metal $(5,34,35)$ onde se encontram os elétrons livres, i.e. tanto de seu valor absoluto como da dependência com a frequência da luz utilizada para excitar esses modos plasmônicos. Apesar de também ser dependente da constante dielétrica do substrato (material dielétrico) que utilizaremos, um modelo onde a constante dielétrica do substrato não varia com a frequência da luz descreve satisfatoriamente essa constante ao longo de toda a região na qual estamos interessados.

O modelo mais utilzado na literatura para descrever as propriedades ópticas do metal é o de Drude(36, 37), onde os elétrons são tratados como partículas livres que podem colidir com os átomos que constituem a rede do metal. As colisões são consideradas como elásticas, e a informação sobre a velocidade dos elétrons é perdida após a mesma. Desta maneira, costuma-se introduzir o tempo de relaxação $\tau$, durante o qual o elétron caminha entre uma colisão e outra.

No modelo de Drude, só são considerados os elétrons das camadas de valência do metal, que livres para se mover ao longo da rede estarão sujeitos à ação de campos externos. O tempo de relaxação é que dá origem às perdas no metal, já que apesar de elásticas as 
colisões modificam as distribuições de velocidades adquiridas pelos elétrons sob a ação de campos externos. Seguindo o mesmo procedimento apresentado em $(7,38)$ é possível mostrar que a constante dielétrica do metal pode ser escrita como

$$
\varepsilon(\omega)=\varepsilon_{\infty}-\frac{\omega_{p}^{2}}{\omega^{2}+i \gamma \omega}
$$

onde $\omega_{p}$ é a frequência de plasma do metal, $\gamma=1 / \tau$ e $\varepsilon_{\infty}$ é a constante dielétrica estática do metal.

Na prática, o modelo de Drude se aplica muito bem tanto à prata como ao ouro em nossa região de interesse, conforme a fig. 6. No entanto, para o ouro, devido a uma transição eletrônica (39) presente em torno de 2,3 eV este modelo não se aplica muito bem à parte imaginária quando nos aproximamos de 2,0 eV. Porém, como estamos interessados na interação com pontos quânticos, onde a energia é cerca de $1,1 \mathrm{eV}$, este modelo é suficientemente acurado para descrever esse metal.

A fig. 6 representa os valores experimentais obtidos por (1) para a constante dielétrica tanto do ouro como da prata, bem como o comportamento esperado por estes metais quando utilizamos o modelo de Drude.

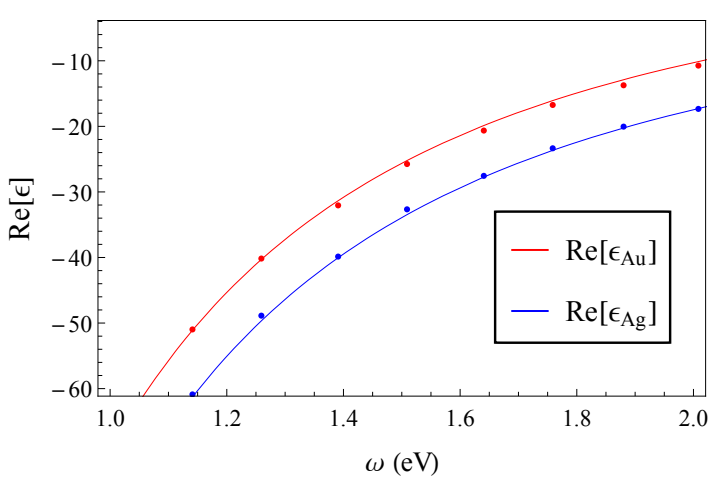

(a) Parte Real de $\varepsilon_{\text {metal }}$

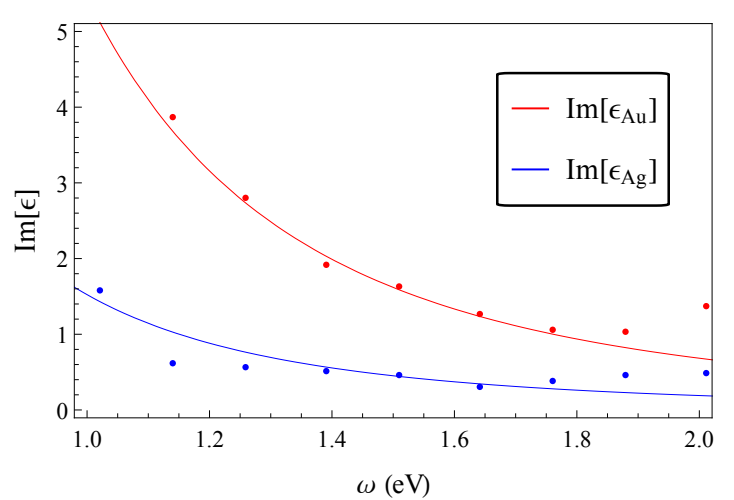

(b) Parte Imaginária de $\varepsilon_{\text {metal }}$

Figura 6 - Modelo de Drude para a constante dielétrica $\varepsilon_{\text {metal }}$ do Au e da Ag. Os valores experimentais obtidos por (1) estão indicados pelos pontos enquanto as linhas contínuas indicam um fitting para os dados considerando os melhores parâmetros que se adequam aos valores experimentais utilizando o modelo de Drude.

Fonte: JOHNSON; CHRISTY. (1)

A partir de 2,0 eV os valores experimentais para a parte imaginária da constante dielétrica tanto para o Au como para a Ag começam a crescer, um comportamento que não é esperado no modelo de Drude onde a parte imaginária decresce monotonicamente. A 
razão para esse conflito se deve ao fato de que o modelo de Drude não leva em consideração que o metal pode absorver luz devido a transições internas, conforme já foi discutido para o ouro. Para descrever de forma mais satisfatória a constante dielétrica do metal, que é necessária quando se consideram as transições com pontos quânticos mais energéticos (como os de InSb ou de nitretos) costuma-se introduzir uma interação na qual os elétrons presos ao metal também possuem frequências próprias de vibração, como no modelo de Lorentz. (7) No entanto, como estas anomalias estão fora de nossa região de interesse, é satisfatório utilizar o modelo de Drude para esses limites de energia.

O fitting apresentado que utiliza o modelo de Drude para interpolar tanto os valores real como imaginário da constante dielétrica do Au e da Ag foi obtido utilizando os valores para a frequência de plasma $\omega_{p}$ e a constante de amortecimento $\gamma$ apresentados na tabela 1.

Tabela 1 - Parâmetros do modelo de Drude utilizados para interpolar as partes real e imaginária da constante dielétrica do Au e da Ag.

\begin{tabular}{cccc}
\hline Metal & $\omega_{p}(\mathrm{eV})$ & $\gamma(\mathrm{meV})$ & $\varepsilon_{\infty}$ \\
\hline Ouro & 8,9 & 69,1 & 9,5 \\
Prata & 9,2 & 18,0 & 3,7 \\
\hline \multicolumn{4}{c}{ Fonte: } \\
Elaborada pelo autor.
\end{tabular}

Além dos metais que utilizamos ao longo deste trabalho, preferencialmente o ouro, é necessário ter em mãos a constante dielétrica do dielétrico que utilizaremos. Apesar de não apresentar grandes diferenças em termos numéricos, a utilização do Au se deu primordialmente devido à estabilidade das amostras feitas com este material.

As amostras produzidas utilizando filmes de Ag apresentavam manchas esbranquiçadas ao passar do tempo. Isso diminui a qualidade óptica das mesmas e produz modificações no espectro de luminescência dos pontos quânticos que não podiam ser controlados.

Em todo este trabalho, lidamos com pontos quânticos de InAs imersos em uma matriz de GaAs. A espessura do filme de InAs depositado no substrato é muito inferior às dimensões da matriz de GaAs. Essa camada, que chamamos de wetting layer, possui de 2 a $5 \mathrm{~nm}$ de espessura. O comprimento de onda da luz utilizada, conforme veremos ao descrever os plásmons de superfície, são da ordem de algumas centenas de nm. Sendo assim, a wetting layer não produz modificações apreciáveis na estrutura dos plásmons e 
podemos considerar que todo o substrato onde se encontram os pontos quânticos possui uma constante dielétrica $\varepsilon_{d}=13,1$, correspondente ao GaAs, que é aproximadamente constante em toda a nossa região de interesse. $(40,41)$

Um comentário válido neste ponto é que para energias $\gtrsim 1,5 \mathrm{eV}$, a luz começa a ser fortemente absorvida pelo GaAs, devido ao seu gap de energia. No entanto, como iremos estudar a interação de plásmons que estão em ressonância com os pontos quânticos, as modificações produzidas na dispersão dos plásmons por esta borda de energia não são apreciáveis. Isso reforça também que a utilização do modelo de Drude para esse tipo de sistema é adequado, já que nas regiões de absorção por excitações internas dos metais também estão na região acima do gap de energia do GaAs.

\subsection{Plásmon Polaritons de Superfície}

Como na região do visível e do infravermelho próximo a constante dielétrica do Au é negativa e seu módulo é maior que a constante dielétrica do GaAs (dielétrico utilizado em nosso modelo), ela dá origem a modos de luz confinados à interface entre o Au e o GaAs. (42) Este tipo de confinamento, que será discutido nas próximas seções é que dá origem às propriedades exóticas da luz nesses sistemas e que desejamos explorar neste trabalho.

Em essência, os plásmon polaritons de superfície, são o resultado do acoplamento de um gás de elétrons presente no metal com uma onda eletromagnética (42), daí o termo plásmon polaritons. Esses novos modos de elétrons "vestidos" de luz, têm a propriedade de se propagar na interface entre o metal e o dielétrico. Ao se acoplar com essas densidades de carga, a intensidade do campo eletromagnético da luz decai exponencialmente tanto no metal como no dielétrico (campos evanescentes). Além disso, a luz experimenta um decréscimo no seu comprimento de onda, em relação àquela que se propaga no meio dielétrico.

Conforme mostrado na fig. 7(a) há um campo eletromagnético se propagando em conjunto com uma densidade de carga eletrônica nessa onda. A fig. 7(b) é uma representação pictórica da diminuição da intensidade da função de onda (valor do campo elétrico) do SPP à medida que nos afastamos da interface entre o metal e o dielétrico. Em geral, estaremos interessados nos campos gerados pelo SPP na região do dielétrico, onde se 
localizam os QDs, que decaem mais lentamente que no metal.

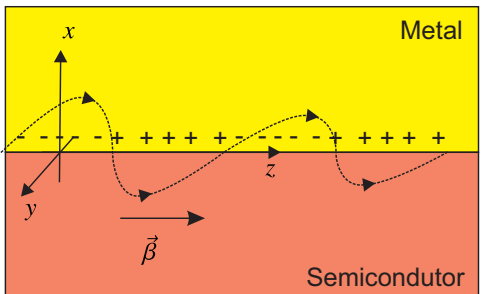

(a) Propagação de um SPP na interface metal/dielétrico.

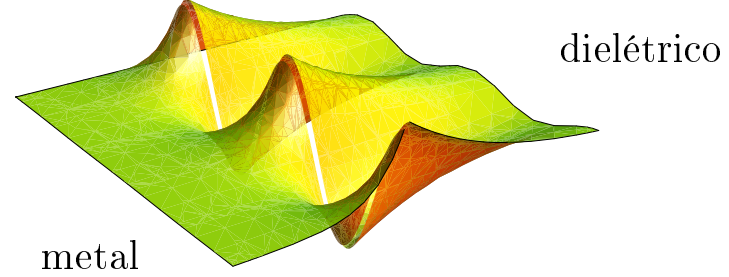

(b) Decaimento do campo do SPP no metal e no dielétrico.

Figura 7 - Modelo de propagação de um SPP no guia plano.

Fonte: Elaborada pelo autor.

A propagação dos SPPs pode ser explicada utilizando a eletrodinâmica clássica, bastando resolver as equações de Maxwell para o sistema que consiste na interface metal/dielétrico. (42) A geometria mostrada na fig. 7(a) (conhecida como guia plano) é a mais simples possível onde ocorre a propagação de SPPs. Ela consiste basicamente de dois planos semi-infinitos, um constituído por um metal e outro por um dielétrico.

A relação de dispersão desses modos de superfície no guia plano será obtida na seção 2.3, onde sua curva de dispersão será apresentada.

\subsection{Dispersão clássica num guia de ondas plano}

Para obter a relação de dispersão clássica de um SPP, podemos inicialmente considerar uma onda eletromagnética que se propaga num guia de onda cilíndrico. (43) Para obter como soluções os SPPs, estaremos interessados em soluções propagantes em guias de onda cilíndricos (cuja seção reta transversal à direção de propagação da onda é constante) e que sejam atenuadas à medida que nos afastamos da interface metal/dielétrico. Assumiremos que o eixo do cilindro está na direção $z$ e partiremos do fato de que, se soubermos os campos $E_{z}$ e $B_{z}$, que devem satisfazer a equação

$$
\left[\nabla_{t}^{2}+\left(\mu \varepsilon \omega^{2} / c^{2}-\beta^{2}\right)\right] \psi=0
$$

onde o campo $\psi(x, y)$ representa $E_{z}(\vec{r})$ ou $B_{z}(\vec{r})$, é possível determinar totalmente os 
campos $\vec{E}$ e $\vec{B}$ através das relações

$$
\left\{\begin{array}{l}
\vec{E}_{t}=\frac{i}{\mu \varepsilon \omega^{2} / c^{2}-\beta^{2}}\left(\beta \vec{\nabla}_{t} E_{z}-\omega \hat{z} \times \vec{\nabla}_{t} B_{z}\right), \\
\vec{B}_{t}=\frac{i}{\mu \varepsilon \omega^{2} / c^{2}-\beta^{2}}\left(\beta \vec{\nabla}_{t} B_{z}+\mu \varepsilon \frac{\omega}{c^{2}} \hat{z} \times \vec{\nabla}_{t} E_{z}\right) .
\end{array}\right.
$$

Aqui, $\beta \hat{z}$ é o vetor de onda do SPP e $\omega$ é a frequência angular do mesmo. O operador $\vec{\nabla}_{t}$ é o operador gradiente no plano transversal à direção de propagação do SPP.

O campo total que se propaga na direção $z$ pode ser escrito como

$$
\vec{\Psi}=\left(\Psi_{t} \hat{t}+\psi \hat{z}\right) \exp [i(\beta z-\omega t)]
$$

Nas expressões (2) e (3), $\mu$ e $\varepsilon$ representam, respectivamente, a permeabilidade magnética relativa e a constante dielétrica do meio onde o SPP se propaga.

No caso do guia de onda plano, a interface entre o metal e o dielétrico corresponde ao plano $x=0$, conforme mostra a fig. $7(\mathrm{a})$. Em todo o texto iremos supor tacitamente que tratamos de meios não magnéticos, i.e. $\mu_{d}=\mu_{m}=\mu_{0}=1$, hipótese que está de acordo com os materiais utilizados experimentalmente. A única propriedade que irá distinguir os meios (metal e dielétrico) é a constante dielétrica, que vale $\varepsilon_{d}$ para o dielétrico $(x<0)$ e $\varepsilon_{m}$ para o metal $x>0$.

Vamos investigar soluções em que os campos não dependem da coordenada $y$ (ondas planas), neste caso a equação a ser satisfeita pela componente $z$ dos campos é

$$
\frac{d^{2} \psi}{d x^{2}}=\left(\beta^{2}-\varepsilon_{i} \frac{\omega^{2}}{c^{2}}\right) \psi \quad \Rightarrow \quad \psi(x)=A_{i} \exp \left(-\kappa_{i}|x|\right),
$$

onde $\kappa_{i}^{2}=\beta^{2}-\varepsilon_{i} \omega^{2} / c^{2}>0$. Para decidir se o campo $\psi$ pode representar $E_{z}$ ou $B_{z}$ devemos aplicar as condições de contorno dos campos na interface entre o metal e o dielétrico, a saber, continuidade do campo $E_{z}$ e continuidade do campo $H_{z}$.

Ao aplicar as condições de contorno, só serão permitidas soluções com $\psi(x)=E_{z}(x)$, i.e. o campo magnético é transversal à direção de propagação dos SPPs. Nesse caso, diz-se que somente modos TM (transversais magnéticos) são permitidos no guia plano. 
Os campos elétrico e magnético no guia de onda plano são, portanto:

$$
\begin{array}{ll}
\vec{E}_{t}=\hat{x} \frac{i \beta}{k_{i}} \operatorname{sgn}(x) E_{z} & \Rightarrow \vec{E}=\left[\hat{z}+\hat{x} \operatorname{sgn}(x) \frac{i \beta}{k_{i}}\right] E_{0} \exp \left(-\kappa_{i}|x|\right) \exp [i(\beta z-\omega t)] \\
\vec{B}=\vec{B}_{t} & \Rightarrow \vec{B}=\hat{y} \frac{\varepsilon_{i} k_{0}^{2}}{\kappa_{i}} \operatorname{sgn}(x) E_{0} \exp \left(-\kappa_{i}|x|\right) \exp [i(\beta z-\omega t)],
\end{array}
$$

onde $k_{0}=\omega / c$ é a constante de propagação da luz no vácuo e o índice $i$ é utilizado para distinguir a região do metal da região do dielétrico. Aqui utilizamos a função $\operatorname{sgn}(x)=$ $x /|x|$ para escrever os campos em cada região.

As condições de contorno dos campos na interface metal/semicondutor resultam na condição de propagação do SPP no guia plano, i.e.

$$
\frac{\kappa_{m}}{\kappa_{d}}=-\frac{\varepsilon_{m}}{\varepsilon_{d}} \Rightarrow \beta=\frac{\omega}{c} \sqrt{\frac{\varepsilon_{m} \varepsilon_{d}}{\varepsilon_{m}+\varepsilon_{d}}} .
$$

Observe que a parte imaginária da permissividade do metal é responsável por um dos mecanismos de perda importantes para o sistema. Essas perdas se refletem no fato de que $\operatorname{Im}(\beta) \neq 0$, o que produz um comprimento finito de propagação dos SPPs. Além desse, há outros mecanismos de perda importantes como as rugosidades presentes no filme metálico, além das imperfeições na rede cristalina do metal e dielétrico. (44) Algumas dessas perdas e suas consequências serão discutidas nas seção 2.8 .

Desprezando por hora os efeitos de perdas, a curva de dispersão dos SPPs no guia plano é, portanto, aquela disposta na fig. 8. Para esta figura foi utilizado o ouro como metal e o GaAs como dielétrico. Nela, são mostradas a dispersão linear da luz tanto no vácuo como no dielétrico (desprezando a absorção acima do gap do GaAs). Além disso, é mostrado que a dispersão dos SPPs é menor que a frequência de plasma do ouro $\left(\omega_{p}\right)$, o que indica que os modos de superfície têm energia menor que os modos bulk. Como referência, indicamos a energia típica de um QD de InAs/GaAs (1, $1 \mathrm{eV})$.

Observe que a fig. 8 indica que a constante de propagação do SPP no guia metálico é maior que aquela no vácuo $\left(k_{0}=\omega / c\right)$, isso significa que o comprimento de onda do SPP é menor que o da luz no vácuo. Essa característica marcante dos SPPs é que justifica sua 


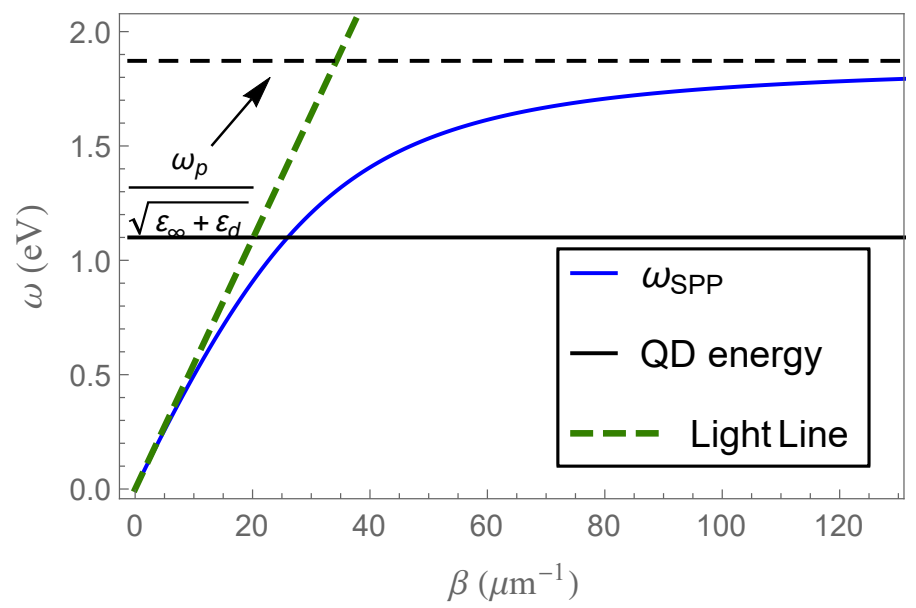

Figura 8 - Curva de dispersão dos SPPs na geometria plana, utilizando-se o ouro como metal e o GaAs como dielétrico, onde $\varepsilon_{d} \sim 13,1$. A frequência $\omega_{p}$ é a frequência de plasma do ouro.

Fonte: Elaborada pelo autor.

utilização para controlar a luz em regiões abaixo do limite de difração.

Isso explica, por exemplo, o fato da luz (na forma de SPPs) ser capaz de se propagar através de orifícios com dimensões abaixo do comprimento de onda com transmissão superior àquela prevista pela teoria de Bethe. (12)

Na teoria de Bethe, que desprezava a existência dos SPPs ao tomar os meios metálicos como condutores perfeitos, a transmissão de luz através de orifícios com dimensões menores que o comprimento de propagação da luz era uma função de $(d / \lambda)^{4}$, onde $d$ representa as dimensões do orifício e $\lambda$ o comprimento de onda da luz utilizada. Em geral, a eficiência na transmissão da luz é atenuada exponencialmente quando a profundidade do orifício é levada em consideração. Essa dependência se reflete no fato de que a luz não pode se propagar através do orifício se $\lambda>2 d$, onde a transmissão passa a ser o resultado de um processo de tunelamento. É preciso ainda observar que a condição $\lambda>2 d$ é uma aproximação em primeira ordem e que em situações reais este corte ocorre em comprimento de onda maiores devido à condutividade finita do material. (45)

A confirmação de que os SPPs tinham um papel importante na transmissão de luz através de pequenos orifícios foi primeiro demonstrada por Ebbesen (11), conforme mostra a fig. 3 onde máximos de transmissão aparecem mesmo quando o diâmetro $a_{0}$ dos orifícios circulares utilizados são maiores que o comprimento de onda $\lambda$ da luz incidente. A transmissão extraordinária de luz através de pequenas fendas metálicas foi atribuída à ressonância na excitação de SPPs suportados pela rede composta pelas fendas. (11) 
É preciso fazer aqui um breve comentário sobre os plásmons de bulk. Quando introduzimos a constante dielétrica de um metal no modelo de Drude, há ainda um ramo que para pequenos valores de $\beta$ pode ser escrito como $\omega^{2}=\omega_{p}^{2}+\beta^{2} c^{2}$, que é correspondente a uma onda volumétrica de cargas que se propaga dentro do metal.

Por vezes ainda há uma confusão entre plásmons de superfície e de bulk, principalmente entre os cientistas que não trabalham com plasmônica. No entanto, para garantir que não haja dúvidas basta observar que ao tratarmos de plásmons de superfície estamos interessados num ramo de baixas energias, enquanto os plásmons de bulk só serão excitados com fótons mais energéticos.

\subsection{Acoplamento de luz com SPPs}

Conforme podemos observar na fig. 8 não há cruzamento entre os ramos que representam a dispersão da luz no meio dielétrico e o ramo que representa os SPPs no guia plano. Por este motivo, ao fazer incidir luz sobre uma interface metal/dielétrico esta não irá excitar modos de SPPs, já que não haverá conservação do momento.

Observe ainda que o vetor de onda $\vec{k}$ para um fóton é puramente real enquanto o

vetor de onda $\vec{k}_{\mathrm{Spp}}=\vec{\beta}+\vec{\kappa}_{i}$ tem uma componente imaginária, que é a responsável pelo decaimento exponencial ao penetrarmos nas regiões do metal e do dielétrico. Esse fato torna impossível o acoplamento direto de luz com SPPs no guia plano.

Para contornar este problema algumas geometrias podem ser empregadas para acoplar luz com plásmons de superfície; é importante lembrar também que é possível excitar SPPs de outras formas, como através da colisão de elétrons numa superfície metálica. As geometrias mais comuns empregam a reflexão total da luz ou o uso de grades de difração. Apesar de utilizarmos o segundo método, iremos discutir como é feito no primeiro caso por que esse método revela e/ou clarifica algumas das propriedades mais importantes dos SPPs, e.g. a existência de campos evanescentes.

\subsubsection{Acoplamento via prismas}

Ao incidir sobre uma interface metal/dielétrico a componente do vetor de onda $k \operatorname{sen} \theta$ da luz, conforme mostra a fig. 9(a), jamais será igual ao valor da constante de propagação 
$\beta$ do SPP já que $\beta>k$. Uma maneira de contornar esse problema é utilizar um meio que aumente o vetor de onda $k$ de forma que sua dispersão cruze a dispersão do SPP na interface que desejamos acoplar.

A fig. 9(b) mostra uma maneira de fazer isso. Com a ajuda de um prisma com constante dielétrica $\varepsilon$, por exemplo, podemos aumentar o valor do vetor de onda $k$ para $\sqrt{\varepsilon} k$ e assim fazê-lo cruzar com a dispersão do SPP na interface metal/ar.

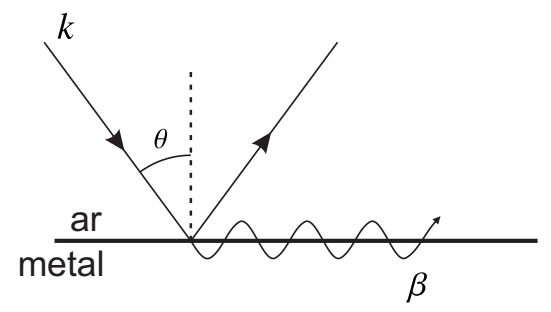

(a) Acoplamento direto da luz com um SPP num guia plano.

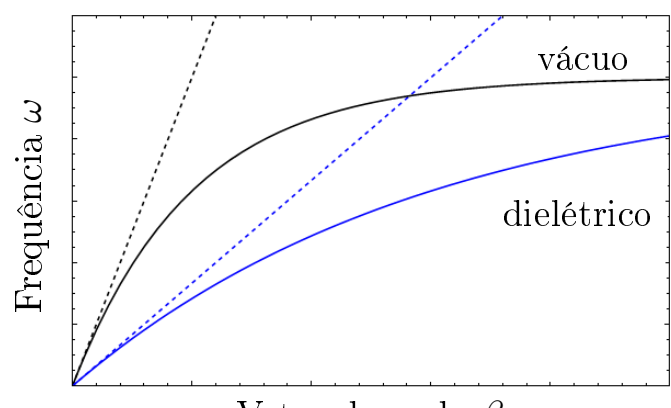

(b) Cruzamento da dispersão da luz num prisma com um SPP que se propaga na interface metal/ar.

Figura 9 - Origem do cruzamento da dispersão da luz com os SPPs através do uso de um meio de acoplamento.

Fonte: Elaborada pelo autor.

A forma como o campo da luz no prisma se acopla com a interface metal/ar é através do fenômeno da reflexão total da luz. A proposta em geral, se baseia em fazer com que a luz que se propaga dentro de um prisma atinja um de seus lados com um ângulo maior que o ângulo limite para a refração de forma que ocorra reflexão total da luz. Essa reflexão gera um campo evanescente na região fora do prisma, que poderá se acoplar com o campo do SPP.

As duas configurações mais conhecidas para acoplar o campo evanescente da reflexão total com o campo de um SPP são apresentadas nas figs. 10(a), configuração de Kretschmann-Raether, e 10(b), configuração de Otto.

Na primeira configuração, mostrada na fig. 10(a), o filme metálico é depositado sobre o prisma. Caso a espessura do filme seja suficientemente pequena, é possível que o campo evanescente gerado na reflexão total penetre até a região onde se encontra o ar de forma que o campo da luz se acopla com o campo do SPP. Neste caso, a espessura do filme metálico deve ser menor ou da ordem do chamado skin depth (ou comprimento de 
penetração) do metal, que é pequeno (da ordem de algumas dezenas a poucas centenas de nanômetros) para a luz visível.

Na fig. 10(b), que mostra a segunda configuração, o filme metálico é colocado próximo ao prisma, de forma que o campo evanescente da luz deverá atravessar o ar ao invés de ser fortemente atenuada pelo metal. Esta configuração é especialmente útil quando se deseja investigar SPPs nas interfaces livres do prisma.

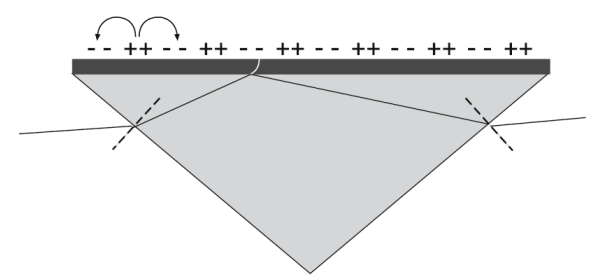

(a) Configuração Kretschmann-Raether.

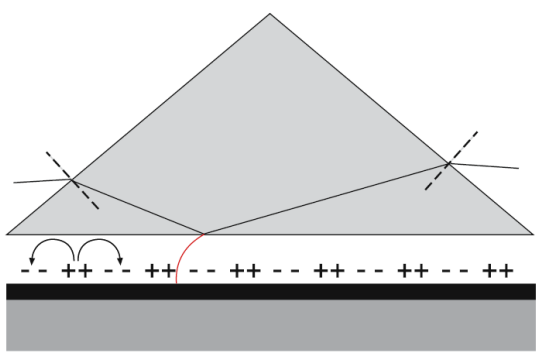

(b) Configuração de Otto.

Figura 10 - Geometrias de acoplamento da luz com um SPP através de um prisma.

Fonte: MAIER. (42)

Para verifcar o acoplamento da luz com os SPPs pelos métodos apresentados o que se faz em geral é investigar a reflexão da luz como função do ângulo de incidência sobre o prisma. É possível mostrar que o acoplamento com os SPPs será máximo quando a taxa de decaimento $\Gamma_{i}$ (devida à parte imaginária da constante dielétrica do metal) for igual à taxa de decaimento radioativo $\Gamma_{\text {rad }}$ (devida ao decaimento de SPPs em luz). Uma outra propriedade importante do acoplamento com os SPPs é a interferência da espessura do filme metálico. Neste caso, o acoplamento funciona de forma análoga ao que ocorre numa cavidade de Fabry-Perot.

\subsubsection{Acoplamento via grades}

Além do acoplamento via utilização de prismas que se baseia na reflexão total, é possível utilizar grades metálicas fabricadas sobre a interface onde se deseja acoplar a luz com os SPPs no plano, conforme mostra a fig. 11.

Esse método, baseado no que se chama de casamento de fase, tem o mesmo princípio da difração de elétrons numa rede cristalina; a diferença entre a componente tangencial do vetor de onda incidente $k_{\|}=k \operatorname{sen} \theta$ e o vetor de onda do SPP $\beta$ é compensada por 


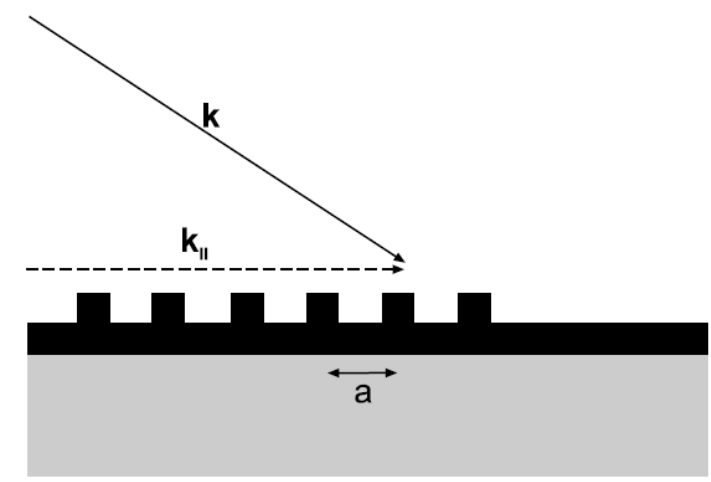

Figura 11 - Acoplamento da luz com SPP através do método do casamento de fase.

Fonte: MAIER. (42)

um número inteiro de vetores da rede recíproca gerada pelo padrão. Em outras palavras, sendo $a$ o espaçamento entre as ranhuras da rede, conforme mostra a fig. 11, teremos:

$$
\beta=k \operatorname{sen} \theta \pm m \frac{2 \pi}{a},
$$

onde $m$ é um número inteiro. Note que a eq. 8 indica que, apesar da componente tangencial do vetor de onda da luz incidente não ser igual ao vetor de onda $\beta$ na primeira zona de Brillouin da rede, ela irá, em geral, ser igual ao valor de $\beta$ para alguma zona superior.

Fica claro neste caso, que a introdução das ranhuras gera naturalmente um espectro de bandas para os SPPs no plano. Dependendo da forma como essas ranhuras são feitas, e.g. utilizando um padrão bidimensional de furos como no experimento de Ebbesen (11), é possível que esse espectro de bandas apresente gaps de energia, dando origem assim ao que chamamos de bandas plasmônicas. (46)

O mecanismo do acoplamento da luz com SPPs através de ranhuras numa rede plasmônica são de fundamental importância para o acoplamento de luz com SPPs em geral. Mesmo que a interface entre os meios não possua um padrão bem definido, a presença de rugosidades irá introduzir mais um canal de decaimento de luz em SPPs e vice-versa. Isso será dicutido na seção 2.8 quando discutiremos os mecanismos de perda dos SPPs. Esse fato, que em partes é prejudicial quando se deseja confinar os SPPs apenas na interface metal/dielétrico por pronunciar as perdas radiativas dos SPPs é útil quando se deseja excitar os SPPs com luz sem a necessidade de uma alta eficiência. 
Outro ponto importante é o fato de que a presença de estruturas plasmônicas fabricadas sobre a interface metal/dielétrico pode selecionar apenas comprimentos de onda bem definidos, funcionando como antenas que podem inclusive ser sintonizadas. $(47,48)$ Além disso, através dessa engenharia é possível desenvolver lentes plasmônicas, que direcionam os SPPs de forma controlável.

Por fim, vale ainda ressaltar que para que o processo de acoplamento com os SPPs utilizando estruturas metálicas seja eficiente não é necessário que as ranhuras sejam fabricadas sobre a superfície metálica. Para entender isso basta lembrar que o campo do SPP, que é aquele que se acopla com a luz, penetra tanto na região do metal como do dielétrico. Dessa maneira, dependendo da aplicação desejada é possível produzir estruturas plasmônicas tanto com fabricações sobre o metal como sobre o dielétrico.

\subsection{SPPs em um guia cilíndrico}

Assim como no guia plano, é possível confinar SPPs em outras geometrias. $(49,50)$ Em alguns casos o confinamento pode produzir plásmons que se propagam em apenas uma dimensão (1D). Esse tipo de sistema é útil para se estudar propriedades de transporte na presença de SPPs. (30) Com esse objetivo, estudamos o espectro de propagação de SPPs num guia cilíndrico circular metálico e introduzimos um modelo de quantização para esses modos. O guia circular foi escolhido pela possibilidade de tratamento analítico, no entanto excitações clássicas já foram estudadas em outras geometrias. (50)

A receita que iremos seguir para a quantização do sistema plasmônico é essencialmente aquela seguida para a quantização da luz numa cavidade óptica. $(20,51,52) \mathrm{O}$ procedimento que iremos seguir pode ser brevemente resumido em três passos:

(i) Descrever os modos clássicos do sistema;

(ii) Discretizar estes modos clássicos;

(iii) Utilizar o modelo de quantização canônica.

Em nosso modelo de SPPs confinados num guia de onda cilíndrico, onde os SPPs irão se propagar num fio metálico de raio menor que o comprimento de onda correspondente à luz no vácuo. Esse fio estará imerso num meio dielétrico (semicondutor) onde estão 
presentes os QDs. Por esse motivo, para analisar os efeitos quânticos decorrentes desses modos, iremos quantizar os SPPs na geometria cilíndrica.

Nosso objeto de estudo teórico é um nanofio metálico finito, conforme (53), onde os modos dos SPPs são bem definidos. Esses modos serão capazes de interagir com uma cadeia de QDs presentes no substrato semicondutor, conforme o diagrama esquemático mostrado na fig. 4.

Há várias dificuldades técnicas na fabricação desse tipo de sistema, uma delas é relativa à localização do nanofio nas proximidades de uma cadeia de QDs. Para contornar esse problema, utilizamos modelos experimentais onde ao invés de nanofios cilíndricos são empregadas fendas fabricadas sobre uma superfície metálica utilizado um feixe de íons, conforme mostra a fig. 12(a).

Na prática, pode-se mapear o campo gerado por uma fenda fabricada na superfície metálica através do uso de um equipamento de microscopia óptica de campo próximo, ou SNOM, e através disso, fabricar fendas com as propriedades desejadas. Assim, um nanofio metálico pode ser fabricado "artificialmente" empregando-se o campo gerado pela fenda. Essa metodologia pode ser utilizada lembrando-se que o principal ingrediente que dá as propriedades do campo no nanofio metálico é a presença do confinamento em mais de uma dimensão, ao contrário do guia plano no qual o SPP só é confinado na direção normal à interface, e que também está presente na fenda metálica.

Do ponto de vista teórico, como estamos interessados em obter uma forma analítica para as expressões para as constantes de propagação do SPP, constante de acoplamento com o QD etc é mais conveniente trabalhar com os resultados da geometria cilíndrica. Isso será útil para separar efeitos de confinamento do SPP com efeitos de perda por absorção do metal, por exemplo. Por esse motivo, vamos lançar mão da seguinte ideia: iremos supor que o sistema plasmônico é composto por um nanofio metálico imerso no semicondutor, conforme a fig. 12(b).

Devido à presença de uma simetria de rotação em torno do eixo do cilindro, a dispersão do modo fundamental faz com que $\omega \rightarrow 0$ quando $\beta \rightarrow 0$, como em (54), fato que não é verdade em sistemas que não a possuem, como em (50) ou em fendas metálicas, que é uma das propostas experimentais que pode ser utilizada. É preciso, no entanto, observar que a 


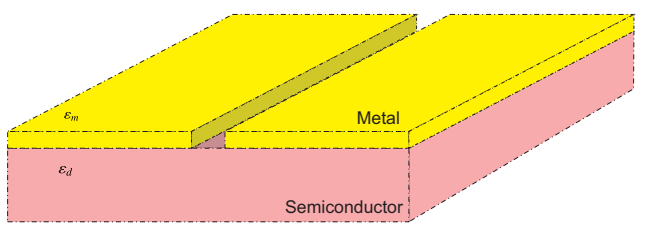

(a) Diagrama esquemático de uma fenda produzida em laboratório.

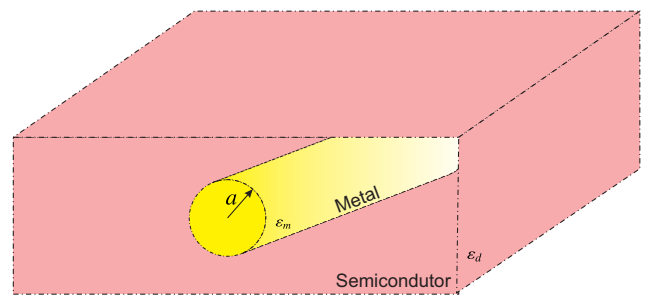

(b) Diagrama do modelo teórico utilizado.

Figura 12 - Diagramas do modelo de SPPs adotado teoricamente e de um modelo experimental.

Fonte: Elaborada pelo autor.

presença do gap de energia em sistemas sem simetria, não deve alterar significativamente a dispersão dos SPPs nas proximidades da energia de QDs ou outros emissores quânticos.

A distância entre os modos permitidos ou a curva de dispersão dos modos dos SPPs longe da região $\omega \rightarrow 0$ não deve variar significativamente desde que seja definido um cilíndro com "raio efetivo" equivalente ao de um sistema realizado em laboratório. Neste último caso, a curva de dispersão da fenda e de um nanofio cilíndrico devem ser parecidas quando a largura da fenda for da ordem do diâmetro do nanofio.

Iremos agora descrever como obter o modo fundamental dos SPPs no guia cilíndrico e discutiremos ainda a presença de modos "excitados", onde há um gap de energia. O estudo de modos excitados pode ser útil pelo fato de eles não possuírem a mesma simetria do modo fundamental, uma nova geometria para o campo, o que pode reproduzir com maior fidelidade o campo de uma fenda metálica.

Para o sistema descrito na fig. 12(b) e discutido anteriormente, a equação a ser satisfeita pelo campo $\psi$ é aquela mostrada da eq. (2), que na geometria cilíndrica pode ser escrita como:

$$
\frac{1}{\rho} \frac{\partial}{\partial \rho}\left(\rho \frac{\partial \psi}{\partial \rho}\right)+\frac{1}{\rho^{2}} \frac{\partial^{2} \psi}{\partial \phi^{2}}+k^{2} \psi=0
$$

onde $k^{2}=\varepsilon \omega^{2} / c^{2}-\beta^{2}$, e $\beta$ é a constante de propagação do SPP, ao longo da direção $z$. A solução para este problema é dada por

$$
\psi_{n}(\rho, \phi)=C_{n} R_{n}(k \rho) e^{i n \phi}
$$

e, a função radial $R_{n}(k \rho)$ é a função de Bessel $J_{n}(k \rho)$ quando se tratar da região interna ao 
fio $(\rho<a)$, ou será igual à função $H_{n}^{(1)}(k \rho)$ de Hankel, quando se tratar da região externa ao fio $(\rho>a)$. O índice $n$ corresponde à ordem do SPP, dizemos que se trata do modo fundamental quando $n=0$ e de modos excitados quando $n>0$. A escolha destas soluções é feita de forma a eliminar os campos que divergem na origem (49) e reter somente os que decaem exponencialmente quando $\rho \rightarrow+\infty$, o que garante o confinamento do campo da onda eletromagnética somente nas proximidades do nanofio.

Como já foi dito, o campo $\psi$ pode representar a componente $z$ tanto do campo elétrico $E_{z}$ como do campo magnético $B_{z}$. Da mesma forma que foi discutida no caso de guias de onda planos, os modos transversais elétricos puros não se propagam e somente os modos transversais magnéticos dão origem a soluções propagantes, qualquer que seja o valor de $n$. No entanto, na geometria cilíndrica é possível que modos que não possuam uma polarização bem definida se propaguem ao longo do fio.

Da mesma maneira que no guia plano, o modo fundamental $(n=0)$ do guia cilíndrico só permite propagação do SPP com polarização TM. Dessa maneira, temos $\psi(z)=E_{z}(z)$ e os campos são dados por

$$
\left\{\begin{array}{l}
\vec{E}_{t}=\frac{i \beta C_{0}}{\kappa_{j}^{2}} \kappa_{j} R_{0}^{\prime}\left(\kappa_{j} \rho\right) \hat{\rho}, \\
\vec{B}_{t}=\frac{i \varepsilon_{0} k_{0} C_{0}}{\kappa_{j}^{2}} \kappa_{j} R_{0}^{\prime}\left(\kappa_{j} \rho\right) \hat{\phi}
\end{array}\right.
$$

onde $C_{0}$ é uma constante que está ligada à amplitude do campo do SPP. As condições de contorno a serem satisfeitas pelo campo eletromagnético, assim como no guia plano, levam à condição de propagação

$$
\frac{\varepsilon_{m}}{\kappa_{m}} \frac{J_{1}\left(\kappa_{m} a\right)}{J_{0}\left(\kappa_{m} a\right)}=\frac{\varepsilon_{d}}{\kappa_{d}} \frac{H_{1}^{(1)}\left(\kappa_{d} a\right)}{H_{0}^{(1)}\left(\kappa_{d} a\right)},
$$

que só é válida para o modo $n=0$. Todos os outros modos com esse tipo de polarização (TM pura) não são permitidos. Sendo assim, o campo não tem dependência angular e a sua única modulação é na direção $z$ de propagação, enquanto é evanescente na direção radial. Observe que a forma como o campo cai e a relação entre cada uma das componentes dos campos devem guardar alguma semelhança com os campos no caso real. A solução 
da eq. 12 será apresentada logo a seguir e é mostrada na fig. 14 para fios de Ag e Au com 100nm de raio e SPPs com 1, 1eV de energia, sob a aproximação de que a parte imaginária da constante dielétrica do metal é nula.

Estamos interessados em casos onde $\kappa_{j}$ é puramente imaginário, de forma que o campo eletromagnético esteja confinado principalmente na interface entre o metal e o semicondutor, constituindo uma onda de superfície.

\subsection{Modelo de quantização}

Uma vez descrito o modo do SPP no qual estamos interessados, vamos agora seguir adiante no processo de quantização. Para fazer isso deve-se inicialmente notar que o tratamento das perdas inclusas pela parte imaginária da constante dielétrica na eq. (1) é mais complicado, pois aqui a condição de propagação do SPP é uma equação transcedental no domínio dos complexos. Apesar de vários métodos serem conhecidos para tratar esse tipo de equação, como nosso objetivo é retirar os ingredientes básicos da solução para uma abordagem mais geral, nós iremos supor que a constante dielétrica do metal (assim como a do dielétrico) seja puramente real. Isso significa fisicamente que iremos supor, em primeira aproximação, que os efeitos das perdas não radiativas, como colisões dos elétrons livres no metal, sejam desprezíveis. Dessa maneira, a constante dielétrica poderá ser escrita como

$$
\varepsilon_{m}(\omega)=\varepsilon_{\infty}-\frac{\omega_{p}^{2}}{\omega^{2}}
$$

Para seguir o mesmo procedimento natural de quantização utilizado em cavidades de microondas(51), precisamos escrever o potencial vetorial. Dado o campo do SPP na eq. 11, podemos escrever o potencial vetorial como

$$
\vec{A}(\vec{r})=\frac{1}{\sqrt{2 \pi L}} \sum_{\beta} A_{\beta} e^{i \beta z}\left[\vec{\xi}_{m} \theta(a-\rho)+\vec{\xi}_{d} \theta(\rho-a)\right]
$$

onde os vetores de polarização 


$$
\begin{aligned}
\vec{\xi}_{m} & =\frac{i \beta}{\kappa_{m}} J_{1}\left(\kappa_{m} \rho\right) \hat{\rho}-J_{0}\left(\kappa_{m} \rho\right) \hat{z} \\
\vec{\xi}_{d} & =\frac{J_{0}\left(\kappa_{m} a\right)}{H_{0}^{(1)}\left(\kappa_{d} a\right)}\left[\frac{i \beta}{\kappa_{d}} H_{1}^{(1)}\left(\kappa_{d} \rho\right) \hat{\rho}-H_{0}^{(1)}\left(\kappa_{d} \rho\right) \hat{z}\right]
\end{aligned}
$$

indicam a polarização do SPP no metal e no dielétrico. A partir da eq. 15 é possível obter os campos elétrico $\vec{E}=-\partial \vec{A} / \partial t$ e magnético $\vec{B}=\vec{\nabla} \times \vec{A}$ no nanofio como função da amplitude $A_{\beta}$ do potencial vetor para o modo com constante de propagação $\beta$.

Partindo das expressões obtidas para os campos, é possivel determinar os perfis radial e azimutal do campo elétrico, além da componente azimutal do campo magnético, do modo fundamental de um SPP. As figs. 13(a) e 13(b) representam o perfil do campo eletromagnético de um SPP com energia $\hbar \omega=1,1 \mathrm{eV}$ para um nanofio com $100 \mathrm{~nm}$ de raio. Essa energia, típica de um ponto quântico de InAs em GaAs, está abaixo da energia de ressonância de um SPP no guia cilíndrico, de acordo com a fig. 14(a).

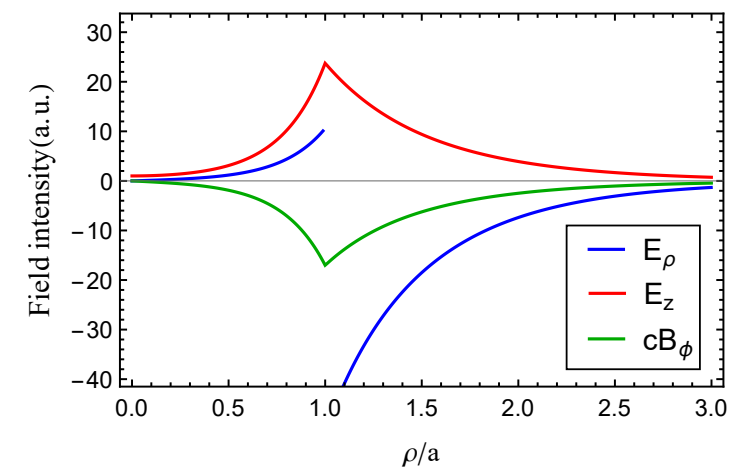

(a) Fio de Ouro.

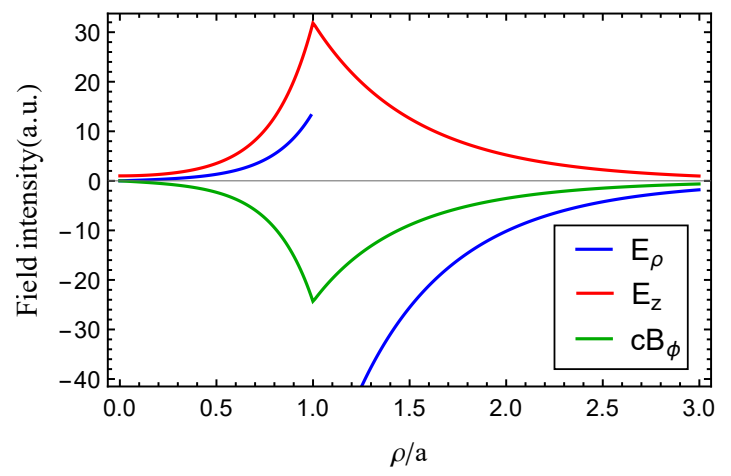

(b) Fio de Prata.

Figura 13 - Perfil do campo eletromagnético em nanofios metálicos com 100nm de raio e com energia correspondente a $1,1 \mathrm{eV}$. Somente a componente $B_{\phi}$ do campo magnético é não nula, indicando um modo transversal magnético puro.

Fonte: Elaborada pelo Autor.

A energia do SPP pode ser escrita como função das amplitudes $A_{\beta}$ e de suas derivadas temporais $\dot{A}_{\beta}$. Dessa forma, podemos dividí-la em dois termos, um "termo cinético" $T$ e outro "termo potencial" $V$ da seguinte forma:

$$
T=\frac{1}{2} \int d^{3} r \vec{E}(\vec{r}) \cdot \vec{D}(\vec{r})=\frac{1}{2} \sum_{\beta} t_{\beta} \dot{A}_{\beta} \dot{A}_{-\beta}
$$




$$
V=\frac{1}{2} \int d^{3} r \vec{B}(\vec{r}) \cdot \vec{H}(\vec{r})=\frac{1}{2} \sum_{\beta} v_{\beta} A_{\beta} A_{-\beta},
$$

onde os termos $t_{\beta}$ e $v_{\beta}$ podem ser obtidos analiticamente.

Podemos, portanto, escrever a Lagrangeana correspondente ao SPP como

$$
\mathcal{L}=\frac{1}{2} \sum_{\beta}\left(t_{\beta} \dot{A}_{\beta} \dot{A}_{-\beta}-v_{\beta} A_{\beta} A_{-\beta}\right)
$$

O momento canonicamente conjugado à amplitude $\dot{A}_{\beta}$ é definido a partir do termo cinético como

$$
\Pi_{\beta} \equiv \frac{\partial T}{\partial \dot{A}_{\beta}}=t_{\beta} \cdot \dot{A}_{-\beta}
$$

Daí, o Hamiltoniano do sistema é dado por

$$
\mathcal{H}=\Pi_{\beta} \dot{A}_{\beta}-\mathcal{L}=\frac{1}{2} \sum_{\beta}\left(\frac{1}{t_{\beta}} \Pi_{\beta} \Pi_{-\beta}+v_{\beta} A_{\beta} A_{-\beta}\right),
$$

que podemos escrever no formato canônico como

$$
\mathcal{H}=\frac{1}{2} \sum_{\beta}\left(\frac{1}{m_{\beta}} \Pi_{\beta} \Pi_{-\beta}+m_{\beta} \omega_{\beta}^{2} A_{\beta} A_{-\beta}\right),
$$

onde o termo de massa está relacionado com a amplitude do termo cinético, $m_{\beta}=t_{\beta}$, e a frequência angular está relacionada com o termo de energia potencial, $\omega_{\beta}^{2}=v_{\beta} / m_{\beta}$.

Por fim, invocamos a quantização canônica e impomos as relações de comutação

$$
\left[A_{\beta}, \Pi_{\beta^{\prime}}\right]=i \delta_{\beta, \beta^{\prime}}
$$

onde fizemos a constante de Planck reduzida $\hbar=1$. O mesmo será feito ao longo do texto com a velocidade da luz, $c=1$. Com estas relações satisfeitas é possível fazer uma transformação de maneira análoga ao oscilador harmônico, e exprimir as amplitudes em termos de operadores bosônicos de criação e aniquilação de SPPs. No nosso caso, escrevemos: 


$$
a_{\beta}=\sqrt{\frac{m_{\beta} \omega_{\beta}}{2}} A_{\beta}+i \frac{1}{\sqrt{2 m_{\beta} \omega_{\beta}}} \Pi_{-\beta},
$$

e, o Hamiltoniano pode ser escrito como

$$
\mathcal{H}=\sum_{\beta} \omega_{\beta}\left(a_{\beta}^{\dagger} a_{\beta}+\frac{1}{2}\right), \quad \omega_{\beta}=\sqrt{\frac{v_{\beta}}{t_{\beta}}} .
$$

A relação de comutação dos operadores de criação e destruição é $\left[a_{\beta}, a_{\beta^{\prime}}^{\dagger}\right]=\delta_{\beta, \beta^{\prime}}$. Em conjunto a isso, o operador de criação $a_{\beta}^{\dagger}$ atua sobre o vácuo de SPPs para criar uma excitação $a_{\beta}^{\dagger}|0\rangle=\left|1_{\beta}\right\rangle$.

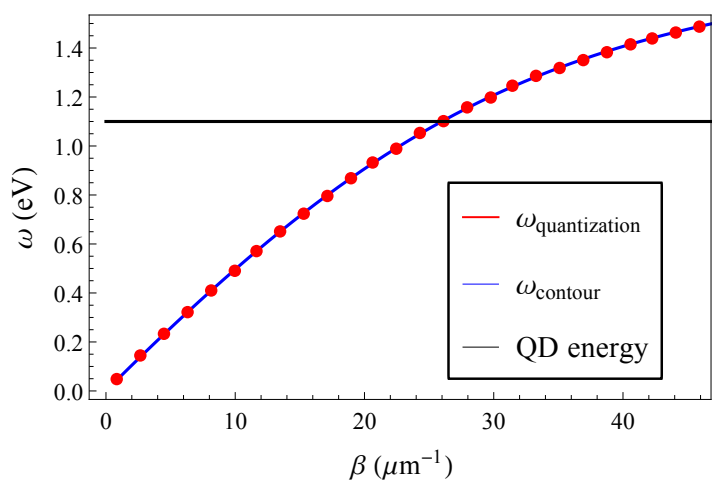

(a) Fio de Ouro.

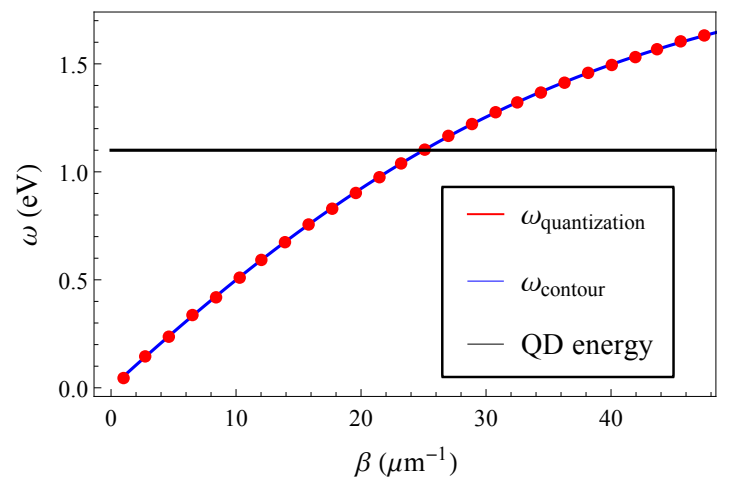

(b) Fio de Prata.

Figura 14 - Dispersão $\omega \times \beta$ para um fio metálico imerso em GaAs, para os valores calculados com a condição de contorno dada pela eq. (12) e pela quantização expressa na eq. (24). A linha horizontal indica a energia de um ponto quântico. Em ambos os casos foi utilizanddo um fio com $100 \mathrm{~nm}$ de raio.

Fonte: Elaborada pelo Autor.

Aqui, é importante ressaltar que a eq. 24 é equivalente à condição de propagação dada pela eq. 12, como mostra a fig. 14, ou seja, as frequências dos modos quantizados são iguais às frequências dos modos clássicos do sistema. Este resultado é esperado pela consistência do processo de quantização, que não altera os modos do sistema, mas tão somente exprime uma outra maneira de apresentá-los. Para verificar que os resultados são idênticos, mostramos na fig. 14 uma comparação entre os resultados obtidos utilizando a eq. 12 e a eq. 24. Para calcular os valores das amplitudes $t_{\beta}$ e $v_{\beta}$ que aparecem nos termos de energia cinética e potencial, determinamos os valores das integrais que aparecem nas eqs. 16 e 17. 


\subsection{Modos excitados e aproximação unidimensional}

O mesmo processo de quantização seguido para o modo fundamental do guia cilíndrico pode ser aplicado à quantização dos modos excitados. Os resultados são análogos àqueles obtidos para o modo fundamental $(n=0)$, com a diferença que a distribuição dos campos dos SPPs permite o aparecimento de modos onde tanto o campo elétrico como o campo magnético possuem componentes na direção de propagação do SPP, i.e. não há modos transversais elétrico ou magnético puros.

A condição de contorno dada pela eq. 12 agora deve ser modificada para incluir o índice $n$ correspondente ao modo de excitação do SPP. Na fig. 15 mostramos o perfil das componentes dos campos $\vec{E}$ e $\vec{B}$ do SPP. A presença de uma componente azimutal do campo elétrico faz com que o campo magnético passe a possuir componentes nas direções do eixo do fio e radial. Observe ainda que para esses modos a penetração na região do dielétrico continua sendo maior que na região do metal, o mesmo comportamento apresentado no modo fundamental e no guia plano.

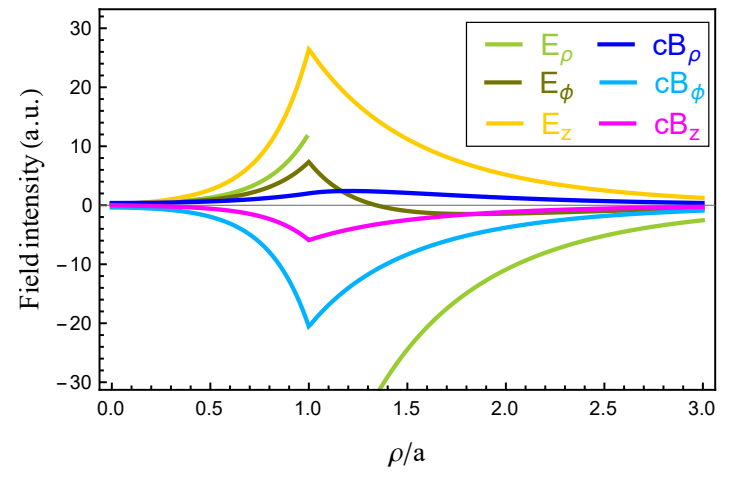

(a) Perfil para $n=1$.

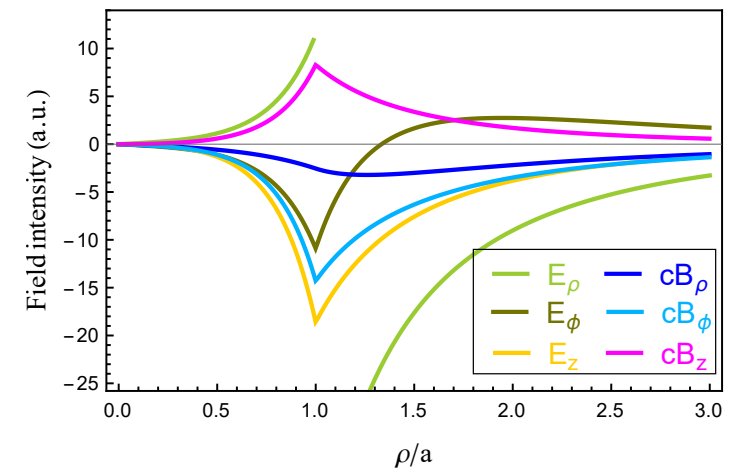

(b) Perfil para $n=2$.

Figura 15 - Perfil do campo eletromagnético para os modos excitados de um SPP num guia de ouro de $100 \mathrm{~nm}$ de raio e com energia correspondente a $1,1 \mathrm{eV}$ envolto por GaAs.

Fonte: Elaborada pelo autor.

Estamos, no entanto, interessados na forma como esses campos interagem com os níveis de energia de um QD. Em princípio, todos os modos suportados pelo nanofio devem interagir com o QD. No entanto, a interação é mais forte para aqueles modos nos quais a dispersão cruza a linha de energia correspondente ao QD. Modos afastados dessa linha devem possuir acoplamento muito fraco, já que o efeito da interação é maior na vizinhança de uma ressonância entre o SPP e o QD. 
Sendo assim, julgamos necessário saber se é coerente utilizar somente o modo fundamental como aquele que interage com o QD ou se devemos incluir alguns modos excitados no nosso modelo, para que o mesmo seja mais realista.

O resultado mostrado na fig. 16(a) indica que o primeiro modo excitado $(n=1)$ dos SPPs num guia ouro com $100 \mathrm{~nm}$ de raio ainda cruza o nível de energia do QD. Isso indica que utilizar somente a dispersão do modo fundamental pode não ser o suficiente para descrever a interação entre o campo dos SPPs no nanofio e os QDs. Para contornar este problema há duas opções: levar em consideração modos superiores ou diminuir o raio do fio de forma que o primeiro modo excitado esteja mais afastado da energia do QD, como é mostrado na fig. 16(b) que indica um nanofio com 20nm de raio.

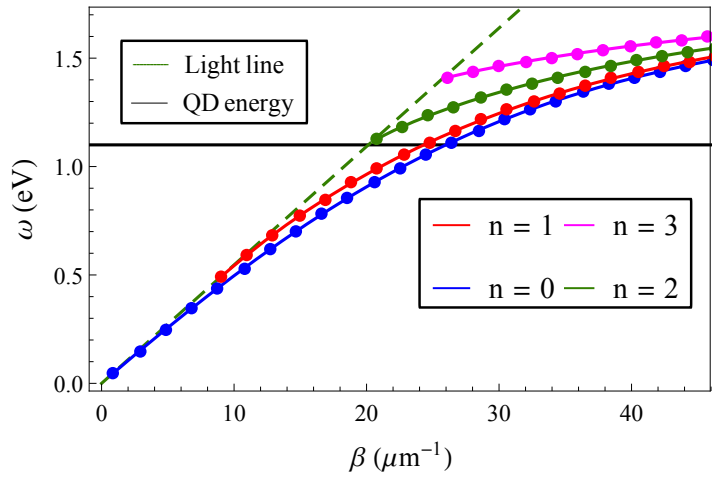

(a) Guia de ouro com 100nm de raio.

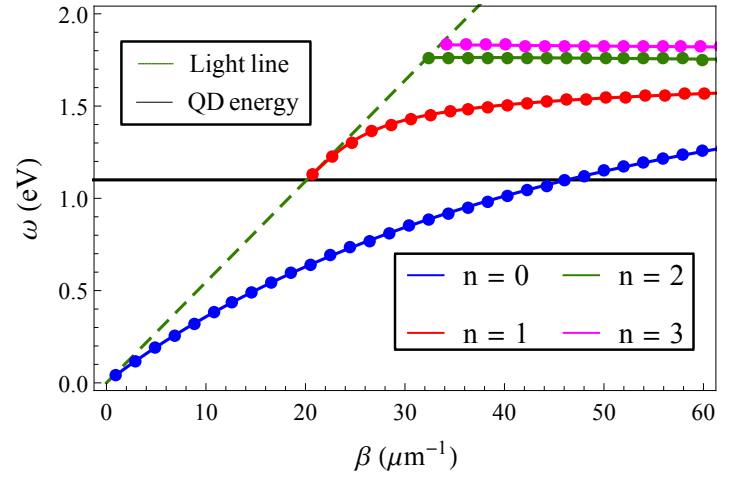

(b) Guia de ouro com 20nm de raio.

Figura 16 - Curva de dispersão para os modos fundamental e primeiros excitados para um nanofio metálico imerso em GaAs. As linhas indicam a dispersão de cada um dos modos. A linha horizontal indica a energia de um $\mathrm{QD}$ com $1,1 \mathrm{eV}$. A linha pontilhada em verde indica a dispersão linear da luz no semicondutor.

Fonte: Elaborada pelo autor.

A fig. 16(b) mostra o caso limite no qual o primeiro modo excitado do guia passa a não cruzar o nível de energia do QD. Dessa maneira, a aproximação de que somente o modo fundamental é o suficiente para descrever a interação SPP-QD passa a ser válida quando o raio do fio é cerca de $20 \mathrm{~nm}$.

Isso indica que, para fios com raios em torno de 100nm, um cálculo mais realista da interação SPP-QD deve levar em conta pelo menos o primeiro modo excitado dos SPPs no fio. Para pequenos raios, no entanto, o ponto de cruzamento dos níveis de energia ocorre com $\beta$ grande. Nesse regime, a atenuação do SPP passa a ser mais sensível a possíveis corrugações presentes no nanofio. Por esse motivo, iremos, em primeira aproximação, supor que o único canal de decaimento dos éxcitons em SPPs seja para o modo fundamental 
mesmo em fios com 100nm de raio, por exemplo. Mesmo sob esta aproximação, podemos obter uma assinatura da interação SPP-QD, deixando claro que um cálculo mais realista deve levar em conta a existência do primeiro modo excitado.

\subsection{Decaimento dos SPPs}

No modelo utilizado até agora para a permissividade do metal considerou-se que a mesma era puramente real. Neste modelo, os efeitos de perda introduzidos pela parte imaginária da constante dielétrica são suprimidos e o SPP pode se propagar sem atenuação na interface metal/dielétrico. No entanto, as perdas são um importante efeito na propagação de SPPs em quaisquer tipos de geometria, mesmo no caso mais simples a dissipação de energia por colisões dos elétrons na rede cristalina do metal já são um importante canal de decaimento.

É preciso estimar as perdas no metal para decidir se desprezá-las se trata ou não de uma boa aproximação. Vale lembrar ainda que, além desse, há vários outros mecanismos de perda importantes e que devem ser levados em conta. Além da absorção de SPPs por colisões no metal, pode haver rugosidades presentes nas estruturas plasmônicas que acentuam a absorção (principalmente por decaimento radiativo), e o fato de que o semicondutor utilizado absorve fortemente a luz acima do seu gap de energia, igual a 1,43 eV para o GaAs a 300K.

Sendo assim, por se tratar de um ponto importante e que deve ser levado em consideração, alguns modelos que incluem as perdas podem ser adotados para descrever o sistema. Uma das maneiras de se fazer isso é utilizar, por exemplo, as soluções que obtivemos no caso sem perdas para obter os novos valores incluindo as perdas.

\subsubsection{Efeito das colisões no metal}

Para levar em conta a parte imaginária da constante dielétrica do metal, devemos voltar ao modelo inicial, mostrado na eq. (1), onde $\gamma$ é o fator que produz as perdas no metal. Conforme mostrado na tablela 1 , temos $\gamma_{A u}=69,1 \mathrm{meV}$ e $\gamma_{A g}=18 \mathrm{meV}$.

Comparando esses valores com a energia de plasma para cada um dos metais, temos 
$\left(\gamma / \omega_{p}\right)_{A u}=7,7 \cdot 10^{-3}$ e $\left(\gamma / \omega_{p}\right)_{A g}=2,0 \cdot 10^{-3}$, o que indica, pelo menos em princípio, que as perdas por dissipação são realmente muito pequenas e justificam nossa aproximação inicial.

Apesar de pequenas, essas perdas são as responsáveis por um comprimento de propagação $\left(L_{\text {spp }}\right)$ e um tempo de vida finito dos SPPs no guia. Através da inclusão desses efeitos será possivel determinar $L_{s p p}$ no guia cilíndrico.

Estaremos interessados numa região onde haja pequenas perdas, i.e. onde é válida a aproximação $\operatorname{Im}\left[\varepsilon_{m}\right] \ll \operatorname{Re}\left[\varepsilon_{m}\right]$. Essa aproximação é válida na vasta região de $\omega$ na qual estamos interessados, se desconsiderarmos a absorção do semicondutor acima de 1,5 eV.

Podemos definir a função

$$
F\left(\omega, \varepsilon_{m}\right)=\frac{\varepsilon_{m}}{\kappa_{m}} \frac{J_{1}\left(\kappa_{m} a\right)}{J_{0}\left(\kappa_{m} a\right)}-\frac{\varepsilon_{d}}{\kappa_{d}} \frac{H_{1}^{(1)}\left(\kappa_{d} a\right)}{H_{0}^{(1)}\left(\kappa_{d} a\right)},
$$

cujos zeros fornecem a condição de propagação do modo fundamental dada pela eq. 12 .

Nessa região, onde as perdas são pequenas, podemos fazer a aproximação

$$
F\left(\omega+i \eta, \varepsilon_{m}\right) \approx F\left(\omega, \varepsilon_{m}\right)+i \eta \frac{\partial F}{\partial \omega}\left(\omega, \varepsilon_{m}\right)
$$

Para obter as perdas introduzidas pela parte imaginária de $\varepsilon_{m}$, utilizamos o fato de que $F\left(\omega+i \eta, \varepsilon_{m}\right)=0$ para um modo do sistema, quando utilizamos o valor de $\varepsilon_{m}$ dado pela eq. 1. A razão $\eta / \omega$ deve ser pequena já que só aparece após a introdução de uma correção $\lesssim 10^{-2}$ na constante dielétrica do metal. O valor de $\eta$, que irá produzir a atenuação do modo fundamental do SPP ao longo do tempo, pode ser obtido através de

$$
\eta=-i \frac{F\left(\omega, \varepsilon_{m}\right)}{F_{, \omega}\left(\omega, \varepsilon_{m}\right)}
$$

onde $F_{, \omega}\left(\omega, \varepsilon_{m}\right)$ representa a derivada de $F$ com relação a $\omega$. Podemos, através do cálculo da parte imaginária da constante de propagação, determinar o valor do comprimento de propagação $L_{s p p}$ do modo fundamental do guia cilíndrico. O valor de $L_{s p p}$ é definido como aquele percorrido pelo SPP até que a intensidade da potência que ele carrega se reduza a 1/e. Esse valor finito é mostrado na fig. 17 como função de $\beta$.

Outra maneira de introduzir o comprimento de propagação é na parte imaginária da 


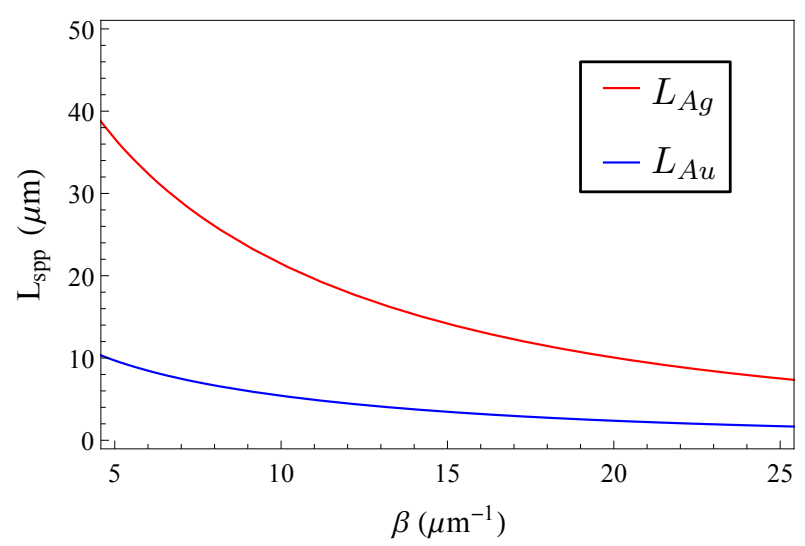

Figura 17 - Comparação entre o comprimento de propagação $L_{s p p}$ de um SPP num guia cilíndrico com $100 \mathrm{~nm}$ de raio para fios de $\mathrm{Au}$ e $\mathrm{Ag}$ imersos em uma matriz de GaAs.

Fonte: Elaborada pelo autor.

constante de propagação $\beta$. Neste caso, teremos $L_{s p p}=1 / 2 \operatorname{Im} \beta$.

Apesar de se tratar de uma aproximação muito simples e que só leva em conta um dos possíveis canais de decaimento dos SPPs, ela retrata bem a ordem de grandeza do comprimento de propagação do nanofio, e está de acordo com resultados experimentais. (53) Essas perdas indicam que os comprimentos típicos dos fios que podem ser utilizados, de forma que os efeitos de perda possam ser contornados, é da ordem de alguns poucos micrômetros $(\leq 5 \mu \mathrm{m})$.

\subsubsection{Efeito das rugosidades no metal}

Assim como a presença de grades metálicas retira as condições de casamento dos vetores de onda no acoplamento de SPPs com fótons, a simples presença de rugosidades na superfície metálica pode induzir a perda de SPPs por radiação. Esse canal de decaimento é ainda mais importante quando a superfície metálica está sobre vidros comerciais, que apresentam falhas em sua estrutura, ou quando a superfície metálica é muito fina (da ordem de alguns $\mathrm{nm}$ ), neste último caso ela é formada por aglomerados do metal ao invés de ser um filme plano.

Esse efeito é modelado, em geral, através de uma função rugosidade $s(y, z)$ que descreve a altura do metal na direção $x$, de acordo com a fig. 7(a). Neste caso, o valor médio da rugosidade é nulo $\bar{s}=0$, enquanto é o valor de $\overline{s^{2}}$ que dá a dimensão das rugosidades presentes no filme.

Costuma-se definir uma função de correlação 


$$
G(y, z)=\frac{1}{\mathcal{S}} \int_{\mathcal{S}} d y^{\prime} d z^{\prime} s\left(y^{\prime}, z^{\prime}\right) s\left(y-y^{\prime}, z-z^{\prime}\right)
$$

através da qual pode-se inferir a perdas por radiação do SPP devido às rugosidades do metal. Vale ressaltar que esse modelo costuma ser empregado para um filme plano. No caso de um fio metálico seria mais conveniente mapear as rugosidades através de uma função $s(a, \phi, z)$.

Se definirmos a transformada de Fourier

$$
|s(\Delta \beta)|^{2}=\frac{1}{2 \pi} \int_{\mathcal{S}} d y d z G(y, z) \exp \left[-i\left(\Delta \beta_{x} x+\Delta \beta_{y} y\right)\right]
$$

o termo $s(\Delta \beta)$, denominado função densidade espectral, dá o valor da variação do vetor de propagação $\Delta \beta$ devido ao espalhamento com as rugosidades do filme.

Em geral, a densidade espectral se aproxima de uma distribuição normal $s(\Delta \beta) \sim$ $\exp \left(-\alpha \Delta \beta^{2}\right)$. Isso explica uma largura finita para a constante de propagação dos SPPs.

Podemos aplicar a mesma condição utilizada para descrever o acoplamento dos SPPs com uma grade plasmônica para obter a condição de espalhamento dos SPPs pelas rugosidades. Isso demonstra que à medida que o comprimento de onda dos SPPs diminui (maiores valores de $\beta$ ), as perdas por radiação se tornam mais importantes.

Para suprimir esse tipo de perda é necessário que se produzam interfaces livres de quaisquer tipo de rugosidades. Isso é natural quando o filme metálico é depositado sobre uma superfície semicondutora, já que no processo de crescimento de nanoestrutras quânticas na região semicondutora, há grande controle sobre sua superfície. Neste caso, tipicamente temos $\sqrt{\overline{s^{2}}}$ da ordem de alguns angstrons em confronto com os melhores vidros, onde esse valor é da ordem de alguns nanômetros.

\subsubsection{Consequências no modelo de quantização}

Uma consequência em adotar diretamente as perdas, como fizemos ao levar em conta a parte imaginária da permissividade do metal, por exemplo, é que o processo de quantização do campo irá produzir um Hamiltoniano que não é hermiteano, e, portanto, não irá conservar a norma das funções de onda dos SPPs. 
Há outras maneiras mais formais de se introduzir os efeitos de absorção pelos materiais, metal e dielétrico, como partir de um modelo onde o meio é introduzido explicitamente. Num modelo desse tipo (55-57) é introduzido um fator de acoplamento da polarização do meio com um banho de campos harmônicos, que é o mecanismo responsável pela absorção da luz.

Em geral, no entanto, o procedimento adotado para inclusão de perdas consiste em considerar a propagação do sistema sem perdas e introduzir fatores fenomenológicos na equação de evolução da matriz de densidade (58), o que também é feito na interação de SPPs com sistemas quânticos. (59)

Um comentário importante que deve ser feito aqui é que as perdas presentes em sistemas plasmônicos representam a maior limitação técnica quando comparados a sistemas em fotônica ou física atômica. Esse efeito, no entanto, pode ser suprimido quando consideramos a grande magnitude do acoplamento presente nesse tipo de sistema em confronto a seus análogos em fotônica ou física atômica, i.e. o comprimento de espalhamento da luz deve diminuir quando o fator de acoplamento se torna maior.

Em paralelo a esses mecanismos naturais estão os processos de perdas dos SPPs através da interação com as bordas do sistema. Um fato experimental importante é que os SPPs podem ser facilmente excitados próximos às bordas do fio, por exemplo. Se por um lado isso é útil quando queremos injetar mais SPPs num fio, por outro lado, esse é um forte mecanismo de atenuação da intensidade dos campos presentes num nanofio, já que ao atingir uma das extremidades parte dos SPPs será irradiado. Para contornar esse efeito é costume se utilizar de antenas plasmônicas que podem ser sintonizadas com determinadas frequencias dos plásmons e facilitar a absorção da luz, além de diminuir as perdas por radiação.

\subsection{Plasmons de superfície localizados (LSPPs)}

Conforme já foi dito anteriormente, quando uma superfície apresentar rugosidades o acoplamento da luz com os SPPs é possível, já que as rugosidades atuam como uma grade na qual a condição de acoplamento com o vetor de onda da luz pode ser satisfeita. Quando isso ocorre é possível ainda que os SPPs não se propaguem ao longo do metal, 
i.e. seu campo pode ficar localizado na região dos aglomerados de partículas metálicas que compõem a superfície do filme. Os modos sustentados por essas "nanopartículas" são chamados de "Plásmon Poláritons de Superfície Localizados" ou LSPP (do inglês Localized Surface Plasmon Polaritons).

Uma boa estimativa para a dimensão de uma nanopartícula que suporta um modo de plásmon localizado é o comprimento de penetração $\delta$ do campo do SPP numa geometria qualquer. Num guia plano, por exemplo, definimos $\delta$ como o valor para o qual o campo do SPP cai para 1/e do seu valor na interface metal/dielétrico. Como o campo no metal cai com $e^{-\kappa_{m} z}$ de acordo com a eq. (6) temos $\delta=1 / \kappa_{m}$. Por extensão desse resultado, no guia cilíndrico costuma-se definir o comprimento de penetração como $\delta=1 / \operatorname{Re}\left[\kappa_{m}\right]$, onde $\kappa$ é definido na eq. 11. As figs. 18 e 19 mostram os comprimentos de propagação do campo do SPP na região do metal e do dielétrico, que modela o GaAs, tanto para um guia de onda plano como para um cilíndrico.

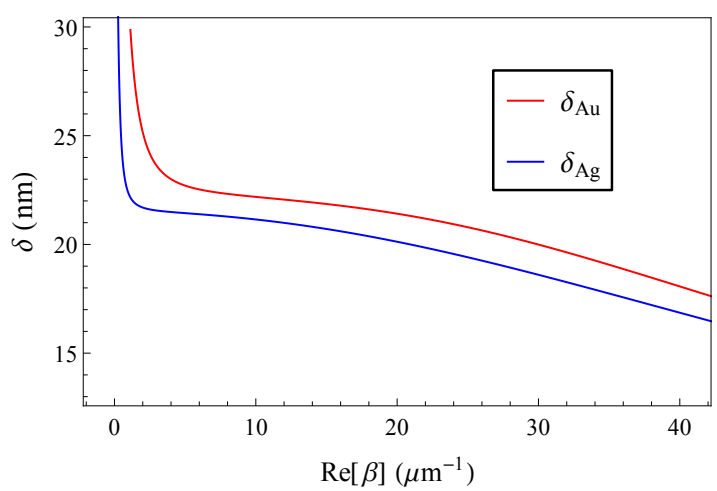

(a) Comprimento de penetração na região do metal.

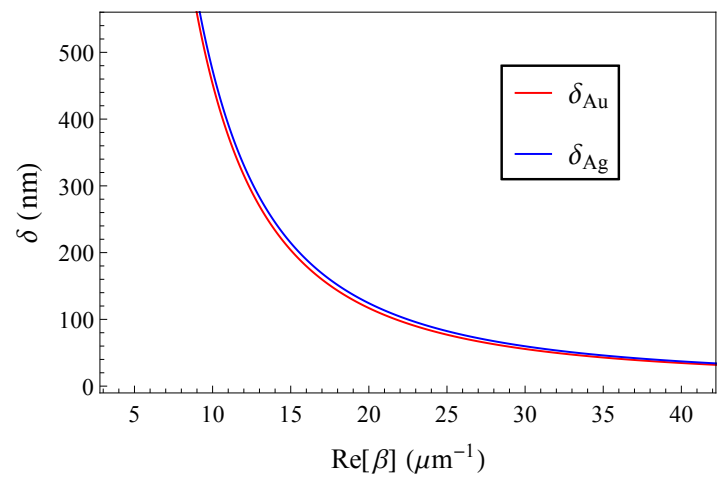

(b) Comprimento de penetração na região do dielétrico.

Figura 18 - Comprimento de penetração $\delta$ do campo do SPP para uma interface plana entre metal/GaAs como função do vetor de propagação $\beta$. As curvas mostradas são correspondentes ao $\mathrm{Au}$ (vermelho) e à $\mathrm{Ag}$ (azul).

Fonte: Elaborada pelo autor.

Fica claro nas figs. 18 e 19 que o campo do SPP penetra mais fortemente na região do dielétrico que na região do metal (cerca de uma ordem de grandeza acima), motivo pelo qual desejamos investigar sua interação com emissores quânticos posicionados na região do dielétrico. Outro fato importante a se observar é que o valor de $\delta$ pode chegar a $0,5 \mu \mathrm{m}$. Como nossos sistemas experimentais tratam-se de pontos quânticos em semicondutores, esse valor representa uma quantidade imensa, já que distâncias típicas de sistemas semicondutores bem controlados são menores ou da ordem de 50nm. 


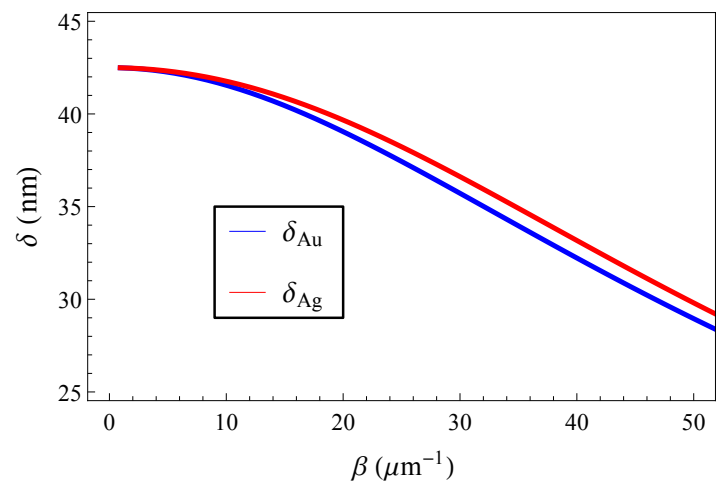

(a) Comprimento de penetração na região do metal.

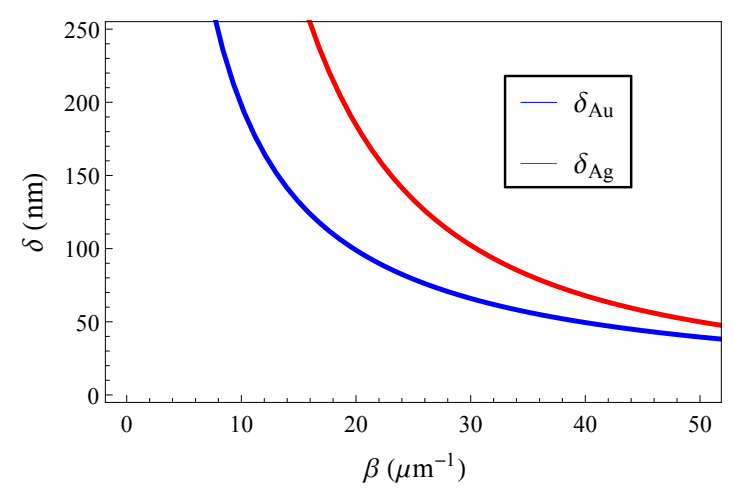

(b) Comprimento de penetração na região do dielétrico.

Figura 19 - Comprimento de penetração $\delta$ do campo do SPP para um guia cilíndrico metal/GaAs com $100 \mathrm{~nm}$ de raio como função do vetor de propagação $\beta$. As curvas mostradas são correspondentes ao $\mathrm{Au}$ (azul) e à $\mathrm{Ag}$ (vermelho).

Fonte: Elaborada pelo autor.

Num guia plano a condição de ressonância do SPP é facilmente obtida; é necessário que $\varepsilon_{m}+\varepsilon_{d}=0$, conforme mostra a eq. 7. No entanto, para uma nanopartícula, tanto a relação entre as constantes dielétricas do metal e do dielétrico como a forma e dimensões da mesma são importantes, conforme mostra a fig. 20.

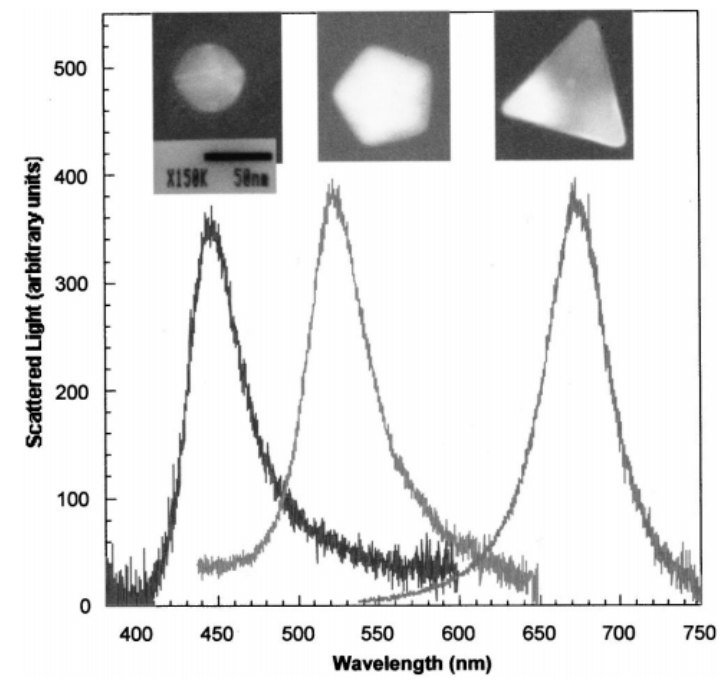

(a) Ressonância de LSPPs como função da geometria das nanopartículas de Ag.

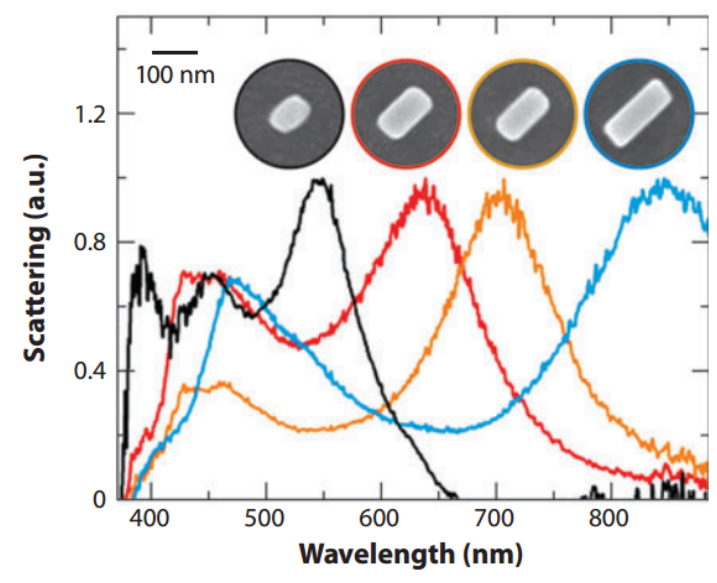

(b) Ressonância de LSPPs como função das dimensões de uma nanobarra metálica de Ag.

Figura 20 - Dependência do comprimento de onda de ressonância de um LSPP como função de sua geometria 20(a) e de suas dimensões 20(b).

Fonte: (a) MOCK et. al. (60); (b) LU et. al. (61)

Em geral, é possível obter nanopartículas esféricas comerciais ou fabricá-las utilizando um feixe de elétrons. (62) Há ainda a possibilidade de fabricar nanopartículas de Gálio durante o crescimento de pontos quânticos. 
A utilização de nanopartículas tem se tornado um importante objeto de estudo em plasmônica pois com esse tipo de sistema é possível aumentar a intensidade do campo eletromagnético em até $\times 10^{6}$. (60) Esse tipo de aumento é útil para se estudar sistemas fortemente correlacionados, para aumentar o constraste em medidas ou mesmo para coibir efeitos de quenching em amostras biológicas. (63)

É ainda possível, através da utilização de nanopartículas metálicas, produzir grades (64), antenas (47) ou até mesmo guias de onda plasmônicos. (65) Alguns trabalhos também investigam a quantização de modos de SPPs localizados (20) com o mesmo objetivo de extrair propriedades quânticas desses sistemas. 


\section{Emissores quânticos}

Conforme vimos no capítulo anterior, os SPPs se comportam como fótons que se propagam em estruturas de baixa dimensionalidade. A interação SPP-SPP é tão pouco efetiva quanto a interação fóton-fóton. (66) No entanto, devido à alta densidade de campo eletromagnético carregado por esses SPPs, a mediação dessa interação por emissores quânticos pode ser ordens de grandeza maiores que a interação fóton-fóton. (67-69)

Em geral, por este motivo, utilizam-se inúmeros emissores quânticos nas proximidades da região onde estão presentes os SPPs para criar uma região de interação efetiva.

\subsection{Vidros dopados}

Apesar de não ser nosso foco de estudo, a utilização de vidros dopados com terras raras (70-72), por exemplo, são de grande utilidade para aplicações de plasmônica. Por este motivo merecem um breve comentário.

Em geral, utilizam-se vidros dopados com Itérbio, Érbio, Túlio, ou composições dos mesmos, que dentro da matriz vítrea aparecem em suas formas iônicas $\mathrm{Yb}^{3+}, \mathrm{Er}^{3+} \mathrm{ou}$ $\mathrm{Tm}^{3+}$ para citar alguns exemplos. $(73,74)$

Não é por acaso a utilização destes elementos, eles já são utilizados há muito tempo em aplicações ópticas e magnéticas. (75) Isso é explicado pela região de emissão luminosa dos mesmos, em torno do espectro visível e do infravermelho próximo $(0,5-1,5 \mu \mathrm{m})$.

Um caso especial destes elementos é o caso do érbio $\left(\mathrm{Er}^{3+}\right)$ e em particular a sua emissão em torno de 1550nm. Essa região é a mesma utilizada em janelas de telecomunicação. Por este motivo, atualmente há um grande interesse em utilizar materiais dopados com érbio para desenvolver elementos com ganho em sistemas de telecomunicação. $(76,77)$

Em particular no caso de SPPs, a presença dessas partículas permite que não somente o campo do SPP sofra um aumento, mas seu comprimento de propagação se torna maior, por isso a denominação destes meios como meios com ganho. 


\subsection{Pontos quânticos}

\subsubsection{Sistema de MBE}

Em nossos estudos, utilizamos como emissores quânticos um conjunto de QDs fabricados em matrizes semicondutoras. Os QDs são essencialmente uma barreira de potencial gerada pela diferença entre os gaps de energia de InAs imersos numa matriz de GaAs.

Para formar os QDs utilizamos a técnica conhecida como epitaxia por feixes moleculares (MBE, "Molecular Beam Epitaxy") (78) no qual o material semicondutor é depositado camada a camada sobre um substrato cristalino. A precisão na espessura de uma camada semicondutora neste tipo de sistema é da ordem de uma camada atômica, ou seja, cerca de $2 \sim 3 \AA$.

A fig. 21(a) mostra num diagrama esquemático um sistema de MBE como o que utilizamos em nosso trabalho.

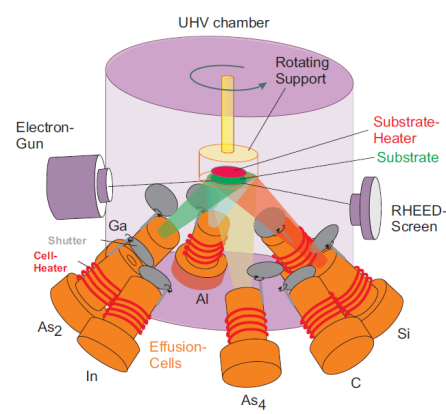

(a) Diagrama esquemático de um sistema de MBE.

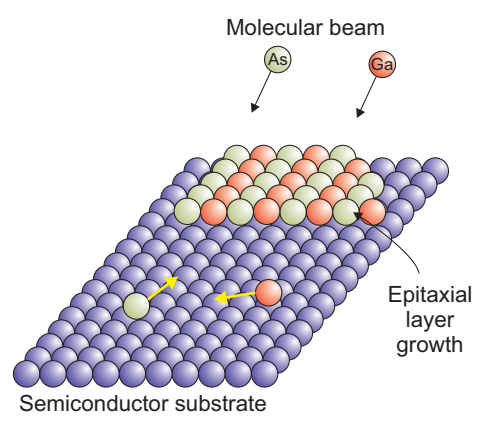

(b) Modelo da evaporação de uma camada atômica.

Figura 21 - Diagrama de funcionamento básico de um sistema de MBE indicando em (a) as câmaras de efusão que contêm os materiais a serem depositados no substrato semicondutor, bem como o RHEED utilizado para acompanhar o processo de deposição. Em (b) é mostrado o processo de deposição do material sobre o substrato indicando a formação de camadas atômicas bem definidas.

Fonte: (a) Roescu2009. (79); (b) Elaborada pelo autor.

A amostra a ser crescida é colocada numa câmara de ultra-alto vácuo e mantida aquecida, para que sejam depositados os materiais contidos nas células de efusão.

A taxa de deposição do filme, ilustrada na fig. 21(b), pode ser controlada através de uma tela fosforescente na qual elétrons difratados sobre a amostra determinam um padrão de interferência bem definido. Estes padrões de interferência são formados por difração de Bragg na superfície cristalina do material depositado. Sempre que uma camada do material cristalino é formada a intensidade de oscilação na tela fosforescente volta ao 
mesmo valor original.

Através destas oscilações de intensidade do padrão de interferência dos elétrons sobre a tela é possível inferir qual a taxa de deposição do filme. Este é o princípio de funcionamento de um "RHEED" (difração de elétrons altamente energéticos, do inglês reflection high energy electron diffraction). (78)

A deposição de uma camada atômica de GaAs sobre a superfície cristalina do substrato original é ilustrada na fig. 21(b). Essencialmente, a deposição é feita da seguinte maneira; o substrato é mantido aquecido (cerca de $600^{\circ} \mathrm{C}$ ) para manter a estequiometria correta dos componentes sobre a amostra, para isso a câmara deve ser mantida sob atmosfera de arsênio. Para manter essa atmosfera em um nível razoável, a célula de efusão que contêm As é mantida aberta durante o processo de crescimento. Para que os átomos de gálio possam aderir à superfície da amostra, a célula que contém este material é aberta, e a reação com o As ocorre sobre a superfície do substrato onde o cristal irá se formar e seguir a mesma orientação do substrato, daí o nome crescimento epitaxial.

É importante ressaltar que a técnica MBE se baseia na repetição de um padrão cristalino sobre um cristal previamente formado, não é possível, por exemplo, crescer um cristal de GaAs sobre uma superfície de um material vítreo, por se tratar de uma estrutura amorfa.

\subsubsection{Crescimento de pontos quânticos}

Ao se depositar um material semicondutor sobre a superfície de outro com gap de energia diferente, é possível que, devido ao forte confinamento energético, os elétrons e buracos presentes nos semicondutores apresentem modos discretos de energia. Isso ocorre, por exemplo, quando uma ilha de InAs se forma dentro de uma matriz de GaAs. (80) Neste caso, se a ilha possuir dimensões características de alguns nanômetros, comparáveis ao comprimento de onda associado ao elétron nestes materiais, ocorrerá o confinamento. Uma estimativa razoável para essas dimensões é que as mesmas sejam menores ou da ordem do raio fundamental de um éxciton no GaAs $(\sim 25 \mathrm{~nm})$ bulk. (80)

Os pontos quânticos consistem nessas regiões onde o elétron só pode possuir energias bem definidas. O sistema é análogo a um átomo gigante, com raio de alguns nanômetros. 
Ao excitar o elétron para a banda de condução do InAs, é formado um buraco na banda de valência. Em paralelo ao confinamento devido à diferença no gap de energia dos dois materiais, este buraco é capaz de interagir com o elétron através da interação de Coulomb (80), que é o mecanismo que dá origem às energias características do sistema.

Na fig. 22(a), está o diagrama simplificado de formação e dissociação de um éxciton. No esquema os principais processos são

- absorção de um fóton pelos portadores de carga nas proximidades de um QD;

- relaxação intrabanda dos portadores (elétron) no QD;

- formação do par elétron-buraco (éxciton);

- recombinação do éxciton e emissão de um fóton com a energia correspondente à energia o éxciton $\hbar \omega_{q d}$. (79)

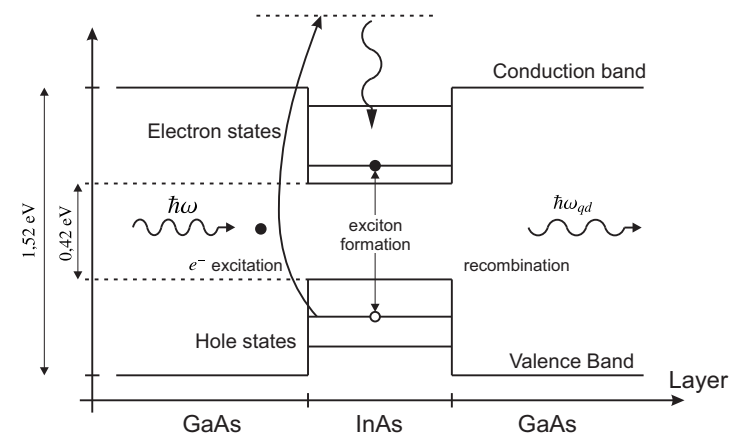

(a) Excitação e relaxação de um QD.

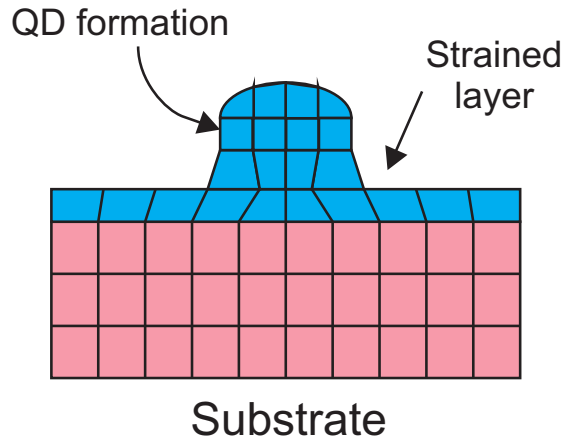

(b) Formação de um self-assembled QD.

Figura 22 - Diagramas indicando os processos de excitação (a) e formação (b) de um QD.

Fonte: Elaborada pelo autor.

A formação de um QD de InAs sobre um substrato de GaAs pode ser auto-organizada (self-assembled) (79), este processo baseia-se na diferença entre os parâmetros de rede de ambos os cristais. Neste caso, o crescimento dos pontos ocorrem em posições distribuídas aleatoriamente sobre o substrato. Há também métodos onde o crescimento dos QDs pode ocorrer em posições bem definidas sobre o substrato, com a utilização de técnicas como o crescimento sobre bordas clivadas (CEO, do inglês cleaved-edge overgrowth). (81)

Apesar de ser uma técnica que não foi utilizada em nossos estudos a CEO, que permite a possibilidade da formação de QDs em posições bem definidas, nos proporcionou 
fundamentação experimental para alguns dos estudos teóricos que podem ser realizados experimentalmente utilizando-se da mesma.

Vamos discutir brevemente os dois processos de formação de QDs no qual estamos interessados.

Primeiramente, o método de crescimento auto-organizado, que é aquele disponível atualmente em nosso laboratório, se baseia na diferença de parâmetro de rede entre o InAs $(\sim 6,06 \AA)$ e o GaAs $(\sim 5,65 \AA)$ e o modo de crescimento é conhecido como modo de Stranski-Krastanov (SK) (79), mostrado na fig. 22(b).

Os processos empregados no modo de crescimento SK estão descritos abaixo:

- Deposição de InAs sobre o GaAs, até atingir uma camada crítica de $\sim 1,7$ monocamadas de InAs;

- Relaxação da camada e formação de pequenos aglomerados de InAs sobre a matriz de GaAs, energeticamente mais favoráveis;

- Tratamento térmico in situ, i.e. dentro da câmara de MBE, para aumentar o tamanho e homogenizar os aglomerados, e formação dos QDs;

- Deposição de uma camada de GaAs (buffer) sobre os QDs para criar uma barreira de potencial e manter as propriedades ópticas.

A última camada de GaAs, chamada de cap layer, é colocada para manter (proteger) as propriedades ópticas dos QDs, que seriam drasticamente modificadas caso uma camada de óxido se depositasse sobre os mesmos após retirá-los da câmara de vácuo do MBE. Além disso, essa camada também atua como uma barreira de potencial para confinar os elétrons na região do QD.

O método do crescimento sobre bordas clivadas (CEO, do inglês cleaved-edge overgrowth) é feito seguindo basicamente receita indicada a seguir (veja a fig. 23)

- Crescer um conjunto de poços quânticos sobre um substrato;

- Clivar o substrato na direção normal ao primeiro crescimento, dentro da câmara de MBE; 
- Mudar a posição de crescimento e depositar mais um poço quântico sobre a superfície clivada;

- Clivar novamente o substrato agora na direção normal ao segundo processo de crescimento;

- Depositar uma última camada de buffer sobre a última superfície clivada.

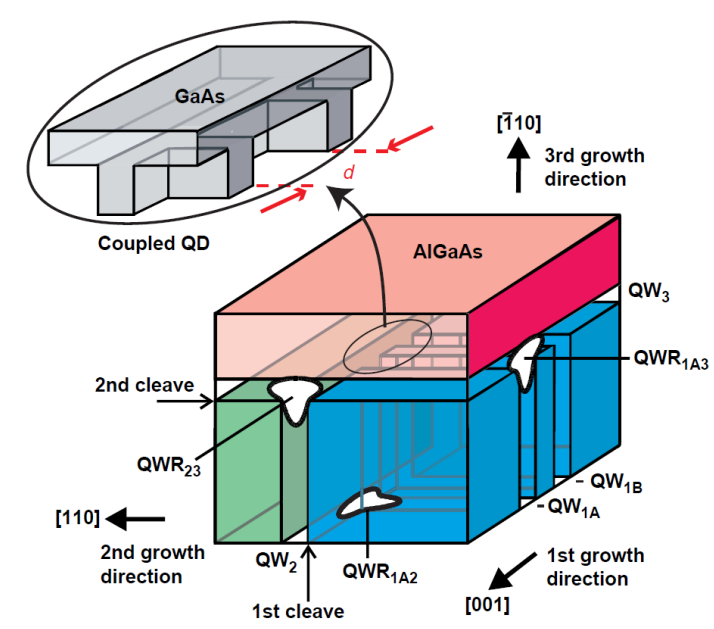

Figura 23 - Esquema indicando os poços quânticos utilizados para a modelagem de QDs crescidos pelo método do CEO.

Fonte: SCHEDELBECK et. al. (81)

Este último processo, apesar de bastante complicado de ser realizado experimentalmente, possui inúmeras possibilidades. Entre elas, é possível formar um conjunto de QDs praticamente idênticos, de forma que a largura natural de energia que ocorre em processos como SK pode ser drasticamente reduzida. Vale ressaltar que a largura espectral dos QDs depende de inúmeros fatores como a distribuição de tamanhos dos QDs, a interação dos mesmos com fônons da rede etc.

Utilizando a técnica das bordas clivadas (82) é possível controlar ainda a estrutura e a energia de cada ponto com o controle sobre seu tamanho. (83-86) Além disso, a distância entre os pontos pode ser ajustada sendo possível, inclusive, obter acoplamento eletrônico entre os mesmos. (81)

Devido à grande precisão disponível em um sistema de MBE, esse tipo de crescimento é o que proporciona o maior controle sobre as características dos QDs. 


\subsubsection{Propriedades do pontos quânticos}

O éxciton formado em QDs possui alguns níveis discretos de energia, mas a primeira transição é a mais importante nos processos de absorção de luz a baixas potências. (87) Isso acontece porque para que a segunda transição comece a ser importante é necessário, em geral, que a primeira transição seja saturada, ou seja o primeiro estado dos QDs seja totalmente populado. Desta maneira, podemos imaginar, em primeira aproximação, que um QD consiste apenas de um sistema de dois níveis.

Os pontos quânticos fabricados em nosso sistema experimental, utilizando o modo de SK, possuem energias em torno de $1,1 \mathrm{eV}$ (veja a fig. 24), essa foi e continuará a ser a energia característica adotada em todo o texto quando quisermos nos referir a valores numéricos. É importante ressaltar, no entanto, que esse valor pode ser ligeiramente alterado dependendo das condições sob as quais os pontos são crescidos. (88, 89) Em nossas amostras, controlamos a relação entre o material (InAs) depositado sobre o material do substrato (GaAs) de forma que a energia seja aproximadamente a mesma qualquer que seja a camada de buffer utilizada. Isso pode ser visto claramente na fig. 24, onde apenas o sistema com QDs a 10nm da superfície da amostra apresenta um pequeno desvio na energia de excitação do modo fundamental. Esse desvio ocorre devido à assimetria da barreira de potencial gerada pelo confinamento eletrônico no GaAs, além dos efeitos de strain que aparecem pelo fato da camada de GaAs não ter atingido seu parâmetro de rede natural.

Os dados mostrados na fig. 24 foram obtidos utilizando-se espectroscopia de fotoluminescência (PL), onde a amostra de QDs é mantida a 7K. A potência do laser utilizada foi escolhida baixa o suficiente para que apenas o estado fundamental do éxciton fosse excitado. Observe que a largura característica correspondente a cada amostra é cerca de $30 \mathrm{meV}$, o que indica que os QDs possuem tamanhos muito próximos. Vale ressaltar neste ponto que a largura espectral da amostra está intimamente ligada à distribuição de tamanhos dos QDs e não à sua largura natural de linha, que é da ordem de alguns $\mu \mathrm{eV}$.

Além dessas propriedades, os QDs possuem momentos de dipolo da transição fundamental da ordem de $6 \AA$, conforme (90, 91); A unidade do momento de dipolo escrita em angstrons é mais útil para sistemas atômicos e é basicamente o momento de dipolo 


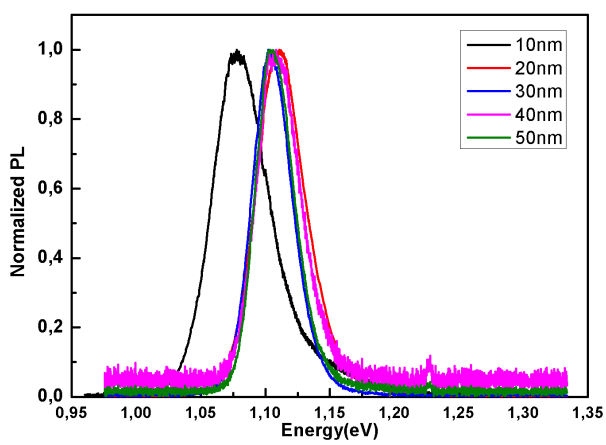

(a) Espectro de PL a baixas potências para um conjunto de amostras com diferentes valores de cap layer.

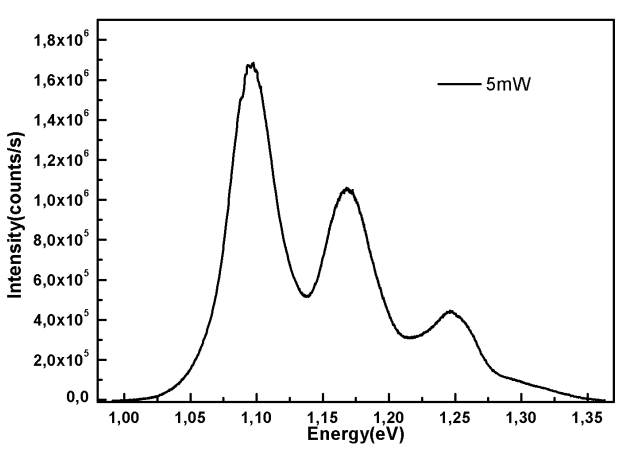

(b) Espectro de PL a alta intensidade indicando os diversos estados de energia dos QDs para a amostra com 50nm de cap layer.

Figura 24 - Espectro normalizado dos níveis de energia dos QDs de InAs obtidos utilizando-se de espectroscopia de fotoluminescência.

Fonte: Elaborada pelo autor.

dividido pela carga do elétron. Alguns autores também utilizam para esse tipo de sistema a unidade Debye para o momento de dipolo. Isso indica que a interação com a luz, que surge do acoplamento por dipolo com o campo elétrico, é muito grande. Em geral, para átomos, o momento de dipolo é da ordem de $1 \AA$ ou menos. Por esse motivo, em óptica quântica, é costume se utilizar átomos de Rydberg, onde o momento de dipolo é da ordem de 2000Å. (92) A deficiência nesses sistemas é que a energia de transição para esses estados é na região de microondas, o que produz um baixo valor na constante de acoplamento átomo-campo. Esse é mais um ponto positivo para a utilização de sistemas plasmônicos para investigar a interação da luz com a matéria na região do espectro visível.

\subsection{Modelo dos QDs}

A ideia por trás da formação dos QDs é a redução da dimensionalidade do confinamento eletrônico dentro de uma estrutura semicondutora. À medida que o elétron é confinado em mais dimensões seus níveis de energia e densidades de estado mudam drasticamente.

Para exemplificar este processo considere o modelo de um elétron aprisionado num poço quântivo; uma estrutura que consiste de camadas alternadas de diferentes materiais como GaAs e $\mathrm{Ga}_{1-x} \mathrm{Al}_{x} \mathrm{As}$, conforme mostra a fig. 25.

A equação de Schrödinger que o elétron satisfaz tem um termo de potencial que depende apenas da direção $z$, conforme mostra a fig. 25. Neste caso, teríamos: 


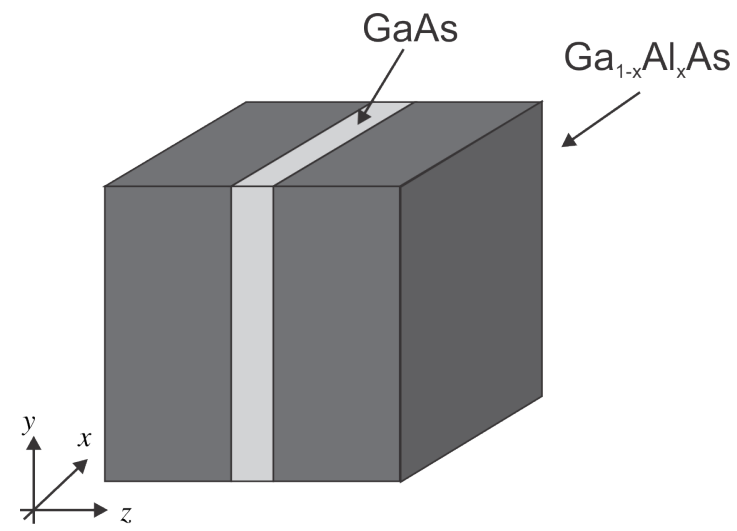

Figura 25 - Diagrama de um poço quântico de GaAs/ $\mathrm{Ga}_{1-x} \mathrm{Al}_{x} \mathrm{As}$ para exemplificar o procedimento de confinamento do elétron numa nanoestrutura quântica.

Fonte: Elaborada pelo autor.

$$
-\frac{\hbar^{2}}{2 m}\left(\frac{\partial^{2}}{\partial x^{2}}+\frac{\partial^{2}}{\partial y^{2}}+\frac{\partial^{2}}{\partial z^{2}}\right) \psi+V(z) \psi=E \psi
$$

Podemos, como é de costume, utilizar a técnica da separação de variáveis para obter a dependência da função de onda $\psi$ do elétron com cada eixo coordenado. Neste caso,

$$
\psi(x, y, z)=\psi_{x}(x) \psi_{y}(y) \psi_{z}(z)
$$

Dessa forma, a energia pode ser escrita como $E=E_{x}+E_{y}+E_{z}$, que indica o "desacoplamento" do movimento em cada direção. Podemos definir as quantidades $k_{x}^{2}=2 m E_{x} / \hbar^{2}$, $k_{y}^{2}=2 m E_{y} / \hbar^{2}$ e $k_{z}^{2}=2 m E_{z} / \hbar^{2}$, para escrever as equações:

$$
\frac{d^{2} \psi_{x}}{d x^{2}}=-k_{x}^{2} \psi_{x}, \quad \frac{d^{2} \psi_{y}}{d y^{2}}=-k_{y}^{2} \psi_{y}, \quad \frac{d^{2} \psi_{z}}{d z^{2}}-\frac{2 m V(z)}{\hbar^{2}}=-k_{z}^{2} \psi_{z}
$$

As duas primeiras equações representam uma partícula livre, enquanto a terceira indica uma partícula confinada em um potencial unidimensional. Na direção $z$, podemos definir um número quântico $n$ que irá governar o comportamento da partícula. Assim a energia total é dada por:

$$
E=E_{n}+\frac{\hbar^{2}}{2 m}\left(k_{x}^{2}+k_{y}^{2}\right) .
$$

A densidade de estados $\rho(E)$ nessa geometria inclui gaps devidos aos estados com diferentes valores de número quântico $n$ e à densidade, constante, de um sistema 2D. 
Neste caso, a densidade de estados se reduz a um conjunto de degraus.

A fig. 26 indica a densidade de estados de um elétron em estruturas quânticas à medida que diminuímos a dimensionalidade.
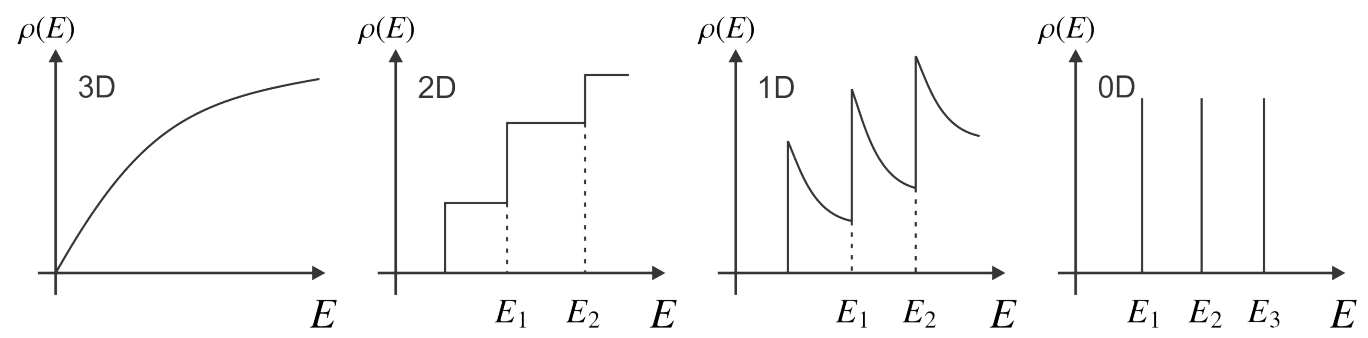

Figura 26 - Densidade de estados para um elétron confinado em diversas estruturas como função da dimensionalidade do sistema.

Fonte: Elaborada pelo autor.

No caso de um QD, a formação do éxciton cria estados de energia bastante próximos entre si. Estes estados possuem ainda um tempo de vida finito (da ordem de alguns ns), o que dá uma largura finita às linhas que representam a densidade de estados num sistema 0D, diferentemente do que é mostrado na fig. 26.

Em nosso trabalho, buscamos obter as características básicas que resultam da interação de SPPs com éxcitons em QDs. É possível observar experimentalmente, conforme veremos nos capítulos 4 e 5, que devido à interação com SPPs estados mais energéticos de um éxciton podem ser excitados mesmo a baixas potências quando comparadas com aquelas típicas de experimentos de PL.

A explicação dessas excitações, que ficará mais clara após uma discussão mais detalhada, está intimamente ligada às propriedades dos estados mais energéticos e suas funções de onda, além do perfil do SPP nas proximidades dos QDs.

No entanto, em se tratando de uma primeira abordagem, os principais efeitos podem ser descritos utilizando apenas o acoplamento de dipolo dos SPPs com os QDs. Por esse motivo, a descrição dos níveis de energia do éxciton formado nos QDs ( 5 ou 6) (87) pode ser aproximada como um sistema de dois níveis de energia mesmo na interação com SPPs, análogo ao que é feito em modelos mais simples utilizados em óptica quântica. Dessa forma, o Hamiltoniano do QD pode ser escrito como

$$
\mathcal{H}_{Q D}=E_{e}|e\rangle\left\langle e\left|+E_{g}\right| g\right\rangle\langle g|,
$$


onde $E_{i}$ representa a enegia do estado $i$, enquanto $|g\rangle$ está para o estado fundamental (elétron na banda de valência) e $|e\rangle$ está para o estado excitado (elétron na banda de condução). Neste caso, o estado $|e\rangle$ significa que um éxciton foi excitado enquanto o estado $|g\rangle$ indica que o sistema não possui éxcitons formados.

Como é costume ao se tratar de um sistema de dois níveis, podemos reescrever o hamiltoniano da eq. (34) como

$$
\mathcal{H}_{Q D}=\left(\frac{E_{e}+E_{g}}{2}\right)(|e\rangle\langle e|+| g\rangle\langle g|)+\left(\frac{E_{e}-E_{g}}{2}\right)(|e\rangle\langle e|-| g\rangle\langle g|) .
$$

O primeiro termo da eq. 35 representa apenas um deslocamento na escala de energia do sistema. Dessa forma, o hamiltoniano do QD pode ser escrito da mesma maneira que um sistema de spin 1/2 num campo magnético como

$$
\mathcal{H}_{Q D}=\frac{1}{2} \Delta \sigma_{z}
$$

onde $\Delta=E_{e}-E_{g}$ representa a separação energética dos dois níveis do éxciton no QD em questão e $\sigma_{z}$ é a matriz de Pauli que atua no estado interno do ponto quântico e que, juntamente com os estados do ponto, podem ser escritas em representação matricial como

$$
|g\rangle=\left(\begin{array}{c}
0 \\
1
\end{array}\right), \quad|e\rangle=\left(\begin{array}{l}
1 \\
0
\end{array}\right), \quad \sigma_{z}=\left(\begin{array}{cc}
1 & 0 \\
0 & -1
\end{array}\right) \text {. }
$$

\subsection{Hamiltoniano de interação}

Em um modelo simples para analisar a interação entre os éxcitons presentes nos QDs, consideremos uma cadeia unidimensional de QDs que podem interagir com os modos dos SPPs num fio metálico, por exemplo como aquele sistema ilustrado na fig. 27. Neste caso, o hamiltoniano não interagente QD-SPP pode ser escrito como

$$
\mathcal{H}_{0}=\sum_{\beta} \omega_{\beta}\left(a_{\beta}^{\dagger} a_{\beta}+\frac{1}{2}\right)+\frac{1}{2} \sum_{j=1}^{N} \Delta \sigma_{j}^{z}
$$

onde a cadeia de QDs é descrita pelo índice $j$.

O campo eletromagnético gerado pelos SPPs interage com o momento de dipolo elétrico 


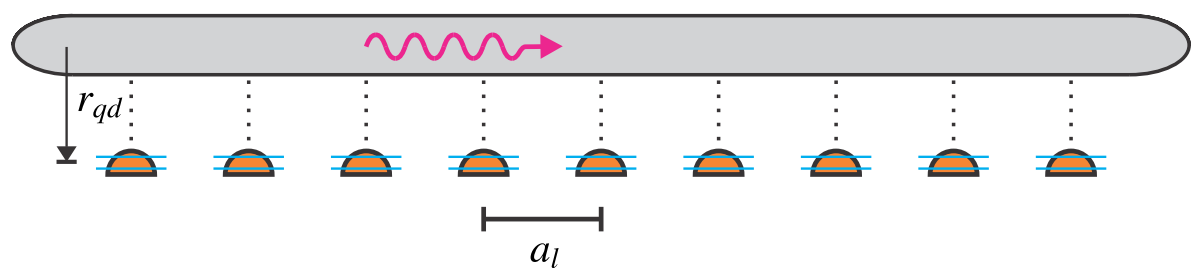

Figura 27 - Diagrama esquemático da interação de uma cadeia de QD com SPPs suportados num nanofio metálico. A distância entre a cadeia e o nanofio é $r_{q d}$ e o parâmetro de rede da cadeia de QDs é $a_{l}$.

Fonte: Elaborada pelo autor.

dos éxcitons no QD, ou seja, o hamiltoniano de interação SPP-QD pode ser escrito como

$$
\mathcal{H}_{I}=-\sum_{j} \vec{p}_{j} \cdot \vec{E}_{j}
$$

onde $\vec{p}_{j}$ e $\vec{E}_{j}$ são respectivamente, o momento de dipolo do $j$-ésimo QD e o campo elétrico do SPP sobre o mesmo. Tomando o cuidado de que para obter o conjugado hermiteano do hamiltoniano do campo devemos trocar $\beta$ por $-\beta$, podemos utilizar as expressões do potencial vetor dado pela eq. 14 e dos operadores de criação na eq. 23 para escrever:

$$
\vec{A}(\vec{r})=\frac{1}{\sqrt{2 \pi L}} \sum_{\beta} \frac{1}{\sqrt{2 m_{\beta} \omega_{\beta}}}\left(a_{\beta}+a_{-\beta}^{\dagger}\right) e^{i \beta z}\left[\vec{\xi}_{m}(\beta) \theta(a-\rho)+\vec{\xi}_{d}(\beta) \theta(\rho-a)\right]
$$

Vale lembrar aqui que os operadores de criação e aniquilação livres evoluem na versão de interação como

$$
a_{\beta}(t)=a_{\beta} e^{-i \omega_{\beta} t}, \quad a_{\beta}^{\dagger}(t)=a_{\beta}^{\dagger} e^{i \omega_{\beta} t}
$$

de forma que podemos escrever o campo elétrico dos SPPs na forma

$$
\vec{E}(\vec{r})=i \sum_{\beta} \sqrt{\frac{\omega_{\beta}}{4 \pi m_{\beta} L}}\left(a_{\beta}-a_{-\beta}^{\dagger}\right) e^{i \beta z}\left[\vec{\xi}_{m}(\beta) \theta(a-\rho)+\vec{\xi}_{d}(\beta) \theta(\rho-a)\right] .
$$

Vamos fazer uma análise considerando o limite termodinâmico, no qual o nanofio plasmônico pode ser considerado infinito e o espectro de modos discretos dos SPPs que se propagam no mesmo pode ser considerado contínuo. Dessa forma, a eq. 42 representa 
o campo do SPP que efetivamente interage com os QDs.

A presença da cadeia induz sobre os SPPs um potencial periódico que pode ser extraído do hamiltoniano de interação do sistema. Antes de aplicar a Aproximação de Ondas Girantes (RWA, do inglês Rotating Wave Approximation) é preciso levar em consideração o fato de que termos lineares nas excitações dos SPPs aparecem na interação com os QDs. Para se desfazer desses termos seria necessário fazer uma transformação unitária que deslocasse os modos dos SPPs e deixasse o hamiltoniano total livre de termos lineares.

Há dois tipos de termos lineares: os que modificam o estado do QD e os que deixam o estado do QD inalterado.

A parte de interação que não modifica o estado do QD deve corresponder a um potencial estático que irá renormalizar a energia dos SPPs próximo à borda da primeira zona de Brillouin (7) da cadeira de QDs. O hamiltoniano de interação correspondente a este caso pode ser escrito como

$$
\mathcal{H}_{\|}^{i n t}=i \sqrt{\frac{1}{L}} \sum_{\beta} \sum_{j}\left(\lambda_{e}(\beta) \mathbb{P}_{e}(j)+\lambda_{g}(\beta) \mathbb{P}_{g}(j)\right)\left(a_{\beta}-a_{-\beta}^{\dagger}\right) e^{i \beta z_{j}},
$$

onde $\lambda_{\alpha}(\beta)=\lambda_{\alpha}^{*}(-\beta)$ e $\mathbb{P}_{\alpha}(j)$ são os projetores nos estados $\alpha=e, g$ do j-ésimo QD. Esses projetores podem ser escritos como função das matrizes de spin

$$
\mathbb{P}_{e}(j)=\frac{1+\sigma_{j}^{z}}{2}, \quad \mathbb{P}_{g}(j)=\frac{1-\sigma_{j}^{z}}{2}
$$

Assim, podemos definir os operadores de projeção nos estados como função de $\beta$

$$
\mathbb{P}_{\alpha}(\beta)=\sqrt{\frac{1}{N}} \sum_{j=1}^{N} \mathbb{P}_{\alpha}(j) e^{-i \beta z_{j}}
$$

De forma que $(\alpha=e, g=+,-)$

$$
\mathbb{P}_{ \pm}(\beta)=\frac{1}{2}\left(\sqrt{N} \delta_{\beta, 0} \pm \sigma_{-\beta}^{z}\right)
$$

Isto significa que os termos proporcionais à identidade no espaço dos QDs, que geram o potencial estático, só ocorrem para SPPs no centro da zona de Brillouin. Este é um resultado esperado já que a interação SPP-QD é invariante por translação da cadeia. 
Dessa maneira, não é necessário deslocar os modos dos SPPs, já que não há termos com $\beta \neq 0$.

A interação SPP-QD pode ser investigada utilizando-se a aproximação de ondas girantes (RWA). (51) Nesta aproximação, supomos que o acoplamento seja fraco, e que a diferença de energia entre os SPPs e os éxcitons não seja grande (quando comparadas com a magnitude do fator de acoplamento). Vale ressaltar aqui que resultados análogos são obtidos caso não seja considerado a priori que o acoplamento é fraco. Ainda em RWA, não se levam em conta termos que podem não conservar energia como algo do tipo que cria uma excitação dos SPPs e excita um QD. Para que essa aproximação seja válida é necessário investigarmos um regime de baixas excitações do sistema e pequena densidade de QDs, o que será feito no nosso modelo. Isso é necessário, pois num sistema grande é possível que processos que não conservam energia ocorram localmente, mas são compensados, em média, por processos ocorrendo em outras regiões do sistema.

Sendo assim, o hamiltoniano que preserva o estado dos QDs pode ser reescrito como (considerando somente modos $\operatorname{com} \beta \neq 0$ )

$$
\mathcal{H}_{\|}^{\text {int }}=i \sqrt{\frac{N}{L}} \sum_{\beta} \tilde{\lambda}(\beta) \sigma_{-\beta}^{z}\left(a_{\beta}-a_{-\beta}^{\dagger}\right),
$$

onde $\tilde{\lambda}(\beta)=\left[\lambda_{e}(\beta)-\lambda_{g}(\beta)\right] / 2$. Após RWA este termo deve ser descartado, já que $\sigma_{-\beta}^{z}$ não oscila no tempo de acordo com os operadores de criação e aniquilação dos SPPs.

O termo de interação que não conserva o estado do QD, onde se forma ou destrói um éxciton, corresponde ao hamiltoniano

$$
\mathcal{H}_{\perp}^{i n t}=i \sqrt{\frac{1}{L}} \sum_{\beta} \sum_{j}\left(G_{-\beta}^{*} \sigma_{j}^{+}+G_{\beta} \sigma_{j}^{-}\right)\left(a_{\beta}-a_{-\beta}^{\dagger}\right) e^{i \beta z_{j}}
$$

onde o fator de acoplamento $G_{\beta}$ pode é obtido pelas equações 39 e 42 e é dado por:

$$
G_{\beta}=-e \sqrt{\frac{\omega_{\beta}}{4 \pi m_{\beta}}} \vec{\mu}_{g e} \cdot \vec{\xi}\left(\beta, \rho_{l}\right), \quad \text { com } \quad G_{-\beta}^{*}=G_{\beta}
$$

Aqui, $\rho_{l}$ é a distância entre a cadeia de pontos e o centro do nanofio metálico e o termo $\vec{\mu}_{g e}=-e\langle g|\vec{r}| e\rangle$ representa o momento de dipolo da transição eletrônica correspondente 
ao estado fundamental do éxciton.

Da mesma maneira, podemos utilizar RWA para descartar termos que não conservam energia, de forma que o hamiltoniano de interação pode ser escrito como

$$
\mathcal{H}^{i n t}=\sqrt{\frac{1}{L}} \sum_{\beta} \sum_{j}\left(g_{-\beta}^{*} \sigma_{j}^{+} a_{\beta}+g_{\beta} a_{-\beta}^{\dagger} \sigma_{j}^{-}\right) e^{i \beta z_{j}},
$$

onde $g_{\beta}=-i G_{\beta}$. Analogamente ao que foi feito com os operadores de projeção, podemos definir os operadores escada do QD no espaço de momento $\beta$ e escrever

$$
\mathcal{H}^{i n t}=\sqrt{\frac{N}{L}} \sum_{\beta}\left[g_{-\beta}^{*} \sigma_{+}(\beta) a_{\beta}+g_{\beta} a_{-\beta}^{\dagger} \sigma_{-}(\beta)\right] .
$$

\subsubsection{Fator de acoplamento}

Valores característicos da constante de acoplamento SPP-QD dependem fortemente da distância entre a cadeia e nanofio, conforme pode ser visto na fig. 28. No entanto, como a constante dielétrica do semicondutor é alta, o campo dos SPPs tem forte penetração no mesmo e é possível obter altos valores para o fator de acoplamento mesmo a distâncias da ordem de 50nm da interface entre o metal e o semicondutor. Em nosso laboratório, somos capazes de produzir amostras de QDs a distâncias de até 10nm da superfície do semicondutor sem que as propriedades ópticas dos pontos seja prejudicada, conforme mostra a fig. 24, por efeitos como a presença de estados de superfície. (93, 94)

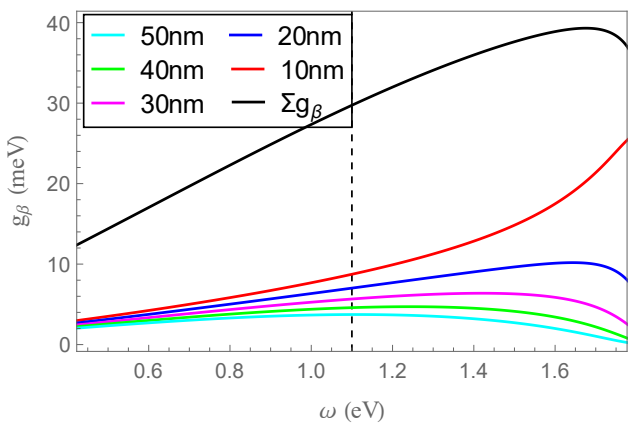

Figura 28 - Módulo do fator de acoplamento $\left|g_{\beta}\right|$ entre os QDs e os SPPs num nanofio metálico de ouro com raio de $100 \mathrm{~nm}$. No gráfico está indicada a distância do QD até a superfície do fio metálico bem como o valor da constante de acoplamento. No modelo, consideramos que há várias camadas de QDs na matriz semicondutora.

Fonte: Elaborada pelo autor.

No processo de crescimento dos QDs, é crescida uma camada com o mesmo material do substrato para proteger a estrutura eletrônica dos pontos. Caso não houvesse essa 
camada, medidas de fotoluminescência (PL) dos QDs não iriam revelar a estrutura eletrônica dos mesmos. Essa camada serve também como uma barreira de potencial para os elétrons e não modifica a estrutura morfológica dos pontos quânticos. Camadas de proteção confiáveis tem dimensões da ordem de 10nm (ou 100A), ou maiores. Isso significa dizer que é possível preparar, em princípio, estruturas onde os QDs estão praticamente sobre a superfície de um nanofio plasmônico.

No esquema mostrado na fig. 28, é apresentado o valor da constante de acoplamento entre os QDs e os SPPs no nanofio metálico considerando uma geometria onde há 20QD / $\mu \mathrm{m}$ na direção da cadeia. Estruturas em cadeias como estas podem ser crescidas numa camara de MBE utilizando um tratamento térmico adequado. (95) Há ainda a possibilidade crescer várias camadas de QDs, diferentes valores de cap layer, de forma a aumentar a densidade de QDs que pode interagir com os SPPs.

Isso é bastante útil porque a densidade de QDs que pode ser produzida em uma única camada não pode atingir altos valores $\left(\sim 10^{3} \mathrm{QD} / \mu \mathrm{m}^{2}\right)$ caso contrário efeitos de acoplamento eletrônico entre QDs vizinhos passa a ser relevante. No nosso caso, essas densidades não são atingidas. No entanto, em alguns sistemas compostos por agregados moleculares, como é o caso das cadeias conhecidas como J-aggregates, é possível atingir densidades da ordem de $10^{6}$ moléculas $/ \mu \mathrm{m}^{2}$. Esses valores, inatingíveis em nossos sistemas devido não somente a propriedades técnicas, mas também a propriedades estruturais, são capazes de gerar fatores de acoplamento da ordem de uma centena de $m e V$, como mostra a fig. 29.

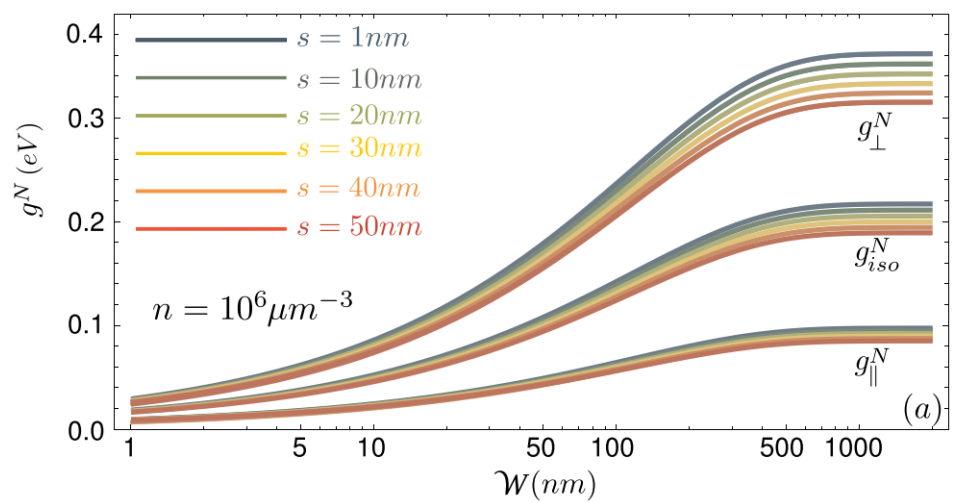

Figura 29 - Fator de acoplamento $g$ para uma camada de J-aggregates com espessura $\mathcal{W}$ colocada a uma distância $s$ de um filme metálico. A densidade de nanopartículas da camada dopada é $n=10^{6} / \mu \mathrm{m}^{-3}$. 
No caso mostrado na fig. 29, estudado por (96), a orientação das moléculas é aleatória, por esse motivo é necessário tomar uma média com relação ao momento de dipolo das mesmas que interage com as componentes do campo elétrico nas direções ortogonal e/ou paralela ao plano metálico.

Vale notar ainda que, como o campo do SPP continua alto até distâncias da ordem de algunas dezenas de nanômetros, a dependência mais forte do fator de acoplamento é com a densidade de emissores quânticos, do que com a camada que os separa do filme metálico. Este resultado é exatamente aquele discutido para os QDs, onde a camada de separação (cap layer) foi escolhida para garantir que a atividade óptica dos mesmos não fosse alterada drasticamente.

\subsection{Estados do sistema interagente}

Com o valor da constante de acoplamento dipolar entre os SPPs e os éxcitons nos QDs, podemos investigar como a excitação dos QDs é alterada pela presença de um reservatório de SPPs.

Com o intuito de retirar a essência da Física por trás dessa interação, podemos nos ater ao sistema do nanofio metálico interagindo com uma cadeia de SPPs.

No limite de baixas excitações dos SPPs e éxcitons nos QDs podemos utilizar a transformação de Holstein-Primakoff (97), que consiste basicamente em descrever os operadores de spin do éxciton como operadores de criação e aniquilação de bósons da seguinte maneira

$$
\sigma^{z}=2 b^{\dagger} b-1, \quad \sigma^{+}=b^{\dagger} \sqrt{1-b^{\dagger} b}, \quad \sigma^{-}=\sqrt{1-b^{\dagger} b} \cdot b,
$$

onde $b$ e $b^{\dagger}$ satisfazem relações de comutação $\left[b, b^{\dagger}\right]=1$ e a transformação preserva a álgebra $\mathrm{SU}(2)$ dos operadores de spin. Essa relação costuma ser utilizada quando se possui baixa ocupação dos estados excitados dos QDs, i.e. $\left\langle b^{\dagger} b\right\rangle \ll 1$, onde \langle\rangle significa a média sobre os estados de baixas energias do sistema. Neste caso, é válida a aproximação linear para a teoria de onda de spin, onde podemos utilizar

$$
\sigma^{z}=2 b^{\dagger} b-1, \quad \sigma^{+} \approx b^{\dagger}, \quad \sigma^{-} \approx b .
$$


Note ainda que no nosso caso, $g \ll \Delta$, i.e. o fator de acoplamento não representa uma grande fração da energia natural do éxciton. Isso reforça a utilização da aproximação de Holstein-Primakoff.

Algumas técnicas experimentais tornaram possível a dopagem de vidros com átomos ou moléculas em regiões específicas, com precisão de alguns nanômetros. Apesar de estar no limite das técnicas experimentais conhecidas, isso torna possível, pelo menos em princípio, que sejam produzidas cadeias com altas densidades locais de emissores quânticos. Em nosso sistema experimental, apesar de não atingir grandes densidades locais, é possível fazer com que várias camadas de cadeias de QDs sejam produzidas umas sobre as outras o que provoca um aumento considerável no fator de acoplamento.

De acordo com a validade destas aproximações, podemos escrever o hamiltoniano do sistema interagente como

$$
\mathcal{H}=-\frac{N \Delta}{4}+\Delta \sum_{\beta} b_{\beta}^{\dagger} b_{\beta}+\sum_{\beta} \omega_{\beta} a_{\beta}^{\dagger} a_{\beta}+\sqrt{\frac{N}{L}} \sum_{\beta}\left(g_{-\beta}^{*} b_{-\beta}^{\dagger} a_{\beta}+g_{\beta} a_{-\beta}^{\dagger} b_{\beta}\right) .
$$

Sendo assim, este hamiltoniano pode ser escrito como

$$
\mathcal{H}=-\frac{N \Delta}{4}+\sum_{\beta} \mathcal{H}_{\beta}
$$

com

$$
\mathcal{H}_{\beta}=\Delta b_{\beta}^{\dagger} b_{\beta}+\omega_{\beta} a_{\beta}^{\dagger} a_{\beta}+g_{-\beta}^{*} b_{-\beta}^{\dagger} a_{\beta}+g_{\beta} a_{-\beta}^{\dagger} b_{\beta} .
$$

A utilização da eq. 56 é de extrema utilidade pois mostra que o hamiltoniano de interação só acopla termos com mesmo número de onda $\beta$, i.e. desacoplamos o hamiltoniano total para cada modo do SPP.

Como neste modelo mais simples estamos desprezando os efeitos de dissipação do sistema, o hamiltoniano dado conserva o número de excitações no sistema. Sendo assim, podemos diagonalizá-lo utilizando a transformação de Bogoliubov (97) 


$$
\begin{aligned}
& a_{-\beta}^{\dagger}=\cos \gamma_{\beta} c_{-\beta}^{\dagger}+e^{i \theta_{\beta}} \operatorname{sen} \gamma_{\beta} d_{-\beta}^{\dagger}, \\
& b_{-\beta}^{\dagger}=\cos \gamma_{\beta} d_{-\beta}^{\dagger}-e^{-i \theta_{\beta}} \operatorname{sen} \gamma_{\beta} c_{-\beta}^{\dagger},
\end{aligned}
$$

onde os novos operadores de criação e destruição também satisfazem as mesmas regras bosônicas de comutação, i.e.

$$
\left[c_{\beta}, c_{\beta^{\prime}}^{\dagger}\right]=\delta_{\beta, \beta^{\prime}}, \quad\left[d_{\beta}, d_{\beta^{\prime}}^{\dagger}\right]=\delta_{\beta, \beta^{\prime}}
$$

As energias $\varepsilon_{\beta}^{ \pm}$dos novos bósons, representados pelos operadores de criação $c_{-\beta}^{\dagger}$ e $d_{-\beta}^{\dagger}$, são dadas por

$$
\varepsilon_{\beta}^{ \pm}=\frac{\omega_{\beta}+\Delta}{2} \pm \sqrt{\left(\frac{\omega_{\beta}-\Delta}{2}\right)^{2}+\left|g_{\beta}\right|^{2}} .
$$

O hamiltoniano diagonalizado pode então ser escrito como

$$
\mathcal{H}_{\beta}=\varepsilon_{\beta}^{+} c_{\beta}^{\dagger} c_{\beta}+\varepsilon_{\beta}^{-} d_{\beta}^{\dagger} d_{\beta}
$$

com os operadores $c_{\beta}^{\dagger}$ e $d_{\beta}^{\dagger}$ representando os novos estados híbridos do sistema SPP-QD, que consistem de partículas com características tanto do QD quanto dos SPPs no guia.

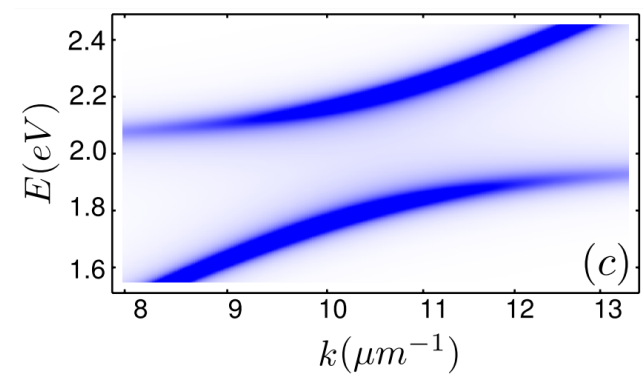

Figura 30 - Anti-cruzamento entre os níveis de energia dos SPPs confinados num plano metálico interagindo com J-aggregates.

Fonte: TUDELA et. al. (96)

Dessa forma, observamos que o sistema apresenta um anticruzamento de níveis de energia quando a dispersão do SPP na estrutura plasmônica atinge a energia do QD. Esse anticruzamento de níveis pode atingir grandes valores, como é mostrado na fig. 30. (96)

Caso fosse utilizado um conjunto com apenas 5 camadas de cadeias de QDs, espaçadas 
entre si por 10nm, e apenas um QD por $\mu \mathrm{m}$ da cadeia, o cruzamento de níveis de energia seria da ordem de $\delta \omega=10 \mathrm{meV}$, conforme mostra a fig. 31. Esse resultado é notável, já que experimentos envolvendo a análise dos níveis de energia de QDs têm sensibilidade capaz de detectar diferenças muito inferiores a $\delta \omega$.

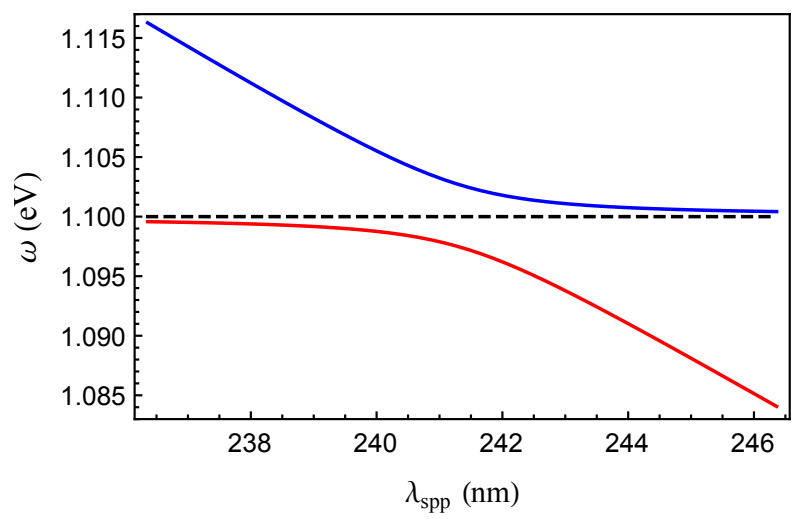

Figura 31 - Anti-cruzamento entre os níveis de energia dos SPPs confinados num nanofio metálico de Au interagindo com éxcitons numa cadeia com $1 \mathrm{QD} / \mu \mathrm{m}$. A amostra de QDs é composta por 5 camadas de cadeias umas sobre as outras.

Fonte: Elaborada pelo autor.

Desta maneira, efeitos desse acoplamento podem ser, pelo menos em princípio, detectados em experimentos envolvendo QDs. Evidências experimentais dessa interação serão discutidas mais oportunamente em capítulos seguintes.

\subsection{Efeito Purcell}

Acabamos de discutir como um sistema de dois níveis (QD) interage com os modos (aproximadamente contínuos) de SPPs num guia metálico. No entanto, não levamos em consideração que estes sistemas possuem mecanismos de decaimento (relaxação) natural, como decaimento em fótons, decaimento em fônons da rede cristalina, interação com estados de superfície, decaimento em estados da wetting layer etc. (80) Esses mecanismos de decaimento natural, i.e. que ocorrem mesmo sem a presença de uma estrutura plasmônica, podem ser expressas em uma taxa de decaimento natural $\Gamma_{0}$. Essa taxa de decaimento é a responsável por uma largura natural na linha de absorção dos éxcitons e pode ser estimada a partir de medidas precisas de fotoluminescência. Em geral, o alargamento natural é de algumas dezenas de $\mu \mathrm{eV}$. (80)

À medida que se coloca uma superfície metálica nas proximidades de emissores quân- 
ticos, a mesma altera a densidade de estados da luz o que culmina na modificação dos mecanismos de decaimento do emissor. Note-se que o acoplamento com os SPPs via acoplamento de dipolo tem características diferentes daquelas da interação com fótons, conforme será demonstrado.

Para garantir que o acoplamento seja feito, é necessário que a dispersão dos plásmons cruze a dispersão característica do emissor quântico. Como o plásmon possui um vetor de onda complexo, que conforme vimos no capítulo anterior é um dos responsáveis pelos mecanismos de dissipação do mesmo, ao tratar o acoplamento de plásmons com a luz é necessário fazer com que a luz também tenha um vetor de onda complexo, de forma a satisfazer a condição de conservação do momento. Por esse motivo utilizam-se métodos como os de Kretschmann e Otto. (42)

Já para o acoplamento de SPPs com emissores quânticos, não é necessário que o decaimento seja do tipo emissor $\rightarrow$ fóton $\rightarrow$ SPP. Como há acoplamento direto entre os estados do emissor e os SPPs na estrutura plasmônica, a condição sobre o momento pode ser desconsiderada. Uma outra interpretação para este fato é que a expansão da função de onda dos estados localizados no emissor quântico e na estrutura plasmônica não são ortogonais, onde o termo de decaimento é aquele responsável pela parte complexa do momento do SPP.

Este efeito na modificação da taxa de decaimento de um estado quântico foi primeiro investigado por E. M. Purcell (33), para as probabilidades de emissão espontânea de momentos nucleares magnéticos em uma cavidade de microondas; este efeito foi denominado posteriormente como efeito Purcell. A razão entre a taxa de decaimento dentro da cavidade $\Gamma$ e a taxa de decaimento natural é conhecida como fator de Purcell e é dada por:

$$
F_{p}=\frac{\Gamma}{\Gamma_{0}}=\frac{3}{4 \pi^{2}}\left(\frac{\lambda_{c}^{3}}{n}\right)\left(\frac{Q}{V_{e f}}\right)
$$

onde $\lambda_{c}$ é o comprimento de onda da luz na cavidade, $n$ é o índice de refração do meio, $Q$ o fator de qualidade da cavidade e $V_{e f}$ o volume efetivo da mesma.

Em geral, o efeito Purcell é um indicativo se o sistema interagente está no regime de 
acoplamento fraco ou no regime de acoplamento forte. O regime de acoplamento fraco ocorre quando o fator de acoplamento $g$ é menor que a taxa de decaimento do emissor quântico $\Gamma$ e do que o fator de decaimento da cavidade $\kappa$, i.e. $g \ll \Gamma, \kappa$. Já o regime de acoplamento forte ocorre quando o fator de acoplamento supera as taxas de decaimento $g \gg \Gamma, \kappa$.

O que ocorre é que em cavidades de microondas, utilizadas comumente em óptica quântica, é que os fatores de qualidade $Q$ podem atingir valores ultra-altos $\sim 10^{6}-10^{10}$. (98) Já em cavidades plasmônicas, devidos às taxas de absorção nos metais no regime óptico, valores típicos de $Q$ são da ordem de $\sim 10^{2}-10^{3}$. $(99,100)$ No entanto, devido ao alto valor de $g$ em cavidades plasmônicas ainda é possível atingir o regime de acoplamento forte.

É possível produzir cavidades plasmônicas capazes de modificar a taxa de decaimento inclusive para induzir que emissores quânticos possam experimentar uma emissão coletiva, que é conhecido como efeito Dicke. (20)

\subsection{Bandas plasmônicas}

Como já foi discutido anteriormente, a presença da cadeia de pontos quânticos nas proximidades do nanofio plasmônico induz um potencial periódico que interage com os modos dos SPPs. Essa situação é diferente daquela comumente encontrada em nanoplasmônica ou fotônica $(46,101,102)$, onde o potencial periódico é introduzido pela própria estrutura plasmônica. Neste último caso, a presença de estruturas periódicas dá origem ao que se conhece como bandas plasmônicas, ou bandas fotônicas, onde vários exemplos já foram explorados para estruturas fotônicas. $(46,101)$

No caso da interação com os emissores quânticos, portanto, é necessário descrever a dinâmica dos SPPs dentro de uma aproximação que leva em conta as bandas de energia geradas pela modulação do potencial sentido pelos modos plasmônicos ao longo da rede de pontos quânticos.

Para fazer isso, utilizamos o esquema de zona reduzida (7), onde os momentos dos SPPs que interagem com os QDs são escritos dentro da primeira zona de Brillouin (ZB) da rede periódica criada pelos QDs. Para ilustrar isso, observe a estrutura de bandas 
criada por uma rede artificial de átomos interagindo com SPPs num guia de onda de ouro, conforme mostra a fig. 32 .

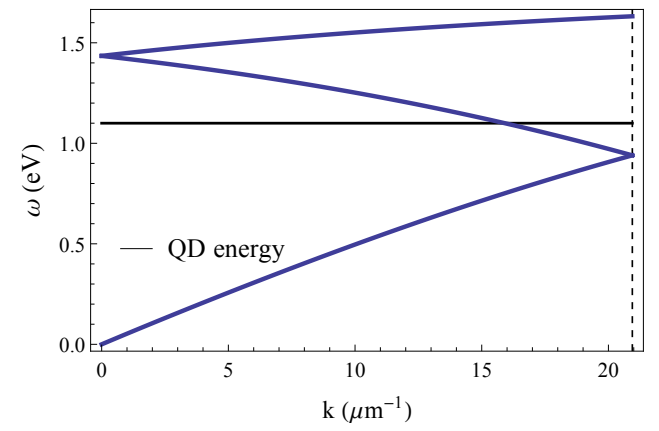

(a) Espectro de bandas sem presença da cadeia de átomos.

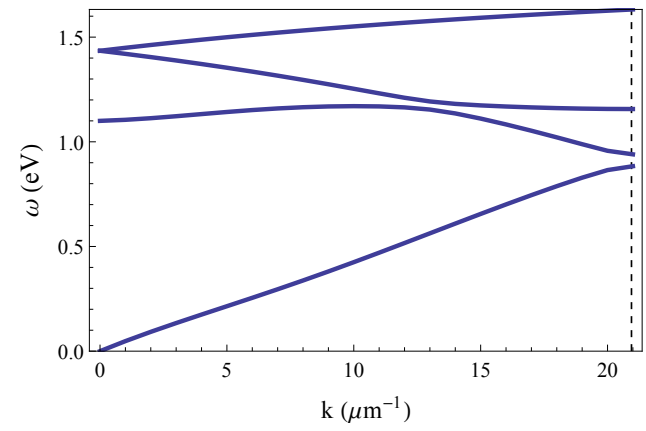

(b) Espectro de bandas na presença da cadeia de átomos.

Figura 32 - Modelo de bandas plamônicas induzidas pela presença de um potencial artificial gerado por uma cadeia de átomos. O parâmetro de rede considerado é $a_{l}=150 \mathrm{~nm}$ e a distância entre a superfície do nanofio e a cadeia é $250 \mathrm{~nm}$. O fator de acoplamento considerado é 10 vezes maior que o fator para um QD simples.

Fonte: Elaborada pelo autor.

Para um fio de ouro com 100nm de raio, o ponto onde ocorre o cruzamento de níveis de energia entre os modos dos SPPs e a energia do QD é em torno de $28 \mu m^{-1}$. Este valor de número de onda, indica que se a separação entre os átomos da cadeia for da ordem de 110nm, o cruzamento entre os níveis de energia do sistema ocorrerá na borda da primeira ZB.

Para evitar que isso ocorra, é necessário que a distância entre os átomos seja ainda menor. No entanto, quando a distância entre os pontos começa a diminuir bastante, é possível que ocorra efeitos de acoplamento de dipolo entre os próprios átomos (103) (note que para QDs esse efeito deve ser ainda mais intenso devido ao menor confinamento da função eletrônica), o que não é considerado no nosso modelo, onde os emissores quânticos só interagem com o campo dos SPPs.

No entanto, simplesmente aumentar a distância entre os átomos poderia agravar a formação das bandas, já que o comprimento da primeira zona de Brillouin seria ainda menor no espaço dos momentos $\left(k \sim 1 / a_{l}\right)$.

O número de bandas dentro da primeira ZB do sistema é, em princípio, infinito. No entanto, as bandas que irão interagir mais fortemente com a cadeia de pontos são aquelas que possuem energia próxima da energia dos átomos (que supomos $\sim 1 \mathrm{eV}$ para contrastar com o caso dos QDs), como é o caso da segunda banda na fig. 32(a). A matriz que 
descreve o acoplamento dos SPPs em cada banda com a cadeia de átomos, para o caso das três bandas representadas na fig. 32(b), é dada por

$$
\mathcal{G}_{\beta}=\left(\begin{array}{cccc}
\omega_{\beta}^{(1)} & 0 & g_{\beta}^{(1)} & 0 \\
0 & \omega_{\beta}^{(2)} & g_{\beta}^{(2)} & 0 \\
g_{\beta}^{(1) *} & g_{\beta}^{(2) *} & \Delta & g_{\beta}^{(3) *} \\
0 & 0 & g_{\beta}^{(3)} & \omega_{\beta}^{(3)}
\end{array}\right)
$$

Os índices que aparecem em $\omega_{\beta}$ e $g_{\beta}$ correspondem à banda do SPP na primeira ZB. $\mathrm{O}$ hamiltoniano que descreve o acoplamento nesse tipo de sistema é dado por

$$
\mathcal{H}_{\beta}=\left|\phi_{\beta}\right\rangle \mathcal{G}_{\beta}\left\langle\phi_{\beta}\right|, \quad \text { onde } \quad|\phi\rangle=\left(\begin{array}{cccc}
a_{-\beta}^{(1) \dagger} & a_{-\beta}^{(2) \dagger} & b_{-\beta}^{\dagger} & a_{-\beta}^{(3) \dagger}
\end{array}\right)
$$

Nesse modelo, a interação com os átomos induz a abertura de gaps de energia nas bordas da ZB conforme mostra a fig. 32(b). No gráfico, é possível observar também que gaps de energia aparecem nas bordas da $1^{\mathrm{a}}$ zona. Isso ocorre por efeito de interferência de Bragg dos modos que possuem momento $\beta$ que diferem por um vetor da rede recíproca.

Além das bordas, é possivel notar que há um anticruzamento de energia em torno da energia do QD, que é o efeito análogo ao observado anteriormente, onde os modos do QD e dos SPPs se hibridizam e dão origem a novas partículas.

Neste ponto vale fazer um comentário de que ideia ao descrever as bandas mostradas nas fig. 32, onde foi considerado que o fator de acoplamento é cerca de 10 vezes maior que aquele para um QD simples, é mostrar que o mesmo efeito de modulação de potencial pode ser obtido tanto com a interação com emissores quânticos como com a engenharia de uma rede plasmônica periódica. A engenharia dessas redes com átomos está ainda nos limites experimentais da tecnologia atual, mas já é possível,pelo menos em princípio, criar tais redes periódicas.

\subsection{Teoria de resposta linear}

Até o presente momento, descrevemos o hamiltoniano de interação entre os SPPs presentes num nanofio metálico de geometria cilíndrica com uma cadeia de emissores 
quânticos (QDs) presentes num substrato semicondutor.

A teoria foi desenvolvida considerando-se o limite termodinâmico no qual o comprimento do nanofio pode ser considerado infinito com relação aos modos dos SPPs presentes no sistema.

Como se sabe, os SPPs consistem de densidades de carga acopladas ao campo eletromagnético da luz. Essas densidades de carga podem ser excitadas através da incidência de luz nas bordas do sistema plasmônico, e.g. nas pontas do nanofio metálico. Exemplos disso são a excitação dos SPPs com a utilização de nanoantenas (47) ou grades de difração (64), que são utilizadas para aumentar o efeito da interação da luz com as densidades de carga.

Além da excitação direta das cargas, é possível que os SPPs sejam excitados através do casamento do vetor de onda da luz com o do SPP na direção de propagação do mesmo. (42, 48) Métodos conhecidos utilizam a reflexão interna total frustada da luz (42), por exemplo, para garantir que o vetor de onda, complexo, da onda evanescente gerada pela reflexão frustrada acople com o vetor de onda evanescente na interface metal/dielétrico.

Conforme foi visto, a presença da cadeia linear de QDs é capaz de afetar a curva de dispersão dos SPPs no nanofio. Devido a esse acoplamento espera-se que a resposta do nanofio à presença de campos externos seja alterada pela presença da cadeia linear.

Da mesma maneira, conforme foi discutido a presença do nanofio que suporta modos dos SPPs é capaz de modificar a interação dos QDs com o meio externo. (30) Esse acoplamento pode ser ajustado de forma a modificar convenientemente as taxas de decaimento do QD.

Nesta seção, mostraremos como a presença da cadeia de pontos é capaz de alterar a excitação dos SPPs através da incidência de um campo elétrico harmônico.

Vamos nos basear num modelo onde um campo elétrico externo é capaz de bombear SPPs num nanofio metálico. O hamiltoniano correspondente a este bombeio pode ser escrito como (26)

$$
\mathcal{H}_{\text {pump }}=i \sum_{\beta} \eta_{\beta}\left[E_{\text {inc }}(t) \hat{a}_{-\beta}^{\dagger}(t)-E_{\text {inc }}^{*}(t) \hat{a}_{\beta}(t)\right] .
$$


O parâmetro $\eta_{\beta}$ leva em conta que o bombeio de SPPs através do campo externo pode depender do parâmetro $\beta$, da forma como o campo incide no nanofio, i.e. ângulo de incidência, polarização da luz, entre outros fatores que possam alterar a absorção da luz. (47) O campo do SPP, dado pela eq. 42, pode ser escrito como

$$
\vec{E}_{s p p}(\vec{r}, t)=i \sum_{\beta} \epsilon_{\beta}\left[a_{\beta}(t)-a_{-\beta}^{\dagger}(t)\right] e^{i \beta z} \vec{\xi}_{\beta}(\rho)
$$

Esse modelo é baseado na teoria de resposta linear (104), onde o campo externo $E_{\text {inc }}(t)=E_{0} e^{-i \omega t}$ é capaz de excitar os modos dos SPPs através das oscilações de carga no nanofio metálico. Supomos que a excitação externa é ligada no instante $t_{0}$ e que ela seja baixa o suficiente para que somente termos em primeira ordem na amplitude $E_{0}$ do campo devam ser levados em consideração.

O valor esperado do campo elétrico dos SPPs pode ser escrito como

$$
\delta\left\langle\vec{E}_{\text {spp }}(\vec{r}, t)\right\rangle=i \int_{t_{0}}^{t} d t^{\prime}\left\langle\Psi_{0}\left|\left[\mathcal{H}_{\text {pump }}\left(t^{\prime}\right), \vec{E}_{\text {spp }}(\vec{r}, t)\right]_{H}\right| \Psi_{0}\right\rangle,
$$

onde $[\cdots]_{H}$ indica que o comutador dos operadores é tomado com os operadores escritos na abordagem de Heisenberg. Além disso, o valor esperado é tomado no estado fundamental do sistema $\left|\Psi_{0}\right\rangle$, onde não há modos dos SPPs e os éxcitons nos QDs não foram excitados.

Na abordagem de Heisenberg, a evolução dos operadores de criação e aniquilação de SPPs pode ser escrita como

$$
\left\{\begin{array}{l}
\hat{a}_{\beta}(t)=\cos \gamma_{\beta} \hat{c}_{\beta} e^{-i \varepsilon_{\beta}^{+} t}+e^{-i \theta_{\beta}} \operatorname{sen} \gamma_{\beta} \hat{d}_{\beta} e^{-i \varepsilon_{\beta}^{-} t}, \\
\hat{a}_{-\beta}^{\dagger}(t)=\cos \gamma_{\beta} \hat{c}_{-\beta}^{\dagger} e^{i \varepsilon_{\beta}^{+} t}+e^{i \theta_{\beta}} \operatorname{sen} \gamma_{\beta} \hat{d}_{-\beta}^{\dagger} e^{i \varepsilon_{\beta}^{-} t} .
\end{array}\right.
$$

De forma que 


$$
\begin{aligned}
\left\langle\Psi_{0}\left|\left[\mathcal{H}_{\text {pump }}\left(t^{\prime}\right), \vec{E}_{\text {spp }}(\vec{r}, t)\right]_{H}\right| \Psi_{0}\right\rangle= & \sum_{\beta} \sum_{\beta^{\prime}} \eta_{\beta^{\prime}} \epsilon_{\beta} e^{i \beta z} \vec{\xi}_{\beta}(\rho) \delta_{\beta, \beta^{\prime}} . \\
& {\left[\cos ^{2} \gamma_{\beta} e^{-i\left(\omega-\varepsilon_{\beta}^{-}\right)\left(t^{\prime}-t\right)} E_{0}^{*} e^{i \omega t}\right.} \\
& +\operatorname{sen}^{2} \gamma_{\beta} e^{-i\left(\omega-\varepsilon_{\beta}^{-}\right)\left(t^{\prime}-t\right)} E_{0}^{*} e^{i \omega t} \\
& -\cos ^{2} \gamma_{\beta} e^{-i\left(\omega-\varepsilon_{\beta}^{+}\right)\left(t^{\prime}-t\right)} E_{0} e^{-i \omega t} \\
& \left.-\operatorname{sen}^{2} \gamma_{\beta} e^{-i\left(\omega-\varepsilon_{\beta}^{+}\right)\left(t^{\prime}-t\right)} E_{0} e^{-i \omega t}\right] .
\end{aligned}
$$

Como para os modos dos SPPs temos $\operatorname{Im}\left(\varepsilon_{\beta}^{ \pm}\right)<0$, as integrais se reduzem a

$$
\int_{t_{0}}^{t} d t^{\prime} e^{-i\left(\omega-\varepsilon_{\beta}^{ \pm}\right)\left(t^{\prime}-t\right)} \rightarrow \int_{-\infty}^{0} d t^{\prime} e^{-i\left(\omega-\varepsilon_{\beta}^{ \pm}\right) t^{\prime}}=\frac{1}{-i\left(\omega-\varepsilon_{\beta}^{ \pm}\right)}
$$

Assim, a resposta dos SPPs ao campo externo pode ser escrita como

$$
\delta\left\langle\vec{E}_{s p p}(\vec{r}, t)\right\rangle=\sum_{\beta} \eta_{\beta} \epsilon_{\beta} e^{i \beta z} \vec{\xi}_{\beta}(\rho)\left(E_{0} e^{i \omega t}-E_{0}^{*} e^{-i \omega t}\right)\left(\frac{\cos ^{2} \gamma_{\beta}}{\omega-\varepsilon_{\beta}^{+}}+\frac{\operatorname{sen}^{2} \gamma_{\beta}}{\omega-\varepsilon_{\beta}^{-}}\right) .
$$

De maneira análoga ao que é feito em (104), podemos definir uma susceptibilidade dinâmica do sistema. Para fazer isso, separamos a parte $\overrightarrow{\mathcal{F}}_{+}=\sum_{\beta} \epsilon_{\beta} e^{i \beta z} \vec{\xi}_{\beta} F_{\beta}$ da resposta da eq. (70) proporcional a $e^{-i \omega t}$ e tomamos o limite

$$
\chi_{\beta}\left(E_{i n c}, \vec{E}_{s p p}, \omega\right)=\lim _{E_{0} \rightarrow 0} \frac{F_{\beta}}{E_{0}}=\eta_{\beta}\left(\frac{\cos ^{2} \gamma_{\beta}}{\omega-\varepsilon_{\beta}^{+}}+\frac{\operatorname{sen}^{2} \gamma_{\beta}}{\omega-\varepsilon_{\beta}^{-}}\right) .
$$

Os pólos da eq. 71 indicam que somente modos dos SPPs com momento $\beta$ e energia $\omega \simeq \varepsilon_{\beta}^{ \pm}$serão excitados, i.e. somente os modos do sistema sofrerão a ação do campo externo, como já era esperado.

O papel dos fatores $\cos ^{2} \gamma_{\beta}$ e $\operatorname{sen}^{2} \gamma_{\beta}$ na eq. 71 é indicar que, devido à hibridização dos modos dos SPPs com as excitações dos QDs, além de uma geração direta do SPP devido à presença do fio é também possível que se forme um éxciton num QD, e depois é capaz de gerar um modo de SPP com a frequência correspondente. Quando as energias do SPP livre e do QD são muito diferentes este último processo é pouco provável, mas à medida que as energias se aproximam, i.e. próximo à região onde há o anticruzamento de níveis na fig. 31, este processo é muito importante na excitação dos SPPs e o que se pode 
observar são as excitações híbridas do sistema. 


\section{Estruturas plasmônicas}

Até o presente momento discutimos quais as caracterísitcas fundamentais por trás da interação entre SPPs numa cavidade metálica e éxcitons aprisionados em QDs numa matriz semicondutora. Não foi nosso objeto de discussão, no entanto, como tais cavidades metálicas são produzidas em laboratório.

Após caracterizar teoricamente o sistema buscando assinaturas de interação do mesmo, a segunda parte deste trabalho foi a produção de amostras em laboratório para buscar observar estas assinaturas. Iremos agora, portanto, discutir as técnicas experimentais através das quais fomos capazes de produzir amostras de QDs nas proximidades de cavidades plasmônicas e que tornaram possíveis os experimentos que buscavam assinaturas claras da interação dos SPPs com os éxcitons nos QDs.

\subsection{Preparação das amostras}

Após a produção das amostras de QDs utilizando um MBE conforme discutido no capítulo 3, é necessário depositar um filme fino de metal sobre a superfície da mesma e depois produzir as cavidades plasmônicas.

Na fig. 33, é mostrada uma camada de QDs crescidos numa câmara de ultra alto vácuo de MBE utilizando o modo de crescimento SK que produz uma amostra de pontos auto-organizados. (80) Na amostra representada a distribuição de tamanhos dos pontos

é bastante larga. Esta não é a mesma que produziu os espectros de fotoluminescência estreitos como aqueles mostrados na fig. 24. No entanto, essa amostra foi crescida apenas para apresentar como os pontos se distribuem, tanto em forma como em posição relativa. Para fazer isso, após a formação dos pontos sobre a superfície da matriz de GaAs o crescimento foi interrompido e a temperatura do sistema diminuída para evitar a evaporação do InAs da superfície, nenhuma camada de buffer foi crescida para evidenciar que as protuberâncias presentes na amostras eram devidas exclusivamente aos pontos quânticos. Com os pontos descobertos foi possível realizar medidas da morfologia dos mesmos utilizando a técnica de microscopia da força atômica (AFM). 
Em nosso modelo teórico, observamos que cadeias de QDs interagindo com SPPs apresentavam um anti-cruzamento de níveis quando a dispersão do SPP cruzava a energia dos pontos. O efeito era aumentado devido à alta densidade de QDs numa cadeia e também à banda criada pelo parâmetro de rede da mesma. No entanto, é de se esperar que mesmo em QDs auto-organizados, como os que produzimos naturalmente numa câmara de MBE mostrados na fig. 33, sejam observados efeitos de acoplamento entre os pontos e a cavidade. Em geral, estaremos interessados em pequenas modificações nos níveis de energia da amostra de QDs como resultado da assinatura característica desse acoplamento.

Por pequenas modificações nos níveis de energia, estamos nos referindo principalmente a modificação na intensidade relativa de picos correspondentes a diferentes níveis de energia dos éxcitons ou mesmo no deslocamento das linhas de energia (shift) que, em geral, acompanha o efeito do anticruzamento de níveis.

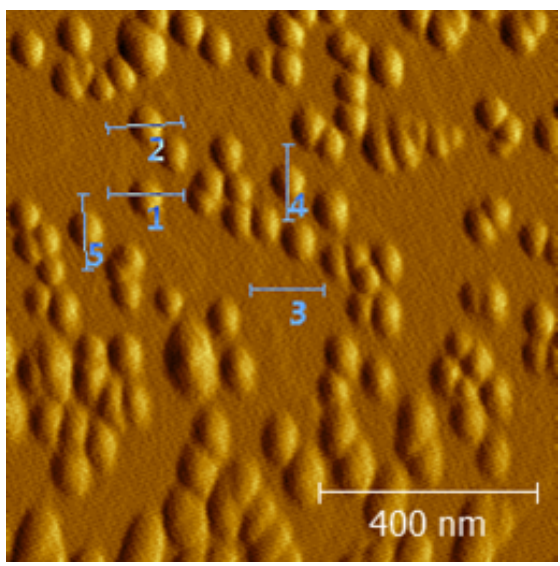

Figura 33 - AFM de uma amostra típica de QDs auto-organizados.

Fonte: Elaborada pelo autor.

\subsection{Evaporação de filmes finos}

Após a produção da camada de pontos quânticos próximos à superfície da amostra, a próxima etapa do processo é a deposição de um filme fino metálico sobre a mesma. Vale aqui ressaltar que para que sejam produzidos finos filmes metálicos de alta qualidade é necessário que a taxa de deposição do mesmo seja muito baixa, por isso utilizamos o processo de evaporação.

Em geral, temos preferência por metais como o ouro e/ou a prata devido às suas propriedades ópticas, mostradas na fig. 6 que apresenta as partes real e imaginária de suas 
constantes dielétricas. Além dessas propriedades, os filmes de Au e Ag produzidos em nossas amostras apresentavam longa durabilidade, i.e. suas propriedades não mudavam quando entravam em contato com o ar. Após alguns meses as amostras fabricadas com filmes de Ag, no entanto, apresentavam manchas esbranquiçadas que modificavam localmente as propriedades de absorção da luz. Por este motivo, iremos discutir as amostras cobertas com filmes de ouro.

Com a técnica da deposição por evaporação, é possível depositar filmes finos de alguns nanômetros $(\gtrsim 6 \mathrm{~nm})$ uniformemente sobre uma área relativamente grande $\left(\sim 1 \mathrm{~cm}^{2}\right)$. O método está descrito esquematicamente na fig. 34. A amostra é colocada num porta amostras com sua face a ser coberta voltada para baixo. Num cadinho feito de material de alto ponto de fusão (em geral Molibdênio, $>2500^{\circ} \mathrm{C}$ ou Tungstênio, $>3400^{\circ} \mathrm{C}$ ) é colocado o material a ser depositado (ouro ou prata). A passagem de uma alta corrente elétrica pelo cadinho $(\sim 80 \mathrm{~A})$ aquece o cadinho por efeito Joule e esquenta a amostra até torná-la líquida. A taxa de deposição do material pode ser ajustada através do ajuste correto da corrente que atravessa o cadinho. Essa taxa pode atingir baixos valores $\sim 0,2 \AA / \mathrm{s}, \mathrm{o}$ que permite a formação de um filme ainda mais uniforme. Todo o processo é feito numa câmara de alto vácuo $\sim 10^{-6} \mathrm{~Pa}$ para garantir que a amostra não seja contaminada com outros elementos.

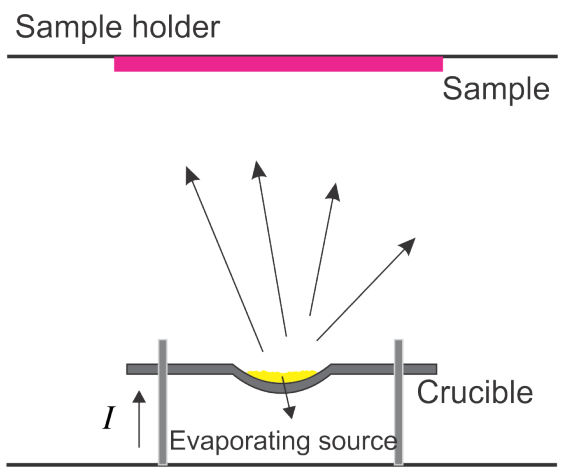

Figura 34 - Diagrama esquemático indicando a deposição de um filmo fino sobre uma amostra (sample) através da evaporação de um metal sólido (evaporating source) contido num cadinho (crucible) de molibdênio ou tungstênio.

Fonte: Elaborada pelo autor.

Vale ressaltar que, em geral, ao fazer a deposição de filmes finos, uma fina camada de alguns nanômetros de cromo é depositada como passivadora da superfície, ela evita que o filme depositado se solte naturalmente da amostra. No entanto, em nossas amostras 
essa camada não foi depositada porque o Cromo altera drasticamente as propriedades ópticas do filme fino, o que modificaria bastante as propriedades plasmônicas do sistema experimental. Um cuidado redobrado com a superfície das amostras teve de ser tomado, mas o filme fino permaneceu preso à amostra sem comprometê-la.

Para garantir que o filme fino foi formado é possível fazer medidas de transmissão da luz através do mesmo para várias espessuras distintas. Sabe-se que para pequenos valores de espessura do filme depositado ocorre a formação de aglomerados metálicos ao invés de um filme fino. (105) A assinatura característica da formação destes aglomerados é a existência de picos de absorção associados a nanopartículas metálicas.

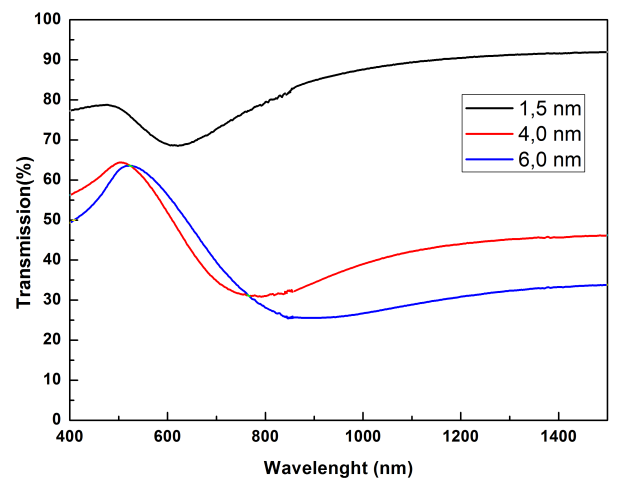

Figura 35 - Transmissão de luz através de filmes finos de Au depositados sobre uma superfície de vidro. As espessuras dos filmes estão mostradas na figura.

Fonte: Elaborada pelo autor.

Como a transmissão da luz visível em amostras de GaAs não pode ser medida, já que o GaAs absorve a luz nessa região, utilizamos um substrato de vidro para analisar as propriedades ópticas do filme metálico depositado utilizando o sistema de evaporação. Quando a espessura do filme depositado é da ordem de 1,5nm, conforme mostra a fig. 35, aparece um pico de absorção em torno de 600nm.

À medida que a espessura do filme aumenta o pico se torna cada vez menos acentuado e é deslocado para maiores comprimentos de onda. O aumento no comprimento de onda é explicado pelo aumento dos aglomerados metálicos, enquanto o desaparecimento gradual do pico demonstra que a superfície de metal evaporada é cada vez mais uniforme. Note que com 6nm o filme já é praticamente uniforme.

No nosso caso de estudo, como estamos interessados em amostras de pontos quânticos 
em GaAs, a região de interesse é em torno de 1100nm, onde a transmissão da luz é aproximadamente uniforme. Vale ressaltar que como a constante dielétrica do GaAs é maior que a do vidro o pico de absorção tem o seu comprimento de onda reduzido.

Outro resultado importante é que a espessura do filme é muito importante no processo de transmissão. A parte imaginária da constante dielétrica do metal, responsável por processos de absorção, torna o filme metálico praticamente refletor para espessuras da ordem de 20 ou 30nm. Em nossos experimentos envolvendo cavidades metálicas utilizamos filmes com 120nm de espessura, o que faz com que o filme não transmita luz e com que a superficie do mesmo seja bastante uniforme.

\subsection{Técnicas de litografia}

A parte crucial do trabalho experimental consiste na fabricação de nanoestruturas sobre a superfície metálica. Utilizando métodos de litografia eletrônica (16) ou por feixe de íons (FIB, Focused ion beam) (17) é possível fabricar desde estruturas simples como fendas ou fios metálicos, como estruturas mais complexas, e.g. redes plasmônicas.

\subsubsection{Litografia por feixe de elétrons}

A litografia por feixe de elétrons representa uma boa escolha em muitos casos. No entanto, parte do processo de produção de nanoestruturas utilizando essa técnica consiste em realizar um ataque químico sobre a amostra. O processo consiste em 5 partes:

- Deposição de um photoresist, em geral PMMA;

- Exposição ao feixe de elétrons da região onde deve ser depositado o metal;

- Remoção da região exposta utilizando um ataque químico;

- Deposição do metal, utilizando a evaporadora;

- Remoção do photoresist utilizando um solvente (lift off).

Os processos indicados acima estão esquematizados na fig. 36. O inconveniente dessa técnica é a baixa taxa de reprodutibilidade experimental de fendas (estruturas) com di- 
mensões abaixo de 100nm. Isso ocorre porque o diâmetro do feixe de elétrons utilizado é, em geral, da ordem de algumas dezenas de nanômetros.

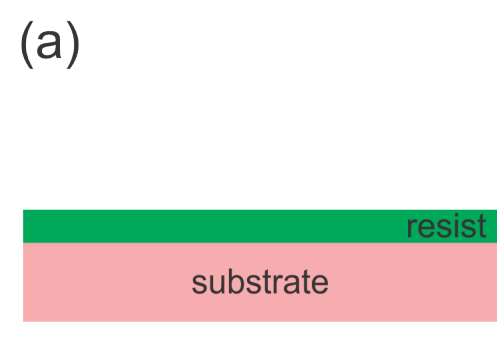

(c)

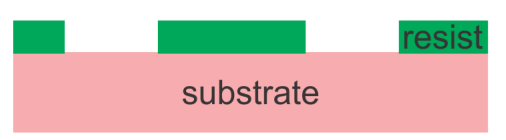

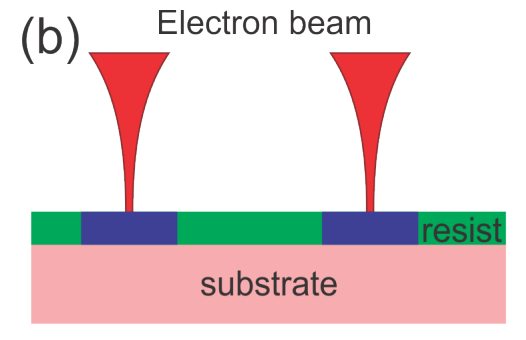

(d)

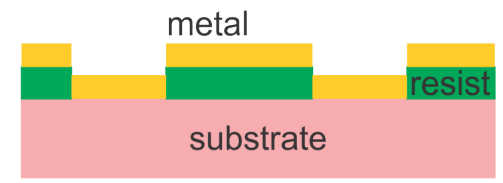

(e)

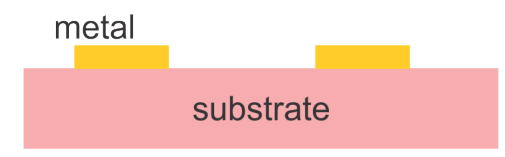

Figura 36 - Etapas da litografia por feixe de elétrons. (a) Deposição do photoresist. (b) Exposição do resist ao feixe de elétrons, alterando suas propriedades químicas. (c) Remoção da parte exposta do resist através de um ataque qúimico. (d) Deposição do metal. (e) Remoção dos excessos de resist e metal com um ataque químico mais violento (lift off).

Fonte: Elaborada pelo autor.

O sistema que permite a litografia por feixe de elétrons é o mesmo que pode ser utilizado para microscopia eletrônica de varredura (SEM). O sistema é constituído por um canhão de elétrons acelerado a altas tensões, em geral de 20 ou $30 \mathrm{keV}$. Nessa técnica, os elétrons são gerados por uma ponta de tungstênio. Os elétrons escapam do metal por tunelamento.

Os elétrons são acelerados e o feixe é colimado através de um sistema de lentes. O sistema presente em nosso laboratório é análogo àquele mostrado na fig. 37. A amostra fica numa câmara de alto vácuo $\sim 10^{-6} \mathrm{~Pa}$ sobre um porta amostra metálico que descarrega a amostra à medida que o feixe de elétrons incide na mesma. 


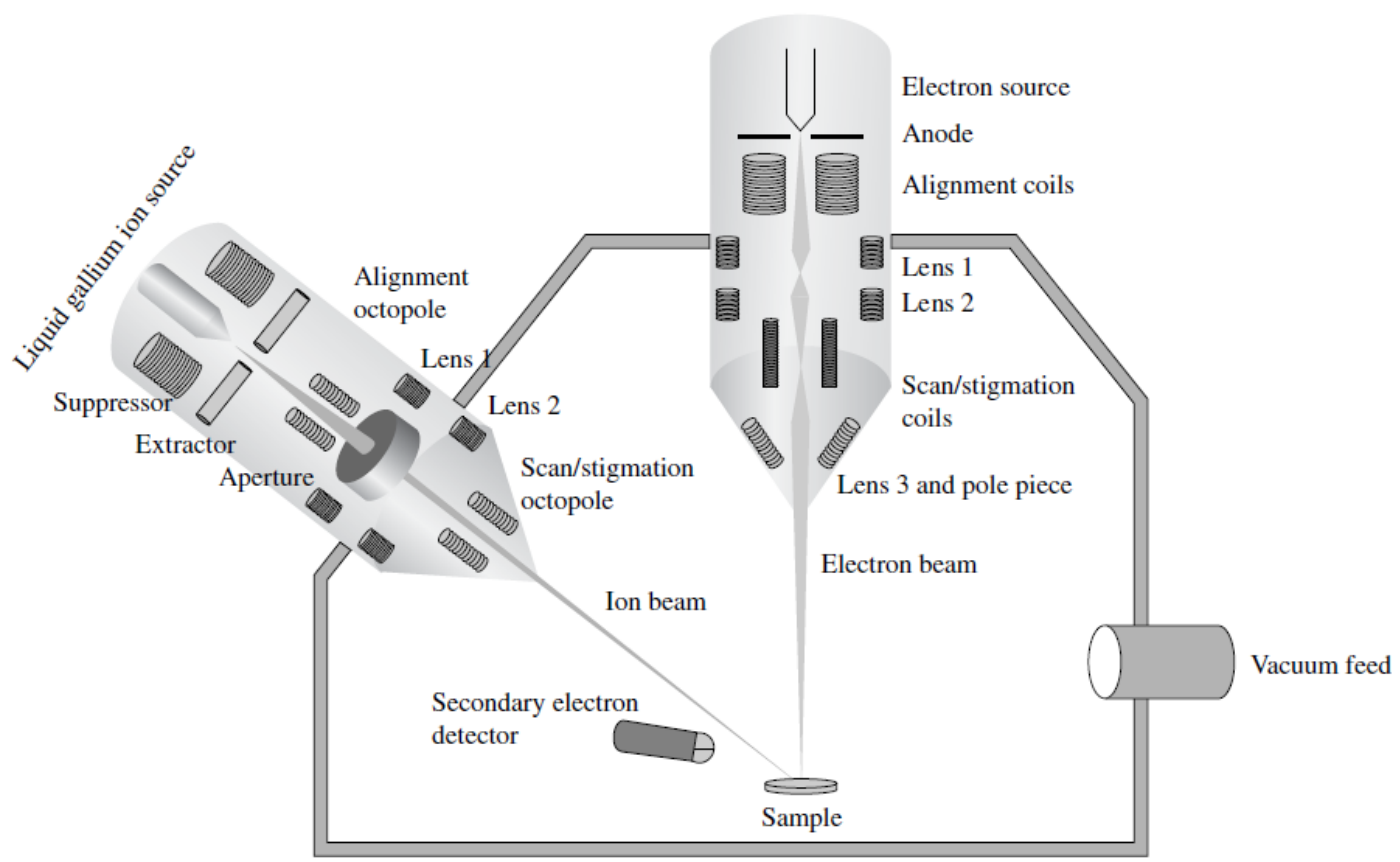

Figura 37 - Diagrama esquemático de um sistema composto por dois feixes, eletrônico e de íons.

Fonte: YAO; WANG. (62)

\subsubsection{Litografia por feixe de íons (FIB)}

Estamos interessados principalmente na litografia por feixe de íons. (17) Há vários motivos para isso, e.g. a precisão obtida através desse método e a capacidade de trabalhar indistintamente com praticamente todos os materiais que utilizamos. Isso ocorre uma vez que a litografia por feixe de elétrons depende de um ataque químico na amostra, os solventes utilizados são diferentes para cada tipo de aplicação. Já com o feixe de íons, pela sua grande massa, é possível executar um processo de milling (extração do material da amostra). Além disso, ela se trata de uma plataforma independente, onde todos os processos podem ser realizados sem a necessidade de utilizar outros equipamentos, i.e. não é necessário retirar a amostra da câmara e reintroduzí-la novamente em uma evaporadora. Ao utilizar o feixe de íons a amostra já sai da máquina pronta para que as medidas sejam realizadas.

No sistema mostrado na fig. 37, também está representada a coluna que produz o feixe de íons. No nosso sistema é utilizado um feixe de íons de $\mathrm{Ga}^{+}$que é acelerado por uma tensão de $30 \mathrm{kV}$ antes de atingir a superfície da amostra.

Um diagrama simplificado (onde somente a parte final de cada uma das colunas) é apresentado na fig. 38(a). Os feixes formam um ângulo característico de $52^{\circ}$, que depende 
do design do equipamento, e o ponto onde se cruzam, chamado de ponto eucêntrico, é ajustado para corresponder ao foco de ambos os feixes. Dessa maneira, é possível fazer imagens de varredura tanto com o feixe de elétrons quanto com o feixe de íons mantendo a posição da amostra inalterada. No entanto, o modo de operação do feixe é íons é preferencialmente aquele no qual a superfície da amostra é ortogonal ao mesmo.

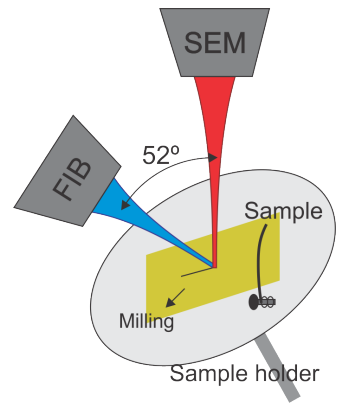

(a) Remoção de um material.

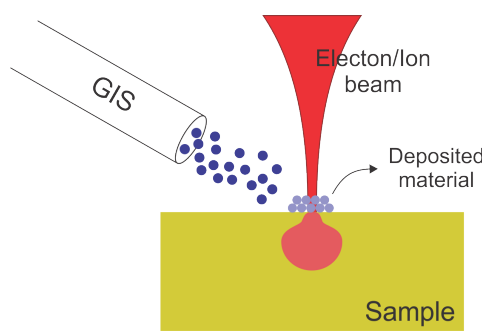

(b) Deposição de um material através do FIB.

Figura 38 - Diagrama esquemático dos modos de funcionamento de um microscópio por feixe de íons.

Fonte: Elaborada pelo autor.

\subsection{Amorfização local da amostra}

Devido à grande aceleração sofrida pelos íons de $\mathrm{Ga}^{+}$e à sua grande massa, ao atingir a superfície da amostra esse feixe é capaz de arrancar os átomos que compõem a amostra. Essa remoção pode ser controlada pelo diâmetro e posição do foco do feixe de íons utilizado. A fig. 39(a) mostra como os íons de $\mathrm{Ga}^{+}$se dispersam no material durante o processo de nanofabricação. Essa interação é capaz de amorfizar localmente a superfície composta por uma rede cristalina do substrato semicondutor, o que pode representar um grande problema por destruir os QDs presentes na matriz. Esse problema é contornado quando utilizamos as propriedades do feixes de íons e um design ótimo para o processo de fabricação da amostra.

Numa amostra como a de $\mathrm{Si}$, a penetração do feixe de $\mathrm{Ga}^{+}$é de cerca de 70nm. Caso a fabricação das estruturas seja feita sobre a superfície de Au é possível que o substrato nem seja atingido. No entanto, como desejamos produzir uma amostra na qual a transmissão de luz seja razoável para que ainda seja possível medir os efeitos da interação dos QDs com os SPPs, o processo de milling é realizado até que todo o filme de Au seja consumido. 


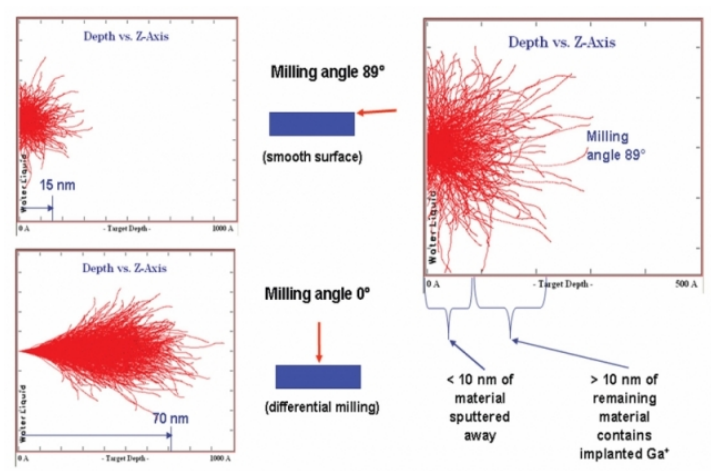

(a) Penetração dos elétrons e dos íons de $\mathrm{Ga}^{+}$ em um substrato de Si cristalino.

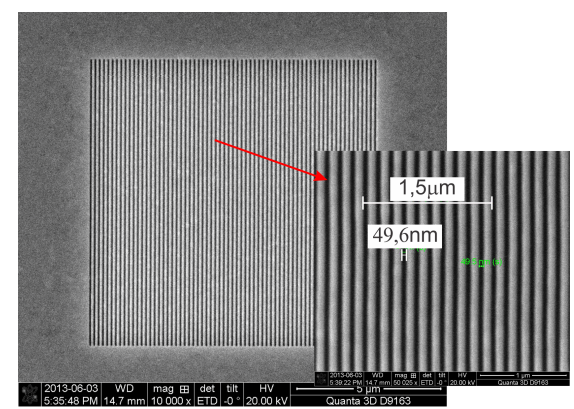

(b) Exemplo de estrutura nanofabricada utilizando o feixe de íons.

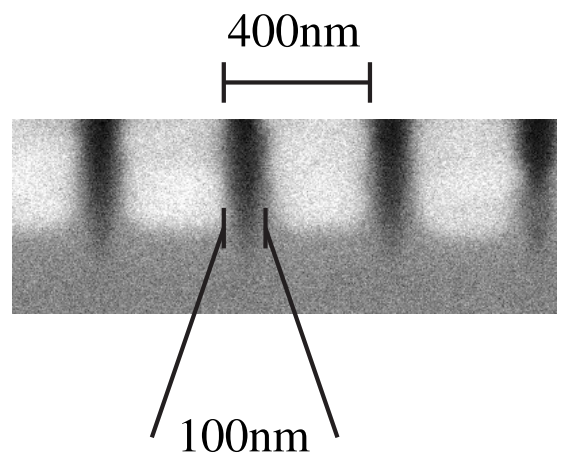

(c) Exemplo de um imagem de seção transversal obtida utilizando microscopia eletrônica e que mostra que o material abaixo da fenda metálica foi parcialmente retirado.

Figura 39 - Penetração dos feixes de litografia em uma amostra cristalina e exemplo de um estrutura capaz de ser produzida num FIB.

Fonte: (a) YAO; WANG. (17); (b) e (c) Elaboradas pelo autor.

Esse processo de fabricação destrói os QDs que são encontrados pelos íons de $\mathrm{Ga}^{+}$ acelerados. No entanto, como pode ser observado na fig. 39(a), a destruição ocorre preferencialmente na direção de propagação do feixe de íons (normal à superfície da amostra). Neste caso, os QDs que estão sob a camada de Au que não sofreu ação dos íons irá ser protegida e sua atividade óptica permanecerá inalterada.

Na fig. 39(b) é mostrado um exemplo de nanofabricação que foi realizado utilizando o feixe de íons presente em nosso laboratório de nanoplasmônica, um FIB FEI Quanta 3Di. Na figura, fabricamos fendas com 50nm de largura e separadas entre si por 150nm. Somente a título de apresentação da técnica, a estrutura foi feita sobre a própria superfície do substrato de GaAs (tipo n). Observe a qualidade das fendas indicando se tratar de um método confiável para a nanofabricação de estruturas plasmônicas. Vale-se notar que com o processo de milling em amostras não condutoras produz um acúmulo de cargas na 
superfície do material. Para fabricar essa amostra foi utilizada uma amostra do tipo $n$ para que seja suprimido o efeito do acúmulo de cargas e que não ocorra interação entre os íons do feixe que atingem a amostra e aqueles que já interagiram com a mesma.

Na fig. 39(c) é mostrado uma imagem de seção transversal de uma amostra que contém uma grade metálica com período de 400nm e fendas de 50nm de largura fabricadas sobre uma superfície de 120nm de Au depositada sobre a superfície de GaAs. A imagem foi obtida utilizando a técnica de cross-section, que é possível graças ao feixe de íons.

\subsection{Deposição de materiais}

Além de remover o material do substrato é possível depositar outros materiais sobre a superfície do substrato com a utilização desse tipo de microscópio. Esse tipo de procedimento é realizado utilizando o que se chama de gas injection system (17), ou simplesmente GIS.

Um esquema do processo de deposição de material dentro da câmara do microscópio é mostrado na fig. 38(b). Nele, o material a ser depositado é inserido na câmara em forma de gás (e.g. um organometálico) através de uma agulha colocada a cerca de $200 \mu \mathrm{m}$ da amostra. A superfície da amostra adsorve este gás que, ao ser atingido pelo feixe de íons, é ativado, quebrando as ligações do mesmo e levando ao processo de deposição, onde o material se agrega à superfície da amostra.

De maneira geral, ao realizar o processo de deposição assitido pelo feixe de íons também é realizado o processo de milling, e o efeito líquido dos dois processos agindo em conjunto é que não haja deposição. Por este motivo, em geral, a deposição inicial é feita utilizando o feixe de elétrons que, apesar de possuir uma taxa mais lenta, não danifica a superfície do substrato. Após a deposição dessa camada de proteção é que utiliza-se o feixe de íons.

Esse tipo de processo é bastante útil quando se deseja por exemplo fazer uma análise da estrutura interna da amostra. Neste caso, uma camada de proteção é depositada sobre a mesma e um processo lento de milling é realizado lateralmente sobre a camada de proteção, que protege a estrutura interna da amostra. Após os cortes laterais é possível ter uma imagem da seção transversal da amostra, o que gera informações sobre sua estrutura interna. Essa é a técnica de cross-section mencionada anteriormente. 
Outra utilidade da deposição de materiais, é a possibilidade de fazer ligações elétricas em nível micrométrico (a precisão do processo de deposição é diferente da do processo de milling), que é bastante útil para agilizar processos de design de microcircuitos elétricos, onde há a possibilidade de corrigir erros de projeto sem a necessidade de produzir novas amostras.

\subsection{Caracterização das amostras}

Parte desse trabalho foi baseada na demonstração de que os efeitos de interação éxciton-SPP poderiam ser isolados dos tipos mais comuns de interação, e.g. éxciton com fótons livres.

Isso deve ser feito porque, ao lidarmos com SPPs em nanoestruturas metálicas, efeitos de "vazamento de fótons" (ou leaking) podem produzir resultados espúrios na interação com SPPs.

O efeito de leaking faz com que a transmissão de luz através da nanoestrututra seja alta o suficiente para produzir sinais mensuráveis em nossos experimentos.

A seguir, demonstramos que esse efeito pode ser desprezado. Depois, buscamos uma assinatura característica do resultado da interação e podemos então analisar o efeito dessa interação mesmo na presença de fótons livres.

\subsubsection{Espectroscopia Raman}

Para garantir que haja algum efeito mensurável apenas devido aos SPPs em nossas amostras, fizemos uso da espectroscopia Raman. Para fazer isso, fabricamos um conjunto com várias grades metálicas como as da fig. 39(b), algumas das quais estão mostradas na fig. 40. Nessas amostras, de $10 \times 10 \mu \mathrm{m}$ de lado cada, o que fizemos foi variar o período e a largura das fendas da rede, além de variar o comprimento de penetração do íons de $\mathrm{Ga}^{+}$ com o intuito de calibrar o equipamento de padronização com os parâmetros ótimos de fabricação. Os parâmetros utilizados para cada uma das redes está mostrado na tabela 2. A espessura do filme de Au utilizado nessas amostras foi de 200nm.

Há inúmeras vantagens para utilizar a espectroscopia Raman como uma das primeiras 


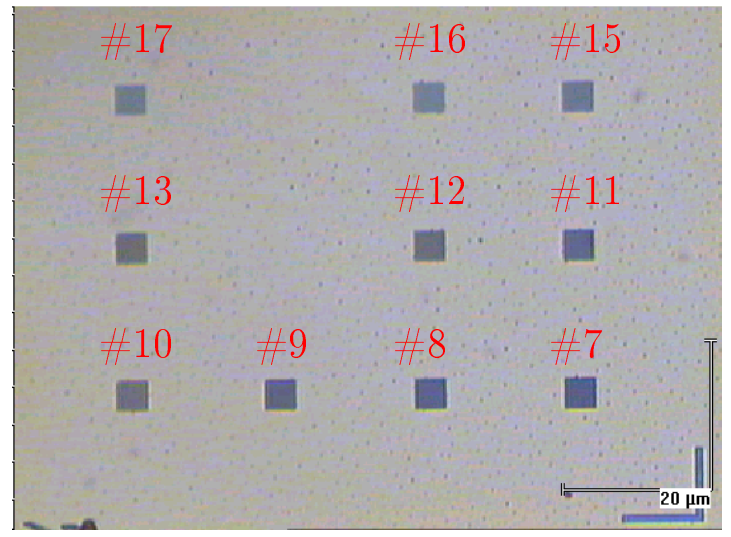

Figura 40 - Conjunto de grades metálicas fabricadas com o feixe de íons sobre a superfície do Au, com diferentes parâmetros de fabricação, a serem analisadas utilizando espectroscopia Raman para determinar os parâmetros ótimos de calibragem do sistema de fabricação.

Fonte: Elaborada pelo autor.

técnicas de análise das amostras, i.e. no estágio de produção das mesmas. Como se sabe, o sinal de Raman é proveniente da interação dos fônons da rede cristalina que compõe a amostra, que no nosso caso trata-se de uma amostra de GaAs, com a luz.

A aplicação dessa técnica é relativamente simples, já que a amostra não precisa ser resfriada para que o sinal seja mensurável, como acontece em medidas de fotoluminescência onde a qualidade do sinal é tanto melhor quanto mais baixa for a temperatura da amostra.

No caso das nossas amostras, as grades metálicas tinham seus centros separados por uma distância de $50 \mu \mathrm{m}$, o que em princípio ainda poderia gerar algum efeito de acoplamento entre grades vizinhas. No entanto, como utilizamos a técnica de micro-Raman, podemos excitar apenas uma das grades e obter o sinal devido apenas a ela. Num experimento típico de Raman, o que iríamos obter seria o sinal de todas as grades em conjunto.

Usando Raman, um primeiro efeito que pode ser estudado na fabricação das grades metálicas é o da amorfização da superfície do GaAs pela interação com o feixe de íons. O espectro Raman característico de uma superfície de GaAs é mostrado na fig. 41(a), onde os picos TO $\left(268 \mathrm{~cm}^{-1}\right)$ e LO $\left(292 \mathrm{~cm}^{-1}\right)$ estão presentes. Na figura observa-se que os picos são bem definidos, indicando que a rede cristalina tem poucas impurezas (átomos estranhos, deslocações, amorfização etc). Analisando o comportamento desses picos de acordo com a dosagem de íons de $\mathrm{Ga}^{+}$que atinge a superfície da amostra somos capazes de verificar qual o dano causado na mesma.

Como pode-se observar nas figs. 41(b), 41(c) e 41(d) a intensidade de luz coletada 
Tabela 2 - Parâmetros de fabricação das grades metálicas apresentadas na fig. 40 utilizadas na análise de espectroscopia Raman. Algumas das grades não estão na figura.

\begin{tabular}{cccc}
\hline Amostra & Profundidade $(\mathrm{nm})$ & Largura $(\mathrm{nm})$ & Período $(\mathrm{nm})$ \\
\hline 07 & 150 & 50 & 150 \\
08 & 150 & 70 & 150 \\
09 & 200 & 50 & 150 \\
10 & 200 & 70 & 150 \\
11 & 150 & 70 & 200 \\
12 & 150 & 50 & 200 \\
13 & 200 & 50 & 200 \\
14 & 200 & 70 & 200 \\
15 & 200 & 50 & 300 \\
16 & 200 & 70 & 300 \\
17 & 200 & 100 & 300 \\
\hline \multicolumn{4}{c}{}
\end{tabular}

depende fortemente da profundidade de milling do feixe de íons. O processo de amorfização é mais notável na amostra com menor período (150nm) indicando que a superfície da amostra foi seriamente danificada. Nas amostras com períodos de 200 e 300nm a volta dos picos TO e LO indica que parte da amostra ainda permaneceu cristalina, i.e. os QDs nessas regiões não seriam afetados pelo processo de fabricação das grades.

É sabido que apenas modos com polarização TM (campo elétrico normal à direção das fendas nas grades) é capaz de excitar modos de SPPs nas grades metálicas. (106) Com isso em mente foram realizadas medidas de Raman com a polarização do feixe nas direções TE e TM para verificar qual dos modos era excitado na propagação da luz através das grades.

A coleta de luz para os modos TE só é vista nas grades com período de 150nm. Isso indica que o vazamento ("leaking") de luz só ocorre porque a superfície de Au, que deveria atuar como um espelho e proibir a propagação de fótons através da nanoestrutura, foi fortemente danificada. No entanto, nas grades com períodos maiores nenhum pico ou sinal apreciável do modo TE foi observado.

Outra análise realizada incluiu incidir sobre as grades metálicas um feixe com polarização TE ou TM e coletá-lo em polarizações distintas. Na fig. 42 verificamos que ao fazer incidir sobre a grade metálica luz com polarização TM e coletá-lo na polarização TE (indicado pela linha vermelha da fig. 42) o sinal apresentado era praticamente nulo, o que demonstra que a luz correspondente à interação fônon-SPP também é polarizada; 


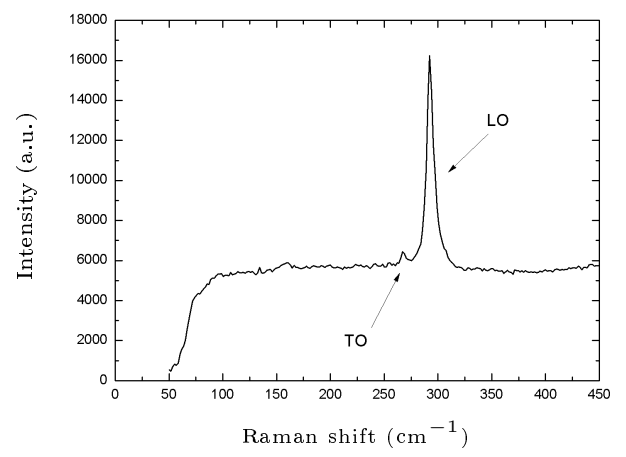

(a) Espectro Raman de um substrato puro de GaAs. Os picos característicos dos modos dos fônons da rede estão indicados.

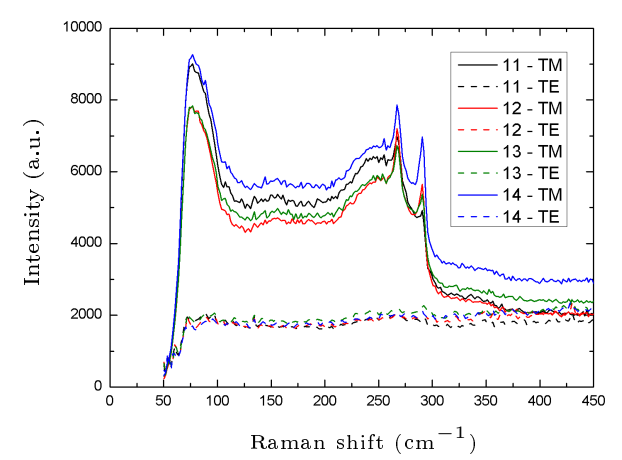

(c) Grades metálicas com período de 200nm.

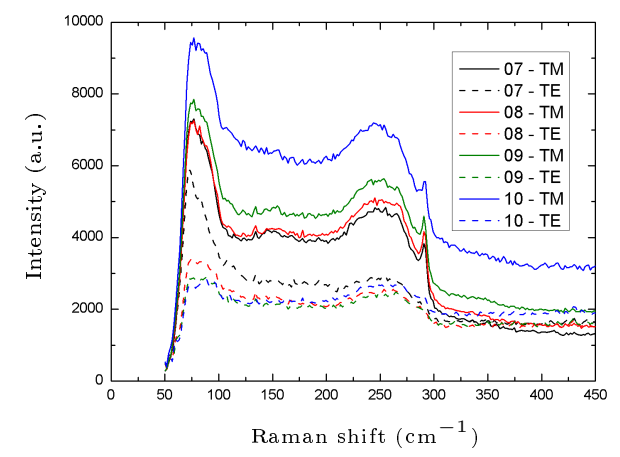

(b) Grades metálicas com período de 150nm.

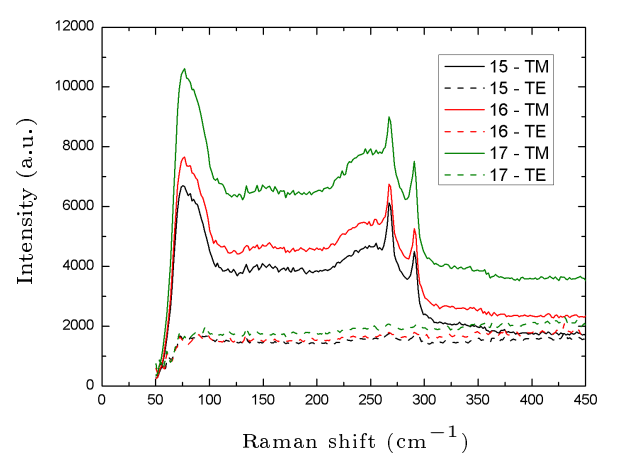

(d) Grades metálicas com período de 300nm.

Figura 41 - Espectro de micro-Raman para amostras fabricadas usando o feixe de íons. As grades metálicas produzidas possuem diferentes parâmetros de fabrização. As medidas foram feitas utilizando o laser nos modos TE e TM. Os dados apresentados aqui são obtidos com a mesma polarização dos feixes de entrada e saída.

Fonte: Elaborada pelo autor.

característica essa correspondente aos SPPs.

Esses resultados reiteram que apenas os SPPs se propagam através das grades metálicas, que atuam como filtros para fótons. Isso nos indica que quaisquer sinais ópticos na região de energia dos QDs obtidos ao fazer incidir luz sobre essas nanoestruturas são provenientes exclusivamente da interação entre os SPPs e os QDs.

Um último fato importante e que reforça a ideia de que apenas SPPs se propagam através das nanoestruturas é que a razão entre os picos devidos aos modos TO e LO são diferentes daquela das amostras simples. Essa característica se apresenta pela diferença entre os mecanismos de acoplamento dos SPPs e fótons com os fônons da rede cristalina. 


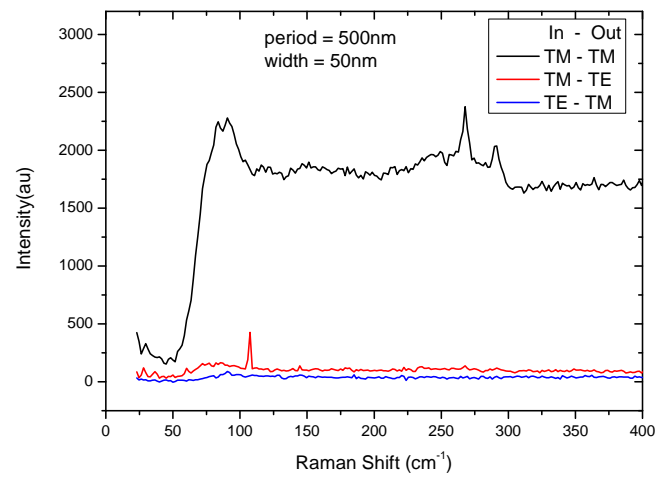

Figura 42 - Espectro de micro-Raman para uma amostra de período $500 \mathrm{~nm}$ e fendas de largura $50 \mathrm{~nm}$. As curvas indicam a resposta do sistema com feixes de entrada com polarização indicada por "In" e coleta da resposta na polarização indicada por "Out".

Fonte: Elaborada pelo autor.

\subsubsection{Presença de nanopartículas metálicas (acoplamento fraco)}

Um primeiro efeito que demonstra a importância de analisar a presença dos SPPs nas proximidades de QDs é demonstrado quando colocamos nanoesferas metálicas sobre a superfície de uma amostra contendo QDs. Através dessa idéia simples fomos capazes de demostrar que o acoplamento entre SPPs e QDs é responsável por modificar o espectro de luminescência de QDs de forma considerável. Neste caso, trata-se de um acoplamento fraco, já que não são observados efeitos de segunda ordem, mas tão somente um aumento na intensidade do espectro de luminescência dos emissores quânticos.

Para fazer isso, nosso experimento de luminescência consistiu de uma amostra semicondutora onde depositamos um conjunto de nanoesferas de ouro comerciais com diâmetros da ordem de 5 a 10nm, conforme mostra a fig. 43(a). Através de medidas de PL na amostra em regiões com e sem a presença das nanopartículas, obtivemos o espectro de emissão dos QDs mostrados na fig. 43(b). Verificamos que a presença das nanopartículas produziu um aumento da ordem de cinco vezes no sinal de intensidade da luminescência do pontos. Um resultado notável, já que a energia da ressonância dos SPPs nas nanopartículas é diferente da energia de recombinação dos éxcitons nos QDs.

Esse tipo de efeito é útil quando se analisam amostras que apresentam baixos valores de luminescência, i.e. que estão no limite de sensibilidade dos detectores. Essa técnica é utilizada por exemplo em amostras biológicas que apresentam um efeito chamado "quenching" (107) que faz com que a luminescência diminua com a exposição à luz, onde a 


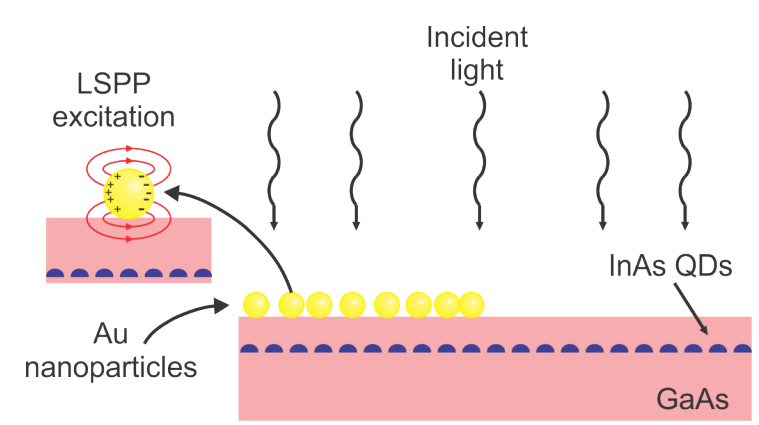

(a) Diagrama esquemático da interação entre o campo dos SPPs em nanopartículas metálicas (LSPPs) e éxcitons em QDs.

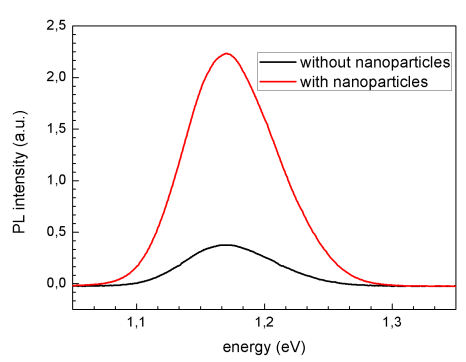

(b) Espectro de PL dos QDs com e sem a presença das nanoesferas metálicas.

Figura 43 - Aumento do espectro de fotoluminescência de uma amostra de QDs na presença de um conjunto de nanoesferas metálicas de ouro. A amostra possui um cap layer (distância entre a camada de QDs e a interface com o ar) de 50nm. As medidas foram realizadas a $7 \mathrm{~K}$.

Fonte: Elaborada pelo autor.

presença das nanopartículas, que induz a excitação de SPPs, aumenta a luminescência das amostras além de aumentar o tempo pelo qual as amostras permanecem luminescendo.

Uma explicação que não emprega nenhum efeito quântico para este aumento na luminescência é o efeito de antena produzido pela nanopartícula metálica, que neste caso aumenta o campo da luz em seu entorno e permite a interação com mais QDs. Neste caso, a nanopartícula funciona como uma cavidade plasmônica suportando modos de SPPs localizados. Vale ressaltar aqui que, o simples aumento na intensidade do campo eletromagnético induzido pela presença das nanopartículas não é o suficiente para saturar localmente os estados de QDs e produzir sinal de luminescência dos estados excitados para baixos valores de intensidade do feixe laser utilizado nas medidas.

No entanto, mecanismos quânticos, como a alteração do tempo de vida dos éxcitons nos pontos quânticos nas proximidades das nanopartículas metálicas também podem ser responsáveis por este tipo de modificação.

\subsubsection{Presença de grades metálicas}

Assim como é possível perceber um aumento no sinal de luminescência, é possível ainda modificar o espectro dos QDs. Isso pode ser feito quando a interação dos QDs com os SPPs se torna forte o suficiente para superar o acoplamento fóton-QD. Aqui, o acoplamento fóton-QD é considerado aquele de fótons livres, i.e. não acoplados à interface metal-dielétrico. 
Para verificar como isso é possível na prática, medimos a interação entre o campo dos SPPs num sistema como aquele mostrado na fig. 5. Para isso, reproduzimos várias grades metálicas idênticas em uma área de $250 \times 250 \mu \mathrm{m}^{2}$. Dessa maneira, utilizando um sistema de PL convencional observamos minuciosamente em que posições sobre a amostra o espectro de PL correspondia ao dos QDS ao mover o feixe de laser sobre a mesma. A correspondência do espectro de PL aos QDs pode ser feita observando-se os picos caracterísiticos dos estados dos pontos.

Como resultado, obtivemos para uma amostra de referência, onde os QDs não estão cobertos pelo filme metálico, e para grades com dois períodos diferentes, de 400nm e 600nm, os espectros de PL mostrados na fig. 44. Mostramos assim que, de acordo com o período da cavidade plasmônica é possível selecionar qual dos níveis de energia do QD será mais pronunciado.

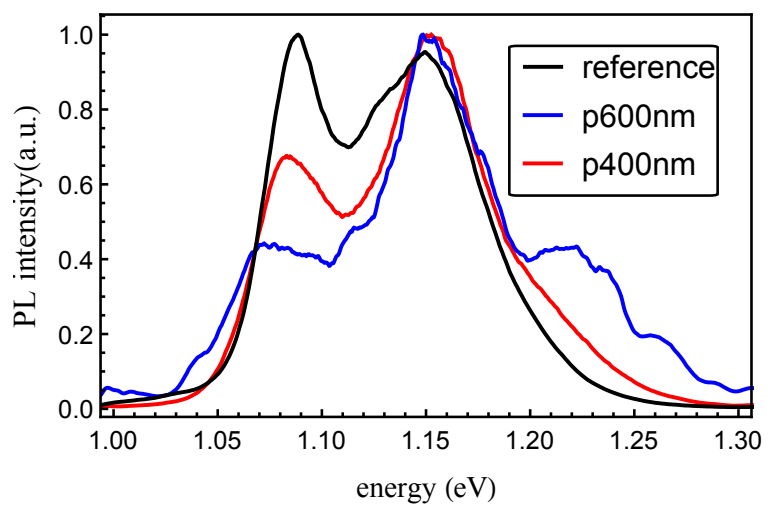

Figura 44 - Espectro de fotoluminescência, normalizado para a unidade, de uma amostra de pontos quânticos empilhados, como na fig. 5, sob uma grade metálica. A potência do laser utilizado é $90 \mathrm{~mW}$ em todas.

Fonte: Elaborada pelo autor.

Observe que à medida que o período da grade aumenta o espectro de PL fica mais ruidoso. Isso se deve ao fato de que há menos luz presente no sistema e a razão sinal/ruído diminui. Esse tipo de problema não deveria ocorrer num sistema de microPL, capaz de reduzir ainda as vibrações do sistema que podem causar o mesmo efeito.

Neste tipo de montagem a intensidade de luz em cada uma das grades é muito pequena, já que o diâmetro do feixe laser é grande $(\sim 70 \mu \mathrm{m})$ e a grade ainda atua como um filtro no qual apenas parte da luz é transmitida. Ainda assim, foi possível excitar não só o modo fundamental de energia dos éxcitons nos QDs, como pode ser visto no caso da amostra com um conjunto de grades de período $600 \mathrm{~nm}$. Vale ressaltar aqui, que a posição do foco 
do laser é ajustada de modo que a maior quantidade de modos possível seja excitada. Verifica-se que com a amostra descoberta é possível detectar o primeiro estado excitado, com a grade de 400nm o estado excitado é mais proeminente que o estado fundamental, já na amostra de 600nm de período é possível observar ainda o sinal devido ao segundo estado excitado.

Com a utilização de grades metálicas podemos ver que o efeito antena produzido pela cavidade, responsável por aumentar a intensidade do sinal e eventualmente dar origem ao sinal de estados excitados, pode ser diferenciado de outros mecanismos de interação com os SPPs; a mudança drástica na razão entre os picos dos estados presentes no espectro de PL indica que a interação SPP-QD apresenta diferenças fundamentais daquela interação fóton-QD. 


\section{Resultados experimentais em cavidades plasmônicas}

Os principais resultados obtidos durante o período desse trabalho e que buscam demonstrar que é possível atingir um regime de acoplamento forte na interação entre SPPs confinados em nanoestruturas plasmônicas e os estados dos éxcitons aprisionados em QDs são apresentados nesse capítulo. Estes resultados têm grande importância tanto no estudo da Física fundamental por trás das interações nesse tipo de sistema, quanto no desenvolvimento de novos dispositivos capazes de operar em regime óptico baseados nessa interação.

\subsection{SPPs numa nanoestrutura metálica}

O alto valor do campo gerado por um SPP nas proximidades de uma nanoestrutura metálica, assim como sua função de onda, são capazes de excitar estados excitônicos nos QDs de forma distinta daquela devida aos fótons livres.

Foi estabelecida uma nova metodologia na qual é possível obter o espectro de vários níveis energéticos dos éxcitons ao fabricar uma camada de QDs abaixo de uma nanoestrutura metálica consistindo de fendas metálicas produzidas sobre um filme de ouro.

Ao modificar a posição sobre sob a nanoestrutura onde os QDs são excitados é possível resolver (diferenciar) entre os diversos modos energéticos. Esta característica única pode ser associada ainda ao aumento da densidade local de estados (LDOS, do inglês "Local density of states") de luz introduzida pela presença dos SPPs, assim como a efeitos mesoscópicos atribuídos ao forte gradiente dos campos eletromagnéticos dos SPPs nas proximidades dos QDs. (108)

Em nossa abordagem, uma amostra semicondutora foi crescida sobre um substrato de GaAs orientado na direção (100). Um método de fabricação padrão foi adotado (109); após a degasagem dos óxidos, uma camada buffer de 300nm de GaAs foi crescida a $580^{\circ} \mathrm{C}$ para suavizar a superfície do GaAs. Utilizando o padrão de interferência do RHEED observamos a reconstrução da camada buffer através de um padrão de linhas $(2 \times 4)$. Após o crescimento da camada buffer, uma camada com 2, 2 monocamadas de InAs foram 
depositadas a $530^{\circ} \mathrm{C}$ e seguidas por um tempo de annealing de 30 s, o que produziu os QDs. Para que a densidade de QDs fosse ainda maior, uma nova camada de 12nm de GaAs foi depositada sobre a camada de QDs e este mesmo processo foi repetido por cinco vezes. A camada de $12 \mathrm{~nm}$ foi escolhida de forma que o acoplamento eletrônico intercamada fosse desprezível. (95) A fig. 45 representa o conjunto de camadas de QDs.

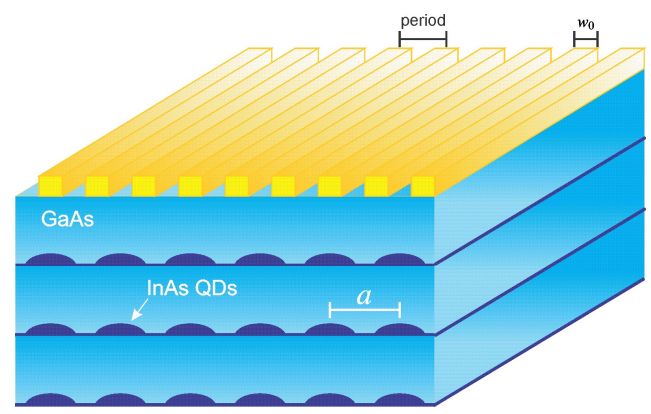

Figura 45 - Modelo do conjunto de camadas com QDs que interage com a grade plasmônica. O objetivo de produzir uma amostra com várias camadas é aumentar a densidade de QDs e, por consequência, aumentar o fator de acoplamento.

Fonte: Elaborada pelo autor.

Após o crescimento dos QDs, uma camada de 120nm de ouro foi depositada sobre a superfície da amostra. Esta espessura do filme é capaz de bloquear a transmissão de luz. Desta forma, utilizando um feixe de íons $\mathrm{Ga}^{+}$um padrão de fendas igualmente espaçadas (rede plasmônica) foi produzida sobre o filme de Au. As fendas possuem 100nm de largura e um período de 400nm, o período é a distância entre os centros de duas fendas adjacentes.

Conforme discutido anteriormente, à medida que o processo de milling é realizado parte do material semicondutor abaixo das fendas sofre um processo de sputtering (é arrancado da rede cristalina) e o restante da rede sofre ainda amorfização. Isso pode ser verificado através de uma imagem de seção transversal realizada com o microscópio eletrônico (veja a fig. 46).

De acordo com a fig. 46, à medida que o padrão é fabricado, uma camada de cerca de 30nm abaixo da interface com o GaAs se torna amorfa ou é arrancada. Dessa maneira, não há qualquer tipo de atividade óptica dos QDs nessa região. No entanto, como a penetração do feixe de íons segue aproximadamente a direção (100), principalmente na interface entre os meios, os QDs abaixo da região não fabricada do filme de Au ainda estão protegidos e sua eficiência quântica não é afetada. Uma nota importante é que 


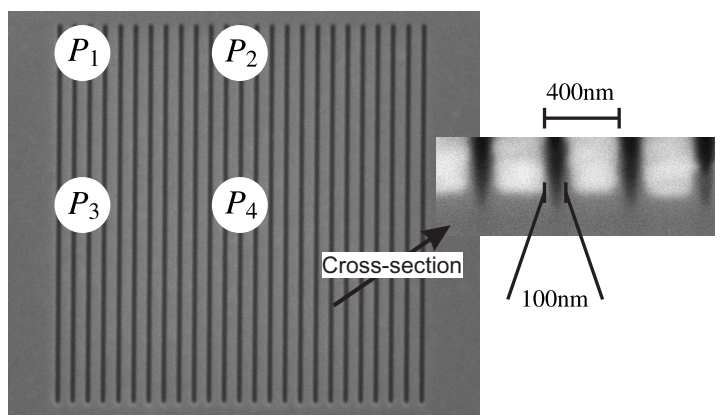

Figura 46 - Imagem de microscopia eletrônica de uma rede plasmônica fabricada utilizando FIB sobre um filme de ouro com 120nm de espessura depositado sobre uma superfície de GaAs. As posições numeradas de $P_{1-4}$ representam as posições onde o espectro de PL da amostra foi obtido. O foco do laser utilizado nas medidas estava sobre a superfície da amostra. A figura mostra ainda uma imagem de seção transversal do padrão fabricado. As fendas possuem $100 \mathrm{~nm}$ de largura, $10 \mu \mathrm{m}$ de comprimento e estão espaçadas de $400 \mathrm{~nm}$.

Fonte: Elaborada pelo autor.

a constante dielétrica do GaAs nessa região não é sensivelmente afetada devido a estes danos, dessa forma não se espera que o espectro dos SPPs seja fortemente afetado pelo processo de amorfização.

O espectro de PL foi medido em diferentes posições da amostra, em todo o padrão fabricado e também em uma amostra de referência sem o filme de Au (UQDs). As medidas foram realizadas com a amostra mantida a $77 \mathrm{~K}$ com um sistema de micro-PL HoribaJobim Yvon LabRAM equipado com uma lente de distância focal infinita. A amostra foi excitada com um laser de HeNe de $633 \mathrm{~nm}$ e $3,8 \mathrm{~mW}$ de potência, e com um laser de Ti-Safira de $785 \mathrm{~nm}$ e 16,5mW de potência; esses valores de potência foram medidos sobre a posição da amostra. A polarização do feixe laser pode ser ajustada na direção paralela (modo TE) ou perpendicular (modo TM) à direção das fendas na nanoestrutura. A cintura do feixe laser utilizado é de $2 \mu \mathrm{m}$, portanto 5 vezes menor que as dimensões da nanoestrutura.

Ao estudar o espectro de PL no ponto $P_{4}$, defocalizamos o feixe laser para iluminar toda a nanoestrutura com aproximadamente a mesma intensidade em cada ponto. Desta forma, podemos investigar os efeitos de tamanho finito da rede plasmônica. Quando o foco do laser está sobre a amostra o sinal integrado de PL atinge um máximo, indicando que mais QDs são excitados por SPPs e vice-versa. Após o máximo, como nem todo o feixe atinge as fendas na rede, o sinal passa a diminuir novamente. Este resultado é mostrado na fig. 47 para os lasers de 633nm e 785nm utilizando polarização TM. A posição onde 
o valor máximo do sinal de PL é atingido varia levemente por causa da dependência da transmissão da luz através da rede com o comprimento de onda do laser. No entanto, para ambos os casos essa distância é da ordem de $30 \mu \mathrm{m}$ a $40 \mu \mathrm{m}$ do foco do laser sobre a superfície da amostra.

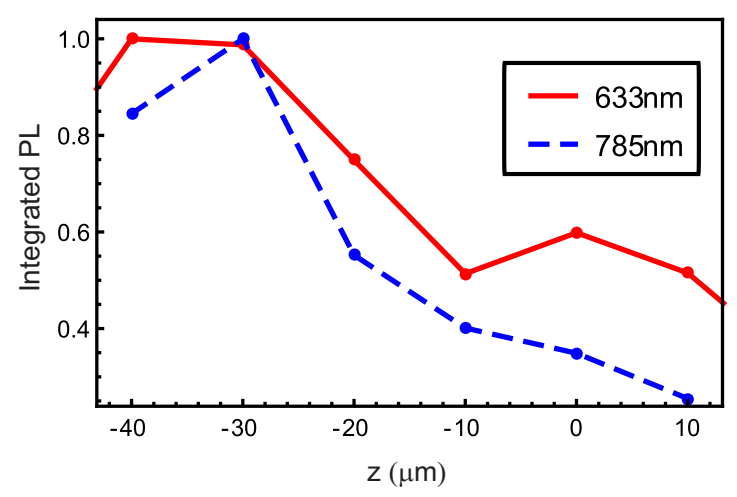

Figura 47 - Sinal integrado de PL para a rede plasmônica para os lasers de 633nm (linha vermelha) e 785nm (linha azul pontilhada). O sinal máximo foi normalizado para ambos os lasers e foi atingido quando o foco dos mesmos estava entre $30 \mu \mathrm{m}$ e $40 \mu \mathrm{m}$ acima da superfície da amostra $(z<0 \mu \mathrm{m})$, a posição $z=0 \mu \mathrm{m}$ corresponde ao foco do laser sobre a superfície da amostra. Os pontos experimentais estão conectados por segmentos de reta que servem como guia de olho. Veja a fig. 48 para o sinal de PL.

Fonte: Elaborada pelo autor.

Para demonstrar que os efeitos de borda são importantes na análise dos modos de SPPs suportados pela rede e na sua interação com os QDs, analisamos como a polarização do feixe laser (TE ou TM) modificava o espectro coletado numa medida de PL. A fig. 48 mostra o espectro obtido quando as condições do foco do laser de 633nm são ajustadas de forma a obter o maior sinal integrado de PL para ambas as polarizações.

No caso ideal de uma rede infinita, nenhum sinal é esperado para o modo TE porque ele não é capaz de excitar modos de SPPs. No entanto, como cada fenda possui um tamanho finito, é possível excitar SPPs com este modo, de forma que o sinal obtido é não nulo. O acoplamento para o modo TE é nas bordas das fendas e nas imperfeições das mesmas. Apesar de não ser nulo, o sinal devido ao modo TE é mais fraco do que aquele devido ao modo TM.

Para efeitos de comparação, o espectro de transmissão da luz foi calculado usando um modelo baseado em Diferenças Finitas no Domínio do Tempo (FDTD, do inglês Finite Difference Time Domain) (110) e o resultado foi que a transmissão para o modo TM é de $20 \%(45 \%)$ e de $0,7 \%(0,4 \%)$ para o modo TE quando se utiliza o laser com $633 \mathrm{~nm}$ (785nm). Na simulação, a rede foi excitada por uma onda plana (rede plasmônica longe do 
foco do laser) e com o semicondutor composto apenas de GaAs. Na simulação, o campo eletromagnético devido ao laser decai apenas $5 \%$ entre as camadas superior e inferior de QDs.

Conforme mostra o anexo na fig. 48 há picos em duas energias distintas. Estes picos correspondem a diferentes famílias de QDs, $\mathrm{QD}_{1}$ em 1,11eV e $\mathrm{QD}_{2}$ em 1,16eV. Uma maneira simples de verificar este fato é observar o aparecimento destes picos a baixas excitações do feixe laser.

Note que ambos os picos aparecem no espectro de PL do modo TE. É possível notar, no entanto, que estados excitados da família de pontos $\mathrm{QD}_{1}$ estão evidentes no espectro devido ao modo TM mas não no espectro do modo TE. Essa é mais uma assinatura da interação com os QDs. Como a excitação com a polarização TE é fraca, os QDs não são localmente saturados, devido ao campo eletromagnético do SPP. Dessa maneira, apenas os modos de mais baixa energia são responsáveis pelo espectro.

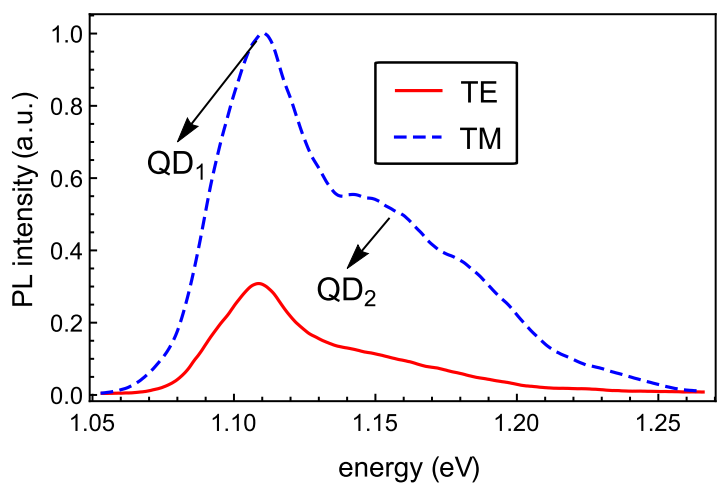

(a) Sinal de PL para os modos TE (linha vermelha) e TM (linha azul pontilhada) para o laser de $633 \mathrm{~nm}$ incidindo sobre a rede plasmônica.

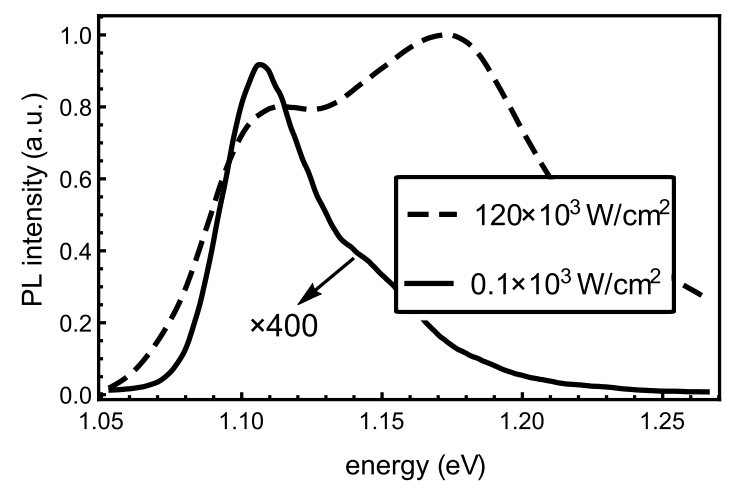

(b) Sinal de PL para os UQDS a baixa $(0,1 \times$ $\left.10^{3} \mathrm{~W} / \mathrm{cm}^{2}\right)$ e alta $\left(120 \times 10^{3} \mathrm{~W} / \mathrm{cm}^{2}\right)$ intensidade do feixe laser.

Figura 48 - Comparativo entre os sinais de PL para uma amostra de QDs abaixo de uma estrutura metálica fabricada em Au com 400nm de período e fendas com largura de 100nm.

Fonte: Elaborada pelo autor.

A resposta do sistema à excitação com o feixe laser para cada uma das posições $P_{1-4}$ indicadas na fig. 46 também pode ser estudada utilizando um modelo de FDTD. Para isso, foram realizadas simulações da incidência de um feixe laser de 785nm (o mais intenso disponível) considerando uma polarização TM e um feixe gaussiano de cintura $2 \mu \mathrm{m}$. O perfil de intensidade do campo dos SPPs (logo abaixo da rede plasmônica) foi determinado. Na fig. 49 está indicado o perfil de intensidade do campo luminoso sobre a camada de QDs mais próxima da interface $\mathrm{Au} / \mathrm{GaAs}$. 
O maior valor do campo eletromagnético foi obtido na posição $P_{1}$ e seguido pelas posições $P_{2}, P_{3}$ e $P_{4}$, onde a razão entre os máximos é $1: 0,88: 0,95: 0,78$, respectivamente. O sinal de PL para amostra de QDs foi obtido em cada um destes pontos. Os resultados obtidos são mostrados na fig. 50. Aqui nosso interesse foi principalmente na forma do sinal, e não em seu valor integrado. Como sabemos a intensidade é máxima no foco do laser, mas como já foi visto o sinal integrado atinge um máximo quando o foco está sobre a superfície da amostra. Sendo assim, o sinal mostrado na fig. 50 foi normalizado para a unidade. O sinal integrado de PL varia levemente para cada um desses pontos já que a potência total transmitida depende de onde os SPPs são excitados.
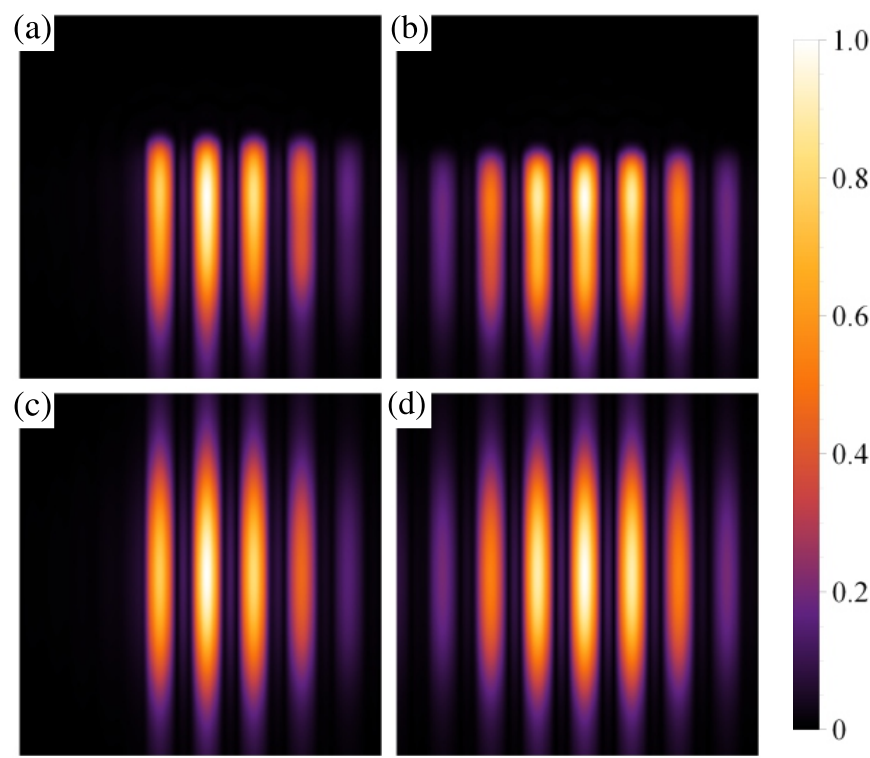

Figura 49 - Simulação FDTD para a intensidade total do campo elétrico do SPP sobre a camada de QDs. Os resultados para a incidência do laser nas posições $P_{1}-P_{4}$, dadas na fig. 46, estão mostradas nas figuras de (a) a (d), respectivamente. Na simulação, o laser de $785 \mathrm{~nm}$ com perfil gaussiano, com modo TM, foi utilizado. A cintura do feixe utilizado é $2 \mu \mathrm{m}$, assim como no sistema experimental, e os perfis de intensidade foram tomados a $12 \mathrm{~nm}$ abaixo da interface $\mathrm{Au} / \mathrm{GaAs}$.

Fonte: Elaborada pelo autor.

O perfil de intensidade obtido para cada uma das posições $P_{1-4}$ indicadas na fig. 46 serve como medida indireta da densidade local de estados dos SPPs em cada ponto. As diferenças entre estes perfis de intensidade podem ser explicadas se observarmos que o mecanismo de excitação dos SPPs baseia-se na quebra da simetria de translação introduzida pela presença das fendas na direção de polarização do campo elétrico. Este é o motivo pelo qual, por exemplo, o modo TM é o mais importante no processo de excitação, e explica porque os pontos $P_{1}$ e $P_{3}$ possuem maior pico de intensidade. 
No ponto $P_{4}$ a rede se comporta como uma estrutura infinita, já que a cintura do feixe é bem menor que o comprimento da fenda. Apesar do modo TE não se acoplar fortemente com a luz, como mostra a fig. 48(a), as bordas das fendas no ponto $P_{2}$ aumentam o confinamento da luz e explicam o aumento da intesidade do campo eletromagnético quando comparado a $P_{4}$.

O resultado do aumento na intensidade do campo devido aos SPPs se apresenta no espectro de PL com o aparecimento de inúmeros estados excitados em cada região da amostra. A figura anexa à fig. 50 mostra o espectro obtido para a amostra de UQDs no foco do feixe laser de 785nm, medidos tanto na intensidade máxima como na intensidade mínima do laser. Podemos observar neste anexo que o pico em $1,18 \mathrm{eV}$, correspondente ao estado excitado da família de pontos $\mathrm{QD}_{1}$, se mistura com o pico de $1,16 \mathrm{eV}$ devido ao estado fundamental da família de pontos $\mathrm{QD}_{2}$.

O espectro para os pontos $P_{2}$ e $P_{4}$ é análogo àquele da amostra de UQDs com a mistura dos estados fundamental e excitados das famílias de pontos $\mathrm{QD}_{1}$ e $\mathrm{QD}_{2}$, respectivamente. Contudo, é possível observar que o estado fundamental de $\mathrm{QD}_{1}$ e $\mathrm{QD}_{2}$ não está completamente populado (como na amostra de UQDs). Por este motivo, há uma maior intensidade em $1,16 \mathrm{eV}$ do que em $1,18 \mathrm{eV}$ e o estado excitado da família de pontos $\mathrm{QD}_{2}$ não pode ser resolvido.

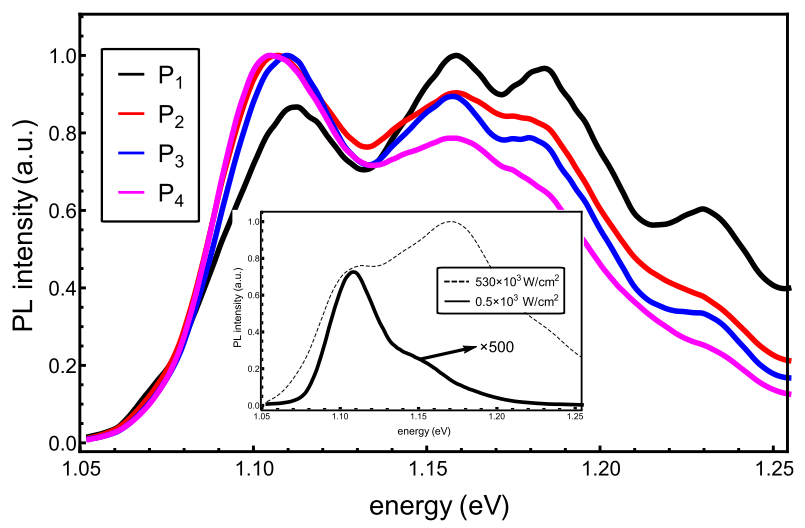

Figura 50 - Sinal de PL normalizado para cada um dos pontos $P_{1-4}$ indicados na fig. 46 . O laser com $785 \mathrm{~nm}$ de comprimento de onda é focalizado sobre a superfície da amostra em cada uma das posições com intensidade máxima de $530 \times 10^{3} \mathrm{~W} / \mathrm{cm}^{2}$ e polarização TM. A figura anexa mostra o espectro normalizado para a amostra de UQDs com intensidade mínima $\left(0,5 \times 10^{3} \mathrm{~W} / \mathrm{cm}^{2}\right)$ e máxima $\left(530 \times 10^{3} \mathrm{~W} / \mathrm{cm}^{2}\right)$ do feixe laser.

Fonte: Elaborada pelo autor.

No ponto $P_{3}$, os picos em $1,18 \mathrm{eV}$ e em $1,16 \mathrm{eV}$ podem ser resolvidos facilmente e há o aparecimento de um novo pico em $1,23 \mathrm{eV}$ que corresponde ao estado excitado da família 
de pontos $\mathrm{QD}_{2}$. Já no ponto $P_{1}$, observamos que o estado fundamental de $\mathrm{QD}_{1}$ é saturado pois sua intensidade tem uma queda relativamente ao estado excitado. Nesta posição, a resolução dos picos em $1,16 \mathrm{eV}$ e em $1,18 \mathrm{eV}$ é ainda melhor e o mesmo ocorre para o pico em $1,23 \mathrm{eV}$.

Dessa forma, verificamos que as bordas nas estruturas plasmônicas, que implicam numa alta intensidade de campo eletromagnético, explica a excitação de inúmeros níveis energéticos nos QDs, o que foi observado pela saturação do estado fundamental e através do aparecimento de estados excitados bem resolvidos.

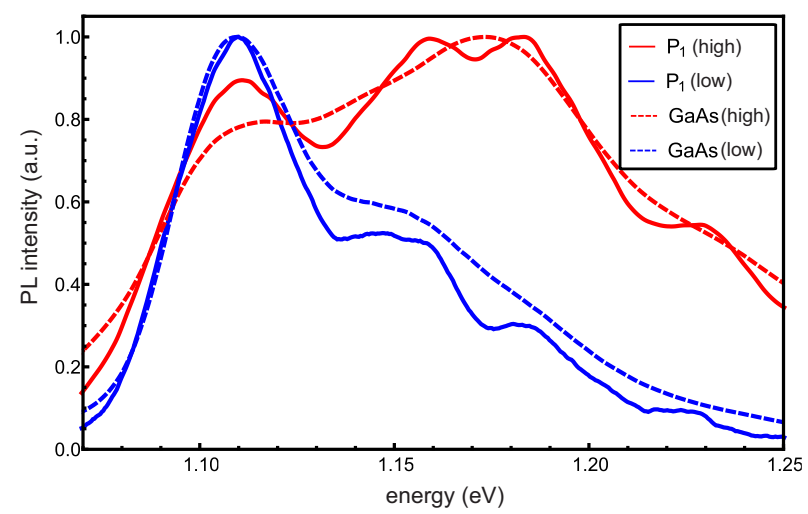

Figura 51 - Sinal de PL normalizado quando o laser de 633nm incide sobre a amostra de UQDs (linhas pontilhadas) ou quando é colocado na posição $P_{1}$ (linha contínua). No espectro são comparados os sinais obtidos quando a intensidade do feixe laser é máxima (high, $120 \times 10^{3} \mathrm{~W} / \mathrm{cm}^{2}$ ) e duas ordens de magnitude menor (low, $1,2 \times 10^{3} \mathrm{~W} / \mathrm{cm}^{2}$ ).

Fonte: Elaborada pelo autor.

A resolução notável dos níveis de energia que pode ser obtida através deste procedimento simples pode ser explicada pelas características únicas da interação dos SPPs com os QDs. Quando comparada com a amostra de UQD, o espectro para a posição $P_{1}$ é capaz de resolver os vários níveis de energia até mesmo a baixas intensidades do feixe laser. A fig. 51 mostra que o resultado ainda é válido para a excitação com o laser de $633 \mathrm{~nm}$, i.e. mostra que o decaimento dos QDs em SPPs é o principal mecanismo capaz de explicar a forma do espectro de PL.

Isto é o resultado da alta taxa de recombinação dos estados de energia dos QDs, que decaem em SPPs, quando comparada com as taxas de decaimento em fótons livres ou fônons na rede de GaAs. O aumento na LDOS à medida que nos aproximamos da ressonância de plásmon, o alto valor do fator de acoplamento para a interação SPPséxciton (96), assim como os efeitos mesoscópicos da função de onda introduzidos pelas 
proximidades com o filme metálico (108) são mecanismos importantes. O último é mais pronunciado para estados excitados, onde momentos de quadrupolo da função de onda do éxciton são mais intensos. (111)

Além da modificação no espectro de fotoluminescência da amostra de QDs, uma análise mais cuidadosa da fig. 50 revela que há um deslocamento sistemático do pico de ressonância referente ao estado fundamental dos éxcitons nos QDs.

Este efeito pode ser explicado se levarmos em conta que o processo de interação dos SPPs com os QDs também induz um shift de energia. Um cálculo utilizando teoria de perturbação (112) revela que este shift é dado por

$$
\delta \omega=\int d \omega \frac{\rho(\omega)|g(\omega)|^{2}}{\omega-\Delta}
$$

Nesta expressão, onde utilizamos $\hbar=1$, a energia do estado fundamental do QD é representada por $\Delta, g(\omega)$ é o fator de acoplamento na interação éxciton-SPP e $\rho(\omega)$ é a densidade de estados local dos SPPs.

Apesar de não acessar diretamente a densidade de estados dos SPPs neste caso, podemos retirar informações da assinatura da mesma utilizando um modelo de um guia plano, por exemplo. Neste caso, o cálculo do shift de energia de um emissor quântico revela que há uma mudança de comportamento, onde para baixas energias o shift é positivo e para energias mais altas (próximas da frequência de SPP) ele é negativo. A fig. 52 indica esse comportamento que ja foi questionado na literatura para alguns sistemas de emissores quânticos. $(113,114)$

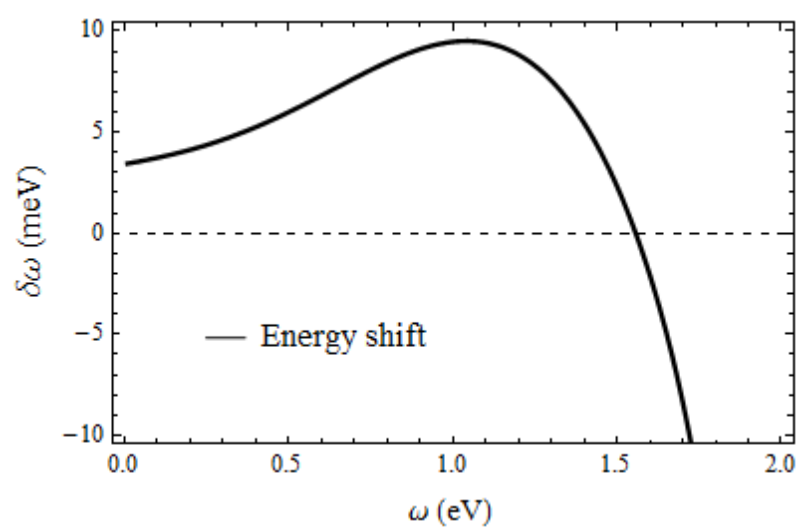

Figura 52 - Shift de energia induzido pela interação do SPP com um emissor quântico como função da energia $(\omega)$ do emissor. O modelo utilizado é aquele mostrado na fig. 45.

Fonte: Elaborada pelo autor. 
No nosso caso, podemos interpretar a intensidade de luz devida aos SPPs como uma medida indireta da densidade local de estado dos SPPs e escrever o shift de energia do éxciton como função deste parâmetro, veja a fig. 49 para o perfil e intensidade do campo nas posições onde o espectro de PL foi tomado. A fig. 53 mostra essa relação, onde a intensidade no ponto $P_{1}$ foi normalizada para a unidade. Como a energia do éxciton é em torno de $1,1 \mathrm{eV}$ o shift positivo está de acordo com o resultado da fig. 52. Observe ainda o aumento sistemático do shift, observado experimentalmente, com a medida (indireta) de densidade de estados.

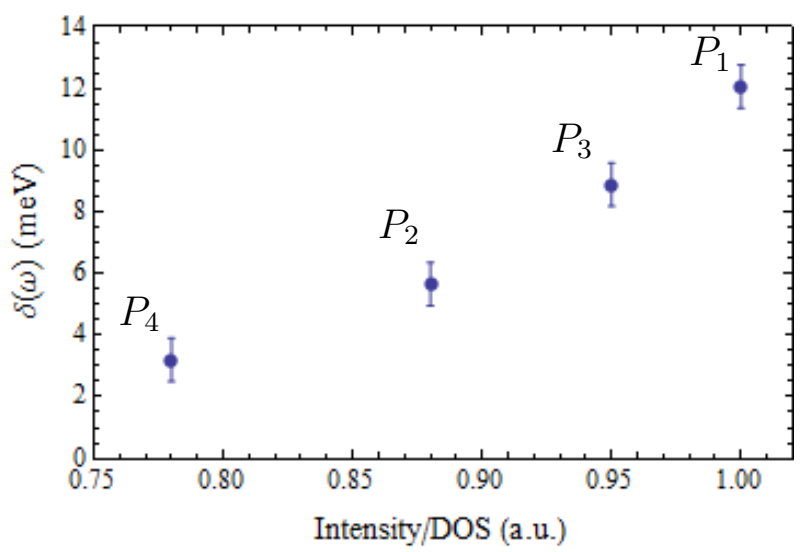

Figura 53 - Shift de energia do estado fundamental da amostra de SPPs como função da medida (indireta) de densidade de estados dos SPPs.

Fonte: Elaborada pelo autor.

Na fig. 53 as intensidades do campo eletromagnéticos dos SPPs nos pontos $P_{1}-P_{4}$ são aquelas medidas utilizando o modelo de FDTD mostrado na fig. 49. A razão das intensidades para estes pontos é $1: 0,88: 0,95: 0,78$, do maior para o menor.

\subsection{Modificação no tempo de vida}

A obtenção do tempo de vida dos estados dos éxcitos nas amostras mencionadas acima depara-se com alguns problemas técnicos. Em primeiro lugar, e mais importante, é que o sinal de luminescência obtido para essas amostras é muito baixo; apesar de haver uma forte interação entre os SPPs e os QDs, a transmissão de luz através da rede plasmônica ainda é baixa. Outra dificuldade é que as medidas de luminescência em redes plasmônicas necessitam de um sistema de microPL, o que indica que ambos os sistemas deveriam estar 
acoplados.

Tendo em vista essas dificuldades, montamos uma nova configuração onde a luz poderia ser capturada e o tempo de vida dos éxcitons nos QDs pôde ser determinado através de um experimento padrão de tempo de vida.

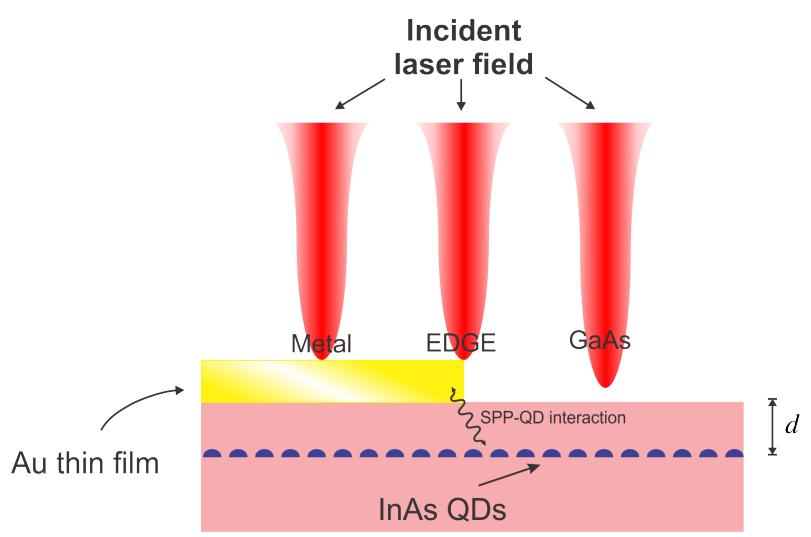

Figura 54 - Esquema representando a montagem para a medida de fotoluminescência de QDs de InAs em GaAs cobertos (ou não) por um filme de Au de $6 \mathrm{~nm}$ de espessura. A figura ilustra a competição entre o decaimento radiativo e o decaimento em SPPs de um emissor quântico nas proximidades de um filme metálico.

Fonte: Elaborada pelo autor.

Na fig. 54, representamos um esquema no qual parte de uma amostra contendo uma camada de QDs é coberta por um filme de Au enquanto a outra parte está descoberta. A precisão na espessura do cap layer torna possível a análise da interação do SPP com os QDs como função da distância entre os mesmos, considerando que o SPP se desloca sobre a interface metal/semicondutor.

Utilizamos um filme de Au com 6nm de espessura devido às suas propriedades mostradas na fig. 35, i.e. na região de $1,1 \mathrm{eV}$ correspondente à ressonância do estado fundamental do éxciton, o filme não apresenta picos correspondentes a SPPs localizados. Dessa forma, apenas plásmons de superfície deslocalizados serão importantes no cálculo da interação.

Investigamos o tempo de vida dos QDs nas regiões com e sem o filme de ouro como função da distância entre a camada de QDs e o filme metálico. Os valores dessa distância, controlada pelo valor do cap layer, foram de $d=10,20,30,40$ e $50 \mathrm{~nm}$. O espectro do estado fundamental para cada uma dessas amostras de QDs é mostrado na fig. 24.

As medidas de tempo de vida foram realizadas com as amostras mantidas a 7K. Foi utilizado um laser de diodo de 730nm guiado por uma fibra óptica multimodal que produzia um feixe com $70 \mu \mathrm{m}$ de diâmetro sobre a amostra. A potência de excitação do laser 
variou de $10^{-3}-10^{1} \mathrm{~mW}$, apesar dos resultados mais estáveis terem sido obtidos no intervalo $10^{-1}-10^{1} \mathrm{~mW}$. O espectro de PL obtido foi coletado por outra fibra óptica e guiado para um espectômetro com um detector de InGaAs.

A fig. 24 mostra que para cap layers maiores que 10nm a posição do pico do estado fundamental é em torno de $1,10 \mathrm{eV}$ com largura de linha variando na região $32-38 \mathrm{meV}$. Para a amostra com 10nm de cap layer o pico está deslocado para $1,08 \mathrm{eV}$ e a largura da linha é 45meV. Os QDs com 10nm de cobertura estão totalmente recobertos com GaAs; a altura média de um QD piramidal como estes é $8 \mathrm{~nm}$ com 20nm de base. No entanto, o campo de deformação remanescente é responsável por esse deslocamento do pico para baixas energias. O alto potencial da superfície (da ordem de $5 \mathrm{eV}$ ) não afeta significativamente os níveis de energia dos QDs. Uma redução da intesidade de luz emitida pela amostra de 10nm é devida à recombinação na superfície GaAs/ar. O tempo de vida dos portadores dos QDs também é reduzido devido à recombinação não radiativa na superfície. A troca de cargas entre os QDs e os estados de superfície diminui drasticamente para cap layers maiores que $20 \mathrm{~nm}$.

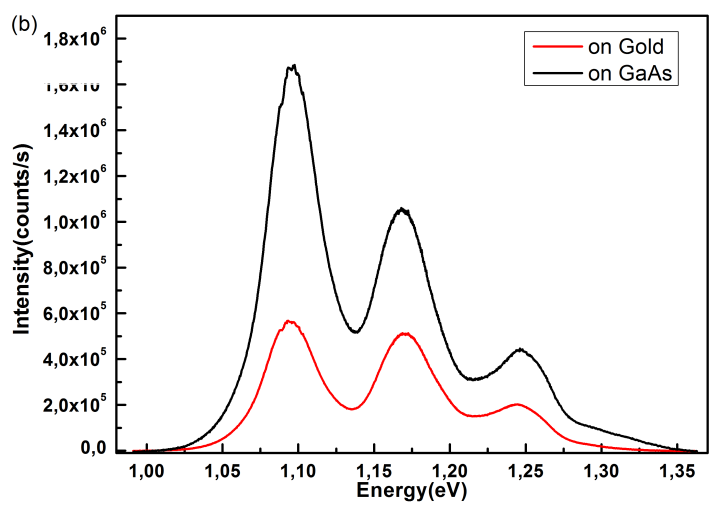

Figura 55 - Espectro de PL para a amostra com cap layer de 50nm de espessura, medida com potência do laser a $5 \mathrm{~mW}$. O espectro foi obtido no GaAs descoberto (linha preta) e na região coberta com o filme de $\mathrm{Au}$ (linha vermelha). O pico em $1,09 \mathrm{eV}$ corresponde ao estado fundamental e os outros aos estados excitados.

Fonte: Elaborada pelo autor.

Para efeitos de comparação da camada de Au, a fig. 55 mostra o espectro de PL com $d=50 \mathrm{~nm}$ em ambas as regiões, com e sem a camada de Au, a $5 \mathrm{~mW}\left(120 \mathrm{~W} / \mathrm{cm}^{2}\right)$ de potência. Os picos em $1,17 \mathrm{eV}$ e $1,24 \mathrm{eV}$ são devidos ao primeiro e segundo estados excitados dos QDs. Para garantir que a distribuição de QDs é aproximadamente a mesma 
em ambas as regiões observamos o sinal nas bordas do filme, veja a fig. 54. Para fazer isso basta observar quando o sinal apresenta patamares constantes de intensidade ao seguir de uma região para a outra. A primeira assinatura clara da interação entre os SPPs e os QDs é a mudança na razão entre os picos do primeiro estado excitado e do estado fundamental dos éxcitons nos QDs quando o laser é colocado sobre a região com o filme de Au.

Para mostrar que esse acoplamento influencia os mecanismos de relaxação do QD, medidas de fotoluminescência resolvida no tempo (TRPL, do inglês Time Resolved PhotoLuminescence) foram realizadas com o laser de 730nm no modo pulsado com 70ps de largura de pulso e taxa de repetição de $80 \mathrm{MHz}$. As medidas de tempo de vida foram obtidas seguindo a posição do pico do estado fundamental como função da potência de excitação. O IRF (resposta do sistema, do inglês Internal Response Function) do sistema foi medido com uma resolução melhor que 100ps.

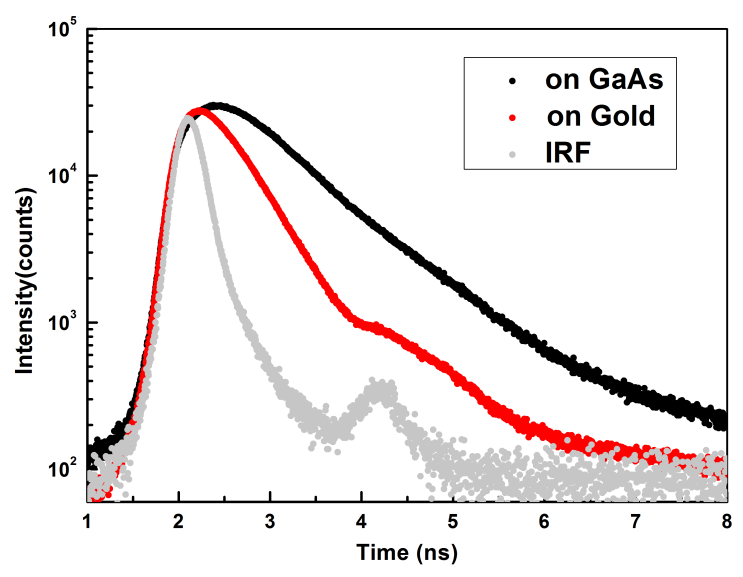

Figura 56 - Medida de TRPL para a amostra com $d=30 \mathrm{~nm}$ de cap layer, a $1 \mathrm{~mW}$ de potência. As medidas são no GaAs descoberto (pontos em preto), sob a camada de Au (pontos em vermelho) e o IRF é mostrado em pontos na cor cinza.

Fonte: Elaborada pelo autor.

A fig. 56 apresenta medidas do sinal de TRPL para uma amostra com $d=30 \mathrm{~nm}$ de espessura de cap layer, a uma potência de $1 \mathrm{~mW}$ do laser, medidas tanto na região do GaAs coberto como na região descoberta. Observamos claramente que a inclinação do decaimento do sinal na região do Au é maior que na região descoberta, indicando um menor tempo de vida do éxciton na presença da camada de Au. O IRF do sistema também é mostrado como referência, e seu pico em torno de 4ns coincide com o ombro nos dados experimentais. O fitting das curvas, não mostrado na figura, é utilizado para 
obter o tempo de vida do estado fundamental.

Os resultados obtidos para o estado fundamental dos QDs estão mostrados na fig. 57 para as regiões sem (a) e com (b) o filme de Au. Os dados foram obtidos como função da potência do laser na região de $100 \mu \mathrm{W}\left(0,2 \mathrm{~W} / \mathrm{cm}^{2}\right)$ até $5 \mathrm{~mW}\left(120 \mathrm{~W} / \mathrm{cm}^{2}\right)$, onde o sinal era alto o suficiente para que as medidas fossem realizadas. O primeiro estado excitado não é importante no mecanismo de decaimento, como pode ser visto na fig. 57(a) onde o tempo de vida do estado fundamental é aproximadamente constante na região de potência do laser utilizada nas medidas. O mesmo argumento também pode ser utilizado para as medidas na região com o filme de Au.
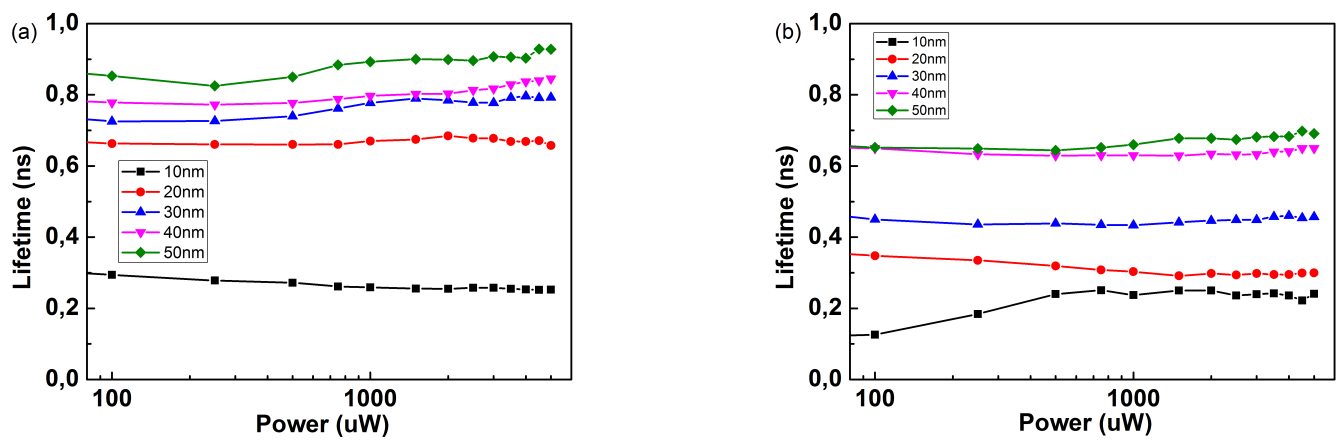

Figura 57 - Tempo de vida do estado fundamental dos QDs extraídos das curvas de TRPL para as amostras com $d=10$ a $50 \mathrm{~nm}$ de cap layer como função da potência do laser. Os resultados são dados para as regiões sem (a) e com (b) o filme de Au.

Fonte: Elaborada pelo autor.

A diminuição no tempo de vida do estado fundamental pode ser explicada pelo acoplamento com os SPPs suportados pelo filme metálico. Os canais de decaimento mais importantes são a taxa de recombinação dos éxcitons com a criação de fótons $\Gamma_{r a d}$ (canal radiativo), e em estados de superfície do $\operatorname{GaAs}\left(\Gamma_{G a A s}\right)$ e $\operatorname{SPPs}\left(\Gamma_{S P P}\right)$ que constituem um canal não-radiativo, já que os SPPs estão livres para se propagar ao longo do filme e não são detectados pelo sistema de PL. A taxa de decaimento total $\Gamma_{T}$ para o éxciton é, portanto, dada por:

$$
\Gamma_{T}=\Gamma_{r a d}+\Gamma_{G a A s}+\Gamma_{S P P}
$$

onde a taxa de decaimento em modos dos SPPs pode ser obtida pela regra de ouro de Fermi $(\operatorname{com} \hbar=1)$ 


$$
\Gamma_{S P P}=2 \pi g^{2}(\Delta) \rho(\omega=\Delta)
$$

Na eq. 74, $\rho(\varepsilon)$ é a densidade local de estados dos SPPs no filme metálico e $g(\Delta)$ é o fator de acoplamento dos SPPs com os éxcitons na energia $\Delta$ do estado fundamental dos QDs. O fator de acoplamento pode ser obtido para uma interface plana (50) e é mostrado na fig. 58(a), onde o resultado é dado como função do cap layer d (a linha vertical é um guia de olho para a energia do QD).
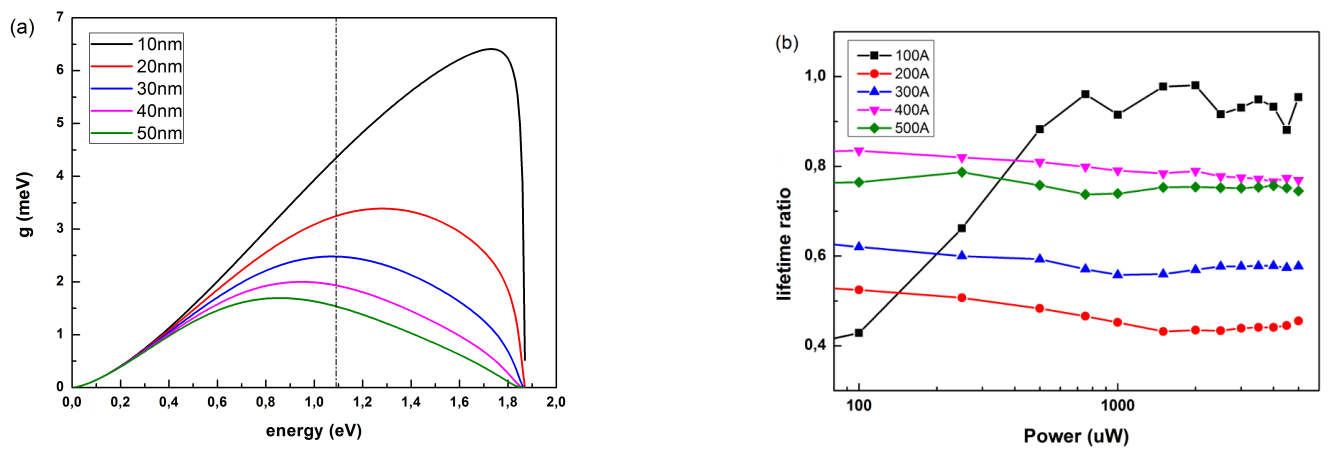

Figura 58 - (a) Fator de acoplamento do SPP como função da energia do QD e da espessura do cap layer. A linha vertical é um guia para o olho indicando a energia do QD em nosso experimento. (b) Razão entre o tempo de vida do estado fundamental do QD na região com Au e sem Au. As linhas conectando os pontos experimentais foram colocadas como guia de olho.

Fonte: Elaborada pelo autor.

A competição entre os mecanismos de acoplamento com SPPs e com os estados de superfície é mais evidente na amostra com $d=10 \mathrm{~nm}$. Contudo, nas amostras com cap layer maior a relaxação dos éxcitons não depende tanto da interação com os estados de superfície da amostra. Para estas amostras, observamos que a razão entre os tempos de vida nas regiões com e sem o filme de Au, conforme mostrado na fig. 58(b), se aproxima de um valor constante.

Estes resultados são mais uma evidência de que os SPPs apresentam grande importância no processo de recombinação dos éxcitons em QDs. Este efeito é mais pronunciado na amostra com $d=20 \mathrm{~nm}$ que na amostra com $d=50 \mathrm{~nm}$, assim como se espera devido à característica do campo eletromagnético dos SPPs decair exponencialmente à medida que nos afastamos da interface entre os meios e mostrada na fig. 58(a) através do decréscimo do fator de acoplamento. 



\section{Conclusão}

O modelo teórico, desenvolvido para investigar possíveis não linearidades na dispersão dos plásmons de superfície introduzidas pela interação com uma cadeia linear de pontos quânticos, resultou na obtenção da resposta dinâmica $\chi_{\beta}(\omega)$ expressa na eq. 71 .

Essa susceptibilidade dinâmica indica que medidas das frequências de ressonância para um nanofio metálico com fator de qualidade grande o suficiente, de forma que o tempo de vida dos plásmons seja o suficiente para que haja interação, podem indicar a repulsão de níveis no sistema SPP-QD. Essa repulsão de níveis é a assinatura do forte acoplamento que existe entre os plásmons no nanofio metálico e os éxcitons na cadeia de QDs. A possibilidade de atingir o regime de forte acoplamento experimentalmente é reforçada pelos resultados de medidas de PL utilizando plásmons localizados como mostram as figs. 44 e 50.

Além disso, o modelo de bandas plasmônicas desenvolvido aqui é essencialmente diferente daqueles discutidos na literatura (102), onde as bandas surgem dos padrões com os quais as estruturas plasmônicas são fabricados. Aqui, o modelo introduz a existência de bandas de energia dos plásmons induzidas pela presença da cadeia de QDs.

Do ponto de vista experimental, mostramos que a produção de grades plasmônicas sobre amostras de QDs ainda permite proteger a atividade óptica dos mesmos desde que respeitados alguns parâmetros de fabricação. Dessa forma, foi possível demonstrar que a modificação dos estados locais de luz nas proximidades de uma estrutura plasmônica altera o espectro de emissão de QDs.

Nesse ponto, mostramos que os estados de mais alta energia dos éxcitons em QDs interagem mais fortemente com o campo dos SPPs devido a efeitos mesoscópicos, i.e. os momentos de quadrupolo e superiores interagem mais fortemente com o campo dos SPPs que penetra fortemente em algumas camadas atômicas (onde os éxcitons estão confinados). Foi visto ainda que numa mesma estrutura plasmônica é possível selecionar diferentes estados de energia do éxciton, devido ao diferente acoplamento dos SPPs com a luz. Este tipo de efeito pode ser explorado para aplicações em dispositivos ópticos, além 
de produzir uma nova plataforma para a investigação de níveis de energia mais altos em éxcitons semicondutores. Um artigo com estes resultados está disponível no ArXiv. (109)

Ainda com relação às grades plasmônicas, observamos um shift de energia no pico correspondente aos estados de mais baixa energia dos éxcitons. Esse resultado, devido ao maior tempo de vida desses estados, demonstra que apesar do baixo fator de qualidade dessas cavidades (que possuem altas perdas) ainda é possível observar características quânticas nesse tipo de sistema. Isso indica que, apesar de não possuir altos fatores de qualidade como em cavidades fotônicas, efeitos de não lineridade em estruturas plasmônicas as tornam candidatas a gerar novas fases de luz fortemente correlacionadas, como um isolante de Mott (115), representando um bom caminho para futuras investigações.

Visto que a presença de SPPs é capaz de alterar a forma como cada estado de um QD interage com o ambiente, demonstramos experimentalmente, utilizando uma montagem bastante simples, que ocorre ainda uma alteração no tempo de vida dos éxcitons mesmo quando os SPPs não estão localizados. Este resultado foi publicado recentemente. (116) Como foi visto, o tempo de vida dos estados dos SPPs pode ser manipulado alterando-se a camada de buffer sobre a camada de QDs, isso abre a possibilidade do desenvolvimento de novos dispositivos, haja vista que a montagem do experimento é bastante simples.

Tendo em mente que um trabalho científico jamais se deve ser encarado como concluído e visando a possibilidade de ramificação deste em trabalhos futuros, listamos a seguir algumas das perspectivas:

- Interação com fônons da rede: conforme foi visto, uma das maneiras que utilizamos para verificar que a rede cristalina pode ser protegida no processo de fabricação das nanoestruturas é investigando o espectro Raman das mesmas após a fabricação. Isto só foi possível porque os SPPs também interagem com os fônons da rede. Há ainda pouca literatura sobre este tipo de interação.

- Propriedades de pontos quânticos pré-padronizados: durante o período da tese várias geometrias de distribuição de QDs foram analisadas. Uma delas empregava a pré-padronização dos substratos semicondutores para o posterior crescimento de QDs em posições bem definidas através de máscaras aplicadas sobre a superfície 
semicondutora. As propriedades dos QDs nestes tipos de estruturas ainda são alvo de investigação devido à modificação na forma de confinamento dos éxcitons.

- As medidas apresentadas nesta tese foram realizadas a baixas temperaturas, onde ainda há a formação do éxciton. Alguns estudos também mostraram que a dependência do espectro de PL dos QDs assim como comportamento do tempo de vida dos éxcitons em função da temperatura é alterado pela presença de SPPs. Apesar de ainda não serem dados conclusivos, algumas ideias pertinentes a esse assunto estão apresentadas no apêndice 1.

- SPPs em fendas simples: alguns resultados foram obtidos utilizando fendas simples ao invés de grades metálicas. O que foi observado é que há modificações drásticas no espectro de luminescência dos QDs próximos a essas estruturas. A análise dos dados ainda não foi concluída, mas eles têm grande potencial para ser objeto de estudos em curto prazo. Alguns destes dados estão apresentados no apêndice 2.

Em suma, do ponto de vista técnico e didático, este trabalho serviu de base para a caracterização de sistemas presentes em nossos laboratórios com vistas a experimentos futuros e do ponto de vista científico ele contribuiu para o entendimento do processo de interação de SPPs com éxcitons em semicondutores e como as propriedades dos éxcitons são alteradas nestes processos. 



\section{Referências}

1 JOHNSON, P. B.; CHRISTY, R. W. Optical constants of the noble metals. Physical Review B, v. 6, n. 12, p. 4370-4379, Dec. 1972.

2 ATWATER, H. A. The promise of plasmonics. Scientific American, v. 296, n. 4, p. 56-63, Apr. 2007.

3 OZBAY, E. Plasmonics: merging photonics and electronics at nanoscale dimensions. Science, v. 311, n. 5758, p. 189-93, Jan. 2006.

4 RAETHER, H. Surface plasmons on smooth and rough surfaces and on gratings. Heidelberg: Springer Berlin Heidelberg, 1988. ISBN 978-3-540-47441-8.

5 NOVOTNY, L.; HAFNER, C. Light propagation in a cylindrical waveguide with a complex, metallic, dielectric function. Physical Review E, v. 50, n. 5, p. 4094-4106, Nov. 1994.

6 BRONGERSMA, M. L.; SHALAEV, V. M. The case for plasmonics. Science, v. 328, n. 5799, p. 440-441, Apr. 2010.

7 ASHCROFT, N. W.; MERMIN, N. D. Solid state physics. Philadelphia: Saunders College, 1976. ISBN 978-0-12-803413-2.

8 BARCHIESI, D. Lycurgus cup: inverse problem using photographs for characterization of matter. Journal of the Optical Society of America A, v. 32, n. 8, p. 1544-1555, Aug. 2015.

9 DYAB, W. M. G. A study for the propagation of electromagnetic waves over imperfect ground planes based on Schelkunoff integrals. 2014. 179 p. Ph. D. Thesis (Doctor of Philosophy in Electrical and Computer Engineering) - Graduate School of Syracuse University, Syracuse University, Syracuse, 2014.

10 SOMMERFELD, A. Electrodynamics. New York, N.Y.: Academic Press, 1952. ISBN 9781483214290.

11 EBBESEN, T. W. et al. Extraordinary optical transmission through sub-wavelength hole arrays. Nature, v. 391, n. 6, p. 667-669, Feb. 1997.

12 BETHE, H. A. Theory of diffraction by small holes. Physical Review, v. 66, n. 7-8, p. 163-182, Oct. 1944.

13 GRAMOTNEV, D. K.; BOZHEVOLNYI, S. I. Plasmonics beyond the diffraction limit. Nature Photonics, v. 4, n. 2, p. 83-91, Jan. 2010.

14 MAIER, S. A. et al. Plasmonics - A route to nanoscale optical devices. Advanced Materials, v. 13, n. 19, p. 1501-1505, Oct. 2001.

15 GULlans, M. et al. Nanoplasmonic lattices for ultracold atoms. Physical Review Letters, v. 109, n. 23, p. 235309, Dec. 2012.

16 WIEDERRECHT, G. P. Handbook of nanofabrication. New York, N.Y.: Academic Press, 2009. ISBN 9780123751775. 
17 YAO, N. Focused ion beam systems. Cambridge: Cambridge University Press, 2007. ISBN 9780521831994.

18 YAO, K.; LIU, Y. Plasmonic metamaterials. Nanotechnology Reviews, v. 3, n. 2, p. 177-210, Jan. 2014.

19 CHANG, D. E. et al. Quantum optics with surface plasmons. Physical Review Letters, v. 97, n. 5, p. 053002, Aug. 2006.

20 TAME, M. S. et al. Quantum plasmonics. Nature Physics, v. 9, n. 6, p. 329-340, Jan. 2013.

21 WALther, H. et al. Cavity quantum electrodynamics. Reports on Progress in Physics, v. 69, n. 5, p. 1325-1382, May 2006.

22 ARAKAWA, Y. et al. Cavity quantum electrodynamics and lasing oscillation in single quantum dot-photonic crystal nanocavity coupled systems. IEEE Journal of Selected Topics in Quantum Electronics, v. 18, n. 6, p. 1818-1829, Nov. 2012.

23 D'ENTERRIA, D.; SILVEIRA, G. G. D. Observing light-by-light scattering at the large hadron collider. Physical Review Letters, v. 111, n. 8, p. 080405, Aug. 2013.

24 CHIAO, R. Y. Bogoliubov dispersion relation for a "photon fluid": is this a superfluid? Optics Communications, v. 179, n. 4, p. 157-166, May 2000.

25 CAZAlilla, M. A. et al. One dimensional bosons: from condensed matter systems to ultracold gases. Reviews of Modern Physics, v. 83, n. 4, p. 1405-1466, Dec. 2011.

26 CARUsotTo, I.; CIUTI, C. Quantum fluids of light. Reviews of Modern Physics, v. 85, n. 1, p. 299-366, Feb. 2013.

27 BARNES, W. L.; DEREUX, A.; EBBESEN, T. W. Surface plasmon subwavelength optics. Nature, v. 424, n. 6950, p. 824-30, Aug. 2003.

28 CHITRA, R.; ZILBERBERG, O. Dynamical many-body phases of the parametrically driven dissipative dicke model. Physical Review A, v. 92, n. 2, p. 023815, Aug. 2015.

29 KHATAB, A. et al. Photoluminescence intensity enhancement in self-assembled inas quantum dots grown on (311)b and (100) gaas substrates and coated with gold nanoparticles. Physica E: low-dimensional systems and nanostructures, v. 54, n. 6, p. 233-236, July 2013.

30 AKIMOV, A. V. et al. Generation of single optical plasmons in metallic nanowires coupled to quantum dots. Nature, v. 450, n. 7168, p. 402-6, Nov. 2007.

31 FEDUTIK, Y. et al. Exciton-plasmon-photon conversion in plasmonic nanostructures. Physical Review Letters, v. 99, n. 13, p. 136802, Sept. 2007.

32 VASA, P. et al. Coherent exciton-surface-plasmon-polariton interaction in hybrid metal-semiconductor nanostructures. Physical Review Letters, v. 101, n. 11, p. 116801, Sept. 2008.

33 PURCELl, E. M.; TORREY, H. C.; POUND, R. V. Resonance absorption by nuclear magnetic moments in a solid. Physical Review, v. 69, n. 1, p. 37-38, Jan. 1946. 
34 MAHMOUD, M. A. et al. Effect of the dielectric constant of the surrounding medium and the substrate on the surface plasmon resonance spectrum and sensitivity factors of highly symmetric systems: Silver nanocubes. Journal of the American Chemical Society, v. 134, n. 14, p. 6434-6442, Mar. 2012.

35 KURYOZ, Y.; POPERENKO, L. V.; KRAVETS, V. G. Correlation between dielectric constants and enhancement of surface plasmon resonances for thin gold films. Physica Status Solidi A, v. 210, n. 11, p. 2445-2455, Aug. 2013.

36 BLAKEMORE, J. S. Solid state physics. Cambridge: Cambridge University Press, 1985. ISBN 978-0521313919.

37 ZIMAN, J. M. Principles of the theory of solids. London: Cambridge University Press, 1964. ISBN 978-0521297332.

38 KITTEL, C. Introduction to solid state physics. New York: John Wiley \& Sons, Inc., 1986. ISBN 978-0-471-41526-8.

39 ZORIC, I. et al. Gold, platinum, and aluminum nanodisk plasmons: Material independence, subradiance, and damping mechanisms. ACS Nano, v. 5, n. 4, p. 2535-2546, Mar. 2011.

40 CAPPELlini, G. et al. Model dielectric function for semiconductors. Physical Review B, v. 47, n. 15, p. 9892-9895, Apr. 1993.

41 SAMARA, G. A. Temperature and pressure dependences of the dielectric constants of semiconductors. Physical Review B, v. 27, n. 6, p. 3494-3505, Mar. 1983.

42 MAIER, S. A. Plasmonics: fundamentals and applications. New York: Springer, 2007. ISBN 978-0-387-37825-1.

43 JACKSON, J. D. Classical electrodynamics. New York: Wiley, 1998. ISBN 978-0471309321.

44 SANCHEZ, A. M. et al. Nanometer-scale strain measurements in semiconductors: an innovative approach using the plasmon peak in electron energy loss spectra. Applied Physics Letters, v. 88, n. 5, p. 051917, Feb. 2006.

45 GORDON, R.; BROLO, A. G. Increased cut-off wavelength for a subwavelength hole in a real metal. Optics Express, v. 13, n. 6, p. 1933-1938, Mar. 2005.

46 YABLONOVITCH, E. Photonic band-gap structures. Journal of the Optical Society of America B, v. 10, n. 2, p. 283-295, Feb. 1993.

47 FANG, Z. et al. Plasmonic coupling of bow tie antennas with Ag nanowire. Nano Letters, v. 11, n. 4, p. 1676-80, Apr. 2011.

48 DORFMÜLLER, J. et al. Plasmonic nanowire antennas: experiment, simulation, and theory. Nano Letters, v. 10, n. 9, p. 3596-603, Aug. 2010.

49 PFEIFFER, C. A.; ECONOMOU, E. N.; NGAI, K. L. Surface polaritons in a circularly cylindrical interface: surface plasmons. Physical Review B, v. 10, n. 8, p. 3038-3051, Oct. 1974. 
50 MORENO, E. et al. Channel plasmon-polaritons: modal shape, dispersion, and losses. Optics Letters, v. 31, n. 23, p. 3447-9, Dec. 2006.

51 SCUlLY, M. O.; ZUBAIRY, M. S. Quantum optics. Cambridge: Cambridge University Press, 1997. ISBN 978-0524235959.

52 WALlS, D. F.; MILBURN, G. J. Quantum optics. Heidelberg: Springer, 2010. ISBN 3642066763.

53 DITLBACHER, H. et al. Silver nanowires as surface plasmon resonators. Physical Review Letters, v. 95, n. 25, p. 257403, Dec. 2005.

54 FERNANDEZ-DOMINGUEZ, A. I. et al. Spoof surface plasmon polariton modes propagating along periodically corrugated wires. IEEE Journal of Selected Topics in Quantum Electronics, v. 14, n. 6, p. 1515-1521, Nov. 2008.

55 HUTTNER, B.; BAUMBERG, J. J.; BARnETT, S. M. Canonical quantization of light in a linear dielectric. Europhysics Letters, v. 16, n. 2, p. 177-182, Sept. 1991.

56 HUTTNER, B.; BARNETT, S. M. Dispersion and loss in a hopfield dielectric. Europhysics Letters, v. 18, n. 6, p. 487-492, Mar. 1992.

57 Q Quantization of the electromagnetic field in dielectrics. Physical Review A, v. 46, n. 7, p. 4306-4322, Oct. 1992.

58 GARDINER, C.; ZOLLER, P. Quantum noise. Stuttgart: Springer, 2010. ISBN 978-3540223016.

59 SUKHAREV, M.; NITZAN, A. Numerical studies of the interaction of an atomic sample with the electromagnetic field in two dimensions. Physical Review A, v. 84, n. 4, p. 043802, Oct. 2011.

60 MOCK, J. J. et al. Shape effects in plasmon resonance of individual colloidal silver nanoparticles. Journal of Chemical Physics, v. 116, n. 2, p. 6755, Apr. 2002.

61 LU, X. et al. Shape effects in plasmon resonance of individual colloidal silver nanoparticles. Annual Review of Physical Chemistry, v. 60, n. 1, p. 167-92, Oct. 2008.

62 YAO, N.; WANG, Z. L. Handbook of microscopy for nanotechnology. New York: Springer, 2005. ISBN 1402080034.

63 PETRYAYEVA, E.; KRULL, U. J. Localized surface plasmon resonance: nanostructures, bioassays and biosensing-a review. Analytica Chimica Acta, v. 706, n. 1, p. 8-24, Nov. 2011.

64 CONSTANT, T. J. Optical excitation of surface plasmon polaritons on novel bigratings. 2013. 152 p. Ph. D. Thesis (Doctor of Philosophy in Physics) - School of Physics, University of Exeter, Exeter, 2013.

65 SHEN, J.; FAN, S. Coherent single photon transport in a one-dimensional waveguide coupled with superconducting quantum bits. Physical Review Letters, v. 95, n. 21, p. 213001, Nov. 2005. 
66 JACCARINI, A. et al. $\gamma \gamma$ collisions with almost real photons. Lettere al Nuovo Cimento (1969-1970), v. 4, n. 20, p. 933-937, Dec. 1970.

67 GORNIACZYK, H. et al. Single-photon transistor mediated by interstate rydberg interactions. Physical Review Letters, v. 113, n. 5, p. 053601, July 2014.

68 FIRSTENBERG, O. et al. Attractive photons in a quantum nonlinear medium. Nature, v. 502, n. 7469, p. 71-75, Oct. 2013.

69 KNOESTER, J.; MUKAMEL, S. Intermolecular forces, spontaneous emission, and superradiance in a dielectric medium: polariton-mediated interactions. Physical Review A, v. 40, n. 12, p. 7065-7080, Dec. 1989.

70 RIVERA, V. A. G.; MESSADDEQ, Y.; MAREGA, E. Photon-plasmon coupling from rare-earth ions and localized surface plasmon. Journal of Nanomedicine \& Nanotechnology, v. 6, n. 3, p. 283, Mar. 2015.

71 RIVERA, V. A. G.; FERRI, F. A.; MAREGA, E. Localized surface plasmon resonances: noble metal nanoparticle interaction with rare-earth ions. In: KIM, K. Y. (Ed.). Plasmonics. Rijeka: Intech, 2012. p. 157-182.

72 RIVERA, V. A. G. et al. Efficient plasmonic coupling between $\mathrm{er}^{3+}:(\mathrm{Ag} / \mathrm{Au})$ in tellurite glasses. Journal of Non-Crystalline Solids, v. 358, n. 2, p. 399-405, Jan. 2012.

73 GONG, Y. et al. Enhanced light emission from erbium doped silicon nitride in plasmonic metal-insulator-metal structures. Optics Express, v. 17, n. 23, p. 20642-20650, Nov. 2009.

74 GHOSHAL, S. K. et al. Gold nanoparticles stimulated surface plasmon resonance effects in erbium-zinc-sodium-tellurite glass. Main Tendencies in Applied Materials Science, v. 846, n. 5, p. 52-57, Apr. 2016.

75 CORN, T. R. Optical and luminescence properties of Erbium, Yterbium and Terbium doped in Aluminum Nitride. 2010. 49 p. Master (Master of Science) - Department of Physics and Astronomy, Ball State University, Muncie, 2010.

76 SAGLAMYUREK, E. et al. Quantum storage of entangled telecom-wavelength photons in an erbium-doped optical fibre. Nature Photonics, v. 9, n. 1, p. 83-87, Nov. 2015 .

77 GRANDIDIER, J. et al. Gain-assisted propagation in a plasmonic waveguide at telecom wavelength. Nano Letters, v. 9, n. 8, p. 2935-2939, July 2009.

78 FARROW, R. F. C. Molecular beam epitaxy. New Jersey: Elsevier Science, 2012. ISBN 978-0-8155-1371-1.

79 ROESCU, R. M. Wavefunctions and carrier-carrier interactions in InAs quantum dots studied by capacitance-voltage spectroscopy. 2009. $\mathrm{Ph}$. D. Thesis (Doctor in Physical Sciences) - Faculty of Physics and Astronomy, Ruhr University Bochum, Bochum, 2009.

80 YOFFE, A. D. Semiconductor quantum dots and related systems: electronic, optical, luminescence and related properties of low dimensional systems. Advances in Physics, v. 50, n. 1, p. 1-208, Jan. 2001. 
81 SCHEDELBECK, G. et al. Coupled quantum dots fabricated by cleaved edge overgrowth: from artificial atoms to molecules. Science, v. 278, n. 5344, p. 1792-1795, Dec. 1997.

82 PFEIFFER, L. et al. Cleaved edge overgrowth for quantum wire fabrication. Journal of Crystal Growth, v. 127, n. 4, p. 849-857, Feb. 1993.

83 KISELEV, A. A.; RÖSSLER, U. Towards optimization of T-shaped quantum structures. Semiconductor Science and Technology, v. 11, n. 2, p. 203-206, Feb. 1996.

84 GRUNDMANN, M.; BIMBERG, D. Formation of quantum dots in twofold cleaved edge overgrowth. Physical Review B, v. 55, n. 7, p. 4054-4056, Feb. 1997.

85 SCHUSTER, R. et al. Optical properties of low-dimensional semiconductor systems fabricated by cleaved edge overgrowth. Physica Status Solidi C, v. 1, n. 8, p. 2028-2055, July 2004.

86 UCCELLI, E. et al. Growth mechanisms of self-assembled InAs quantum dots on (110) AlAs/GaAs cleaved facets. Superlattices and Microstructures, v. 44, n. 4, p. 425-430, Oct. 2008.

87 ITSKEVICH, I. E. et al. Excited states and selection rules in self-assembled InAs/GaAs quantum dots. Physical Review B, v. 60, n. 4, p. R2185-R2188, July 1999.

88 EAR, S.; JHE, W.; ARAKAWA, Y. Near-field optical photoluminescence microscopy of high-density InAs/GaAs single quantum dots. Applied Physics Letters, v. 80, n. 15, p. 2779, Apr. 2002.

89 JIN, P.; YE, X. L.; WANG, Z. G. Growth of low-density InAs/GaAs quantum dots on a substrate with an intentional temperature gradient by molecular beam epitaxy.

Nanotechnology, v. 16, n. 12, p. 2775-2778, Dec. 2005.

90 JIN, P. et al. Quantum-confined Stark effect and built-in dipole moment in self-assembled InAs/GaAs quantum dots. Applied Physics Letters, v. 85, n. 14, p. 2791 , Oct. 2004.

91 ELISEEV, P. G. et al. Transition dipole moment of InAs/InGaAs quantum dots from experiments on ultralow-threshold laser diodes. Applied Physics Letters, v. 77, n. 2, p. 262, May 2000.

92 DIZHUIJZEN, C. E. V. Dipole-dipole interaction between cold Rydbergh atoms. 2009. 137 p. Ph. D. Thesis (Doctor in Sciences) - Faculty of Mathematics and Computer Science, Universit of Amsterdam, Amsterdam, 2009.

93 ABUWAAR, Z. Y. et al. In situ photoluminescence study of uncapped inas/gaas quantum dots. Nanotechnology, v. 19, n. 33, p. 335712, July 2008.

94 WANG, X. D.; NIU, Z.; FENG, S. Influence of $\operatorname{in}_{x}$ ga $_{1-x}$ as $(0 \leq x \leq 0.3)$ cap layer on structural and optical properties of self-assembled inas/gaas quantum dots. Japanese Journal of Applied Physics, v. 39, n. 9, p. 5076, May 2000.

95 MAZUR, Y. I. et al. Mechanisms of interdot coupling in (in,ga)as /gaas quantum dot arrays. Applied Physics Letters, v. 94, n. 12, p. 123112, Mar. 2009. 
96 GONZÁLEZ-TUDELA, A. et al. Theory of strong coupling between quantum emitters and propagating surface plasmons. Physical Review Letters, v. 110, n. 12, p. 126801, Mar. 2013.

97 MAHAN, G. D. Many-particle physics. New York: Springer, 2000. ISBN 0306463385 .

98 GRUDININ, I. S.; ILCHENKO, V. S.; MALEKI, L. Ultrahigh optical q factors of crystalline resonators in the linear regime. Physical Review A, v. 74, n. 6, p. 063806, Dec. 2006.

99 LIU, T.-L. Plasmonic cavities for enhanced spotaneous emission. 2013. $151 \mathrm{p}$. $\mathrm{Ph}$. D. Thesis (Doctor of Philosophy in Engineering Sciences) - School of Engineering and Applied Sciences, Harvard University, Cambridge, 2013.

100 KWON, S.-H.; SHIN, N. Y.; PARK, H.-G. Design of plasmonic cavities. Nano Convergence, v. 1, n. 8, p. 1-9, Mar. 2014.

101 YABLONOVITCH, E. Photonic crystals: semiconductors of light. Scientific American, v. 285, n. 6, p. 47-55, Dec. 2001.

102 FENG, L. et al. Plasmonic photonic crystal with a complete band gap for surface plasmon polariton waves. Applied Physics Letters, v. 93, n. 23, p. 231105, Dec. 2008.

103 KAZIMIERCZUKA, T. et al. Interdot coupling in a self-assembled quantum dot system. Acta Physica Polonica A, v. 112, n. 2, p. 321-324, Mar. 2007.

104 LIPPARINI, E. Modern many-particle physics. Singapore: World Scientific Publishing Company, 2008. ISBN 978-981-270-931-8.

105 HUHN, C.; WONDRACZEK, L.; SIERKA, M. Dynamics of ultrathin gold layers on vitreous silica probed by density functional theory. Physical Chemistry Chemical Physics, v. 17, n. 41, p. 27488-27495, Sept. 2015.

106 WEINER, J. Phase shifts and interference in surface plasmon polariton waves. Optics Express, v. 16, n. 2, p. 950-956, Jan. 2008.

107 LIN, C. et al. Surface plasmon-enhanced and quenched twophoton excited fluorescence. Optics Express, v. 18, n. 12, p. 12807-12817, June 2010.

108 ANDERSEN, M. L. et al. Strongly modified plasmon-matter interaction with mesoscopic quantum emitters. Nature Physics, v. 7, n. 3, p. 215-218, Dec. 2011.

109 SOBREIRA, F. W. A. et al. Probing inas quantum dot states with surface plasmon polaritons. Disponível em: < http://arxiv.org/pdf/1511.03978.pdf >. Acesso em: 24 set. 2016.

110 POH, C. H. et al. Fdtd modeling to enhance the performance of an organic solar cell embedded with gold nanoparticles. Optical Materials Express, v. 1, n. 7, p. 1326-1331, Sept. 2011.

111 TIGHINEANU, P. Electric and magnetic interaction between quantum dots and light. 2015. 178 p. Ph. D. Thesis (Doctor of Philosophy) - Niels Bohr Institute, University of Copenhagen, Copenhagen, 2015. 
112 TANNOUDJI, C. Quantum mechanics. Paris: Wiley, 1977. ISBN 04711633X.

113 ZULOAGA, J.; NORDLANDER, P. On the energy shift between near-field and far-field peak intensities in localized plasmon systems. Nano Letters, v. 11, n. 3, p. 1280-1283, Feb. 2011.

114 DING, T. et al. Controllable tuning plasmonic coupling with nanoscale oxidation. ACS Nano, v. 9, n. 6, p. 6110-6118, May 2015.

115 HARTMANN, M. J.; PLENIO, M. B. Strong photon nonlinearities and photonic Mott insulators. Physical Review Letters, v. 99, n. 10, p. 103601, Sept. 2007.

116 SOBREIRA, F. W. A. et al. Probing semiconductor confined excitons decay into surface plasmon-polaritons. Applied Physics A, v. 122, n. 4, p. 385-1-385-6, Apr. 2016. 
Apêndices 



\section{Apêndice A - Medidas em função da temperatura}

Ao estudar a dispersão dos SPPs ou sua interação com os éxcitons confinados em QDs, desconsideramos quaisquer efeitos de temperatura que possam influenciar nos sistemas. Em geral, isso se trata de uma boa aproximação quando levamos em conta que as medidas realizadas em semicondutores são a baixas temperaturas $(\lesssim 70 \mathrm{~K})$, região na qual ainda há a formação do éxciton, i.e. a ligação entre o elétron livre e o buraco criados na região do QD através de interações de Coulomb.

No entanto, quando são realizadas medidas com temperaturas mais altas $(\gtrsim 110 \mathrm{~K})$ não há mais a formação de éxcitons, pois a energia térmica fornecida aos portadores de carga é o suficiente para superar o potencial Coulombiano que mantêm elétron e buraco unidos.

Isso pode ser visto numa curva típica de tempo de vida de uma excitação no QD como função da temperatura. A fig. 59 mostra uma curva desse tipo para a amostra de uma camada de QDs que está a 10nm da superfície do GaAs e cujo espectro de PL a 7K está mostrado na fig. 24(a).

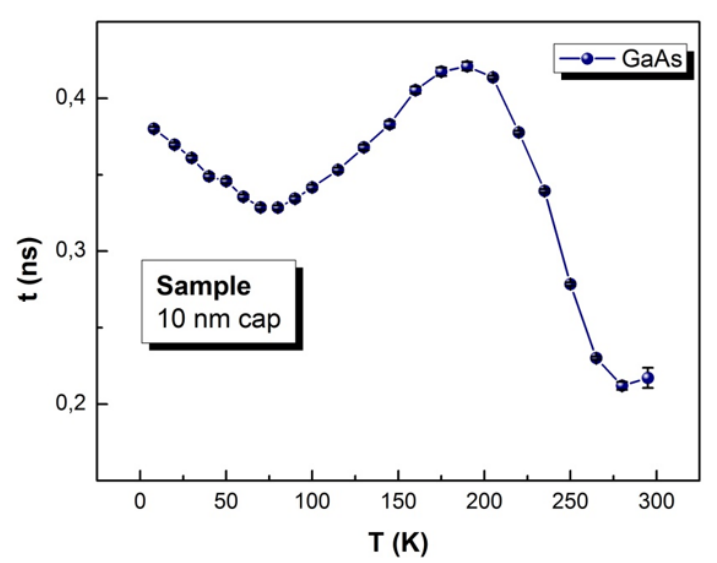

Figura 59 - Tempo de vida como função da temperatura medida para fótons coletados com energia de $1,1 \mathrm{eV}$, típico da recombinação do éxciton na amostra de QD com 10nm de cap layer, cujo espectro de PL está mostrado na fig. 24(a).

Fonte: Elaborada pelo autor.

Como pode ser observado, em torno de $75 \mathrm{~K}$ o tempo de vida correspondente aos estados com $1,1 \mathrm{eV}$ começa a aumentar. O que acontece é que medidas de tempo de vida são baseadas numa comparação entre a defasagem dos feixes de prova de entrada e de saída. Dessa forma, o que se obtêm é o tempo que um elétron com energia de $1,1 \mathrm{eV}$ levou 
para se recombinar com o buraco, i.e. os fótons de $1,1 \mathrm{eV}$ resultantes dessa recombinação típica.

A explicação para o aumento no tempo de vida desse estado é que na realidade o elétron a altas temperaturas não forma mais um éxciton e fica mais tempo em estados de energia mais altos comportados pelo QD, veja a fig. 22(a). Quando ele volta a passar pelo estado fundamental sua probabilidade de recombinação com um buraco aumenta, esse processo gera então um fóton que é capturado pelo sistema de detecção.

Acima de $170 \mathrm{~K}$ o elétron tem energia suficiente para popular estados da wetting layer e do contínuo, a intensidade do sinal de tempo de vida cai, ou seja, outros mecanismos se tornam mais importantes no processo de relaxação dos elétrons. A queda do tempo de vida ocorre principalmente porque apenas os elétrons "mais rápidos", i.e. os mais próximos da energia de recombinação, são detectados e o tempo de vida diminui. Essa explicação é coerente com a diminuição abrupta que se observa para os fótons coletados nessa região dos espectros, indicando a baixa probabilidade de ocorrência desse processo.

Para investigar como os SPPs poderiam alterar o tempo de vida desses estados, foram realizadas medidas de tempo de vida para o estado fundamental do éxciton (em torno de $1,1 \mathrm{eV})$ para as mesmas amostras na qual fizemos medidas de tempo de vida, veja a seção 5.2. Como os éxcitons nos QDs com 10nm de cap layer apresentam baixos valores de tempo de vida mesmo sem a presença dos SPPs, à medida que a temperatura do sistema era modificada não foi possível medir os tempos de vida correspondentes para os éxcitons. Por esse motivo, apenas os resultados correspondentes às amostras com cap layers de $d=20,30,50 \mathrm{~nm}$ são apresentados nas fig. 60.

Como pode ser observado na fig. 60 a presença da camada de Au sobre a camada de QDs produz alguns efeitos caracterísiticos:

- Diminuição da temperatura onde ocorre o valor máximo do tempo de vida dos estados do éxciton.

- Aumento no tempo de vida máximo para o estado fundamental. Note que para a amostra de 20nm apesar de possuir aproximadamente o mesmo valor, a variação no tempo de vida do éxciton, com relação ao seu valor em baixas temperaturas, é 
maior que na amostra sem o filme de Au.

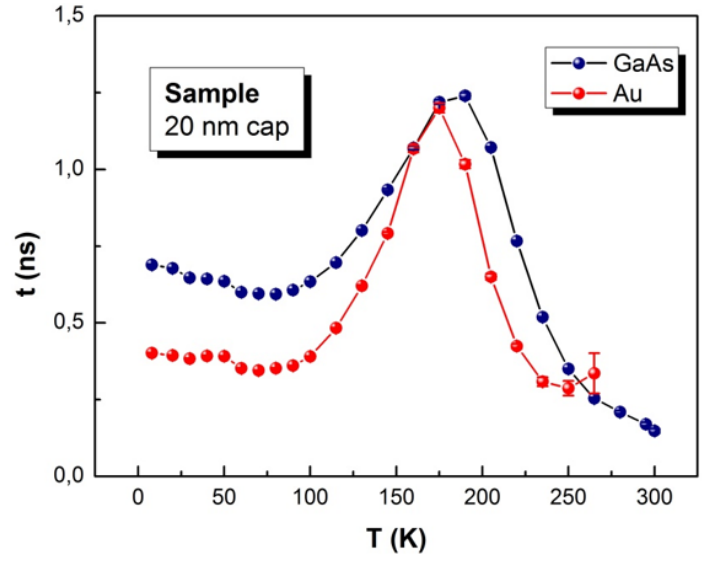

(a) Amostra com 20nm de cap layer.

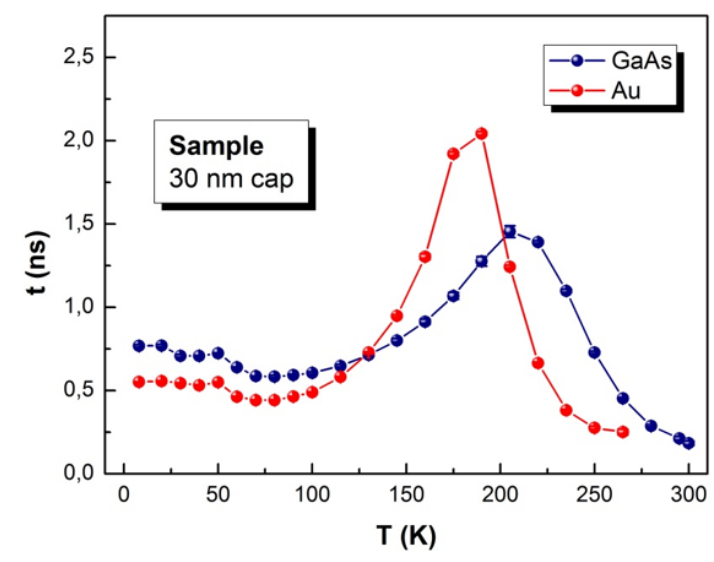

(b) Amostra com 30nm de cap layer.

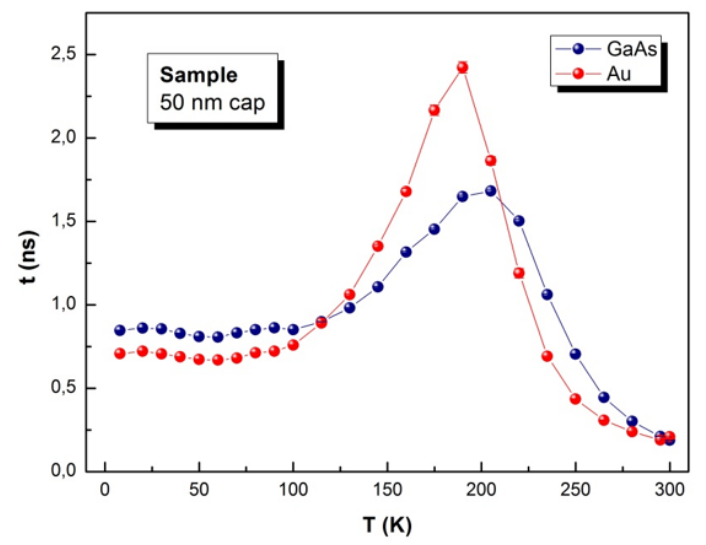

(c) Amostra com 50nm de cap layer.

Figura 60 - Medidas de tempo de vida como função da temperatura para o estado fundamental dos éxcitons confinados num QD de InAs/GaAs, em torno de 1, 1eV. Cada figura indica um valor diferente de cap layer. O esquema experimental utilizado é o mesmo adotado para medidas de tempo de vida a baixas temperaturas e está indicado na fig. 54 .

Fonte: Elaborada pelo autor.

Pode-se observar ainda que os efeitos mencionados não diminuem diretamente com o valor do cap layer, assim como ocorre com a diminuição do tempo de vida a baixas temperaturas. O que se observa é que ele é maior na amostra com 30nm de cap layer que nas amostras com $20 \mathrm{~nm}$ e $50 \mathrm{~nm}$. O deslocamento para baixo da temperatura onde o tempo de vida possui um máximo e o seu valor máximo deve possuir algum tipo de relação.

Como o efeito dos SPPs tende a diminuir à medida que o valor do cap layer aumenta, devido ao campo evanescente dos plásmons, não é de se esperar que esse efeito de temperatura observado seja devido exclusivamente à presença de SPPs no filme metálico. 
Para entender melhor o que deve estar ocorrendo devemos lembrar ainda que para interagir com os SPPs o éxciton deve estar formado, i.e. o nosso fator de acoplamento levou em conta a dinâmica que existe no processo de recombinação do par elétron-buraco. A temperaturas mais altas o elétron não ocupa mais os estados de energia correspondentes ao estado fundamental do éxciton e só se recombina quando está no estado "correto", isso ocorre com mais baixa probabilidade.

O elétron fica praticamente livre dentro do QD, mas sua função de onda ainda fica localizada praticamente toda dentro do mesmo. Como isso faz com que o tempo de vida do elétron aumente, os efeitos de indução de carga no filme metálico devem produzir alguma modificação apreciável.

As cargas imagem induzidas no metal devem produzir um potencial que compete com o dos SPPs a temperaturas mais altas. Como tanto o elétron quanto o buraco devem induzir cargas no metal, o potencial sentido pelo elétron deve ser o tipo de dipolo $\left(\sim 1 / r^{2}\right)$. Devido à rápida dinâmica dos elétrons nas proximidades do filme metálico o potencial gerado pelos SPPs, que cai exponencialmente $\left(\sim-e^{-r / \lambda}\right)$, deve ser o potencial dominante para pequenos valores de cap layer.

Um hipótese é que o potencial sentido pelo elétron seja do tipo

$$
V(r)=\frac{g_{d i p}}{r^{2}}-g_{s p p} e^{-r / \lambda}
$$

onde indicamos os fatores de acoplamento por dipolos induzidos na superfície metálica $\left(g_{d i p}\right)$ e o fator de acoplamento com os SPPs $\left(g_{\text {spp }}\right)$ que possui um comprimento caracterísitico $\lambda$. A competição entre esses dois potenciais está indicada na fig. 61 .

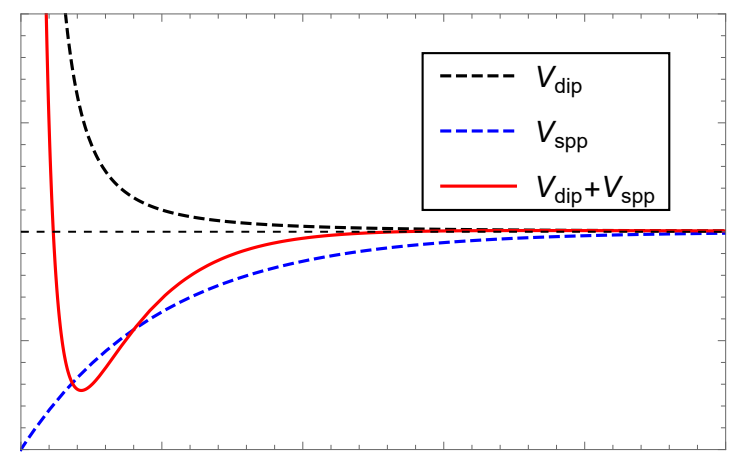

Figura 61 - Diagrama da competição entre o potencial de dipolo e o potencial gerado pelos SPPs interagindo com os elétrons no QD.

Fonte: Elaborada pelo autor. 
O termo de dipolo deve ser mais intenso para baixas frequências (potencial estático), i.e. para o elétron livre, por este motivo ele só se apresenta após a dissociação do éxciton a altas temperaturas. Observe que esse termo não modifica a temperatura de dissociação do éxciton, que se matém aproximadamente igual com e sem a presença do filme de Au.

Para finalizar, o termo de dipolo contribui para uma energia do elétron $\varepsilon_{\text {dip }}$ que quando somada à energia térmica do mesmo produz um deslocamento do pico com maior tempo de vida, o que explica o deslocamento observado nas medidas.

Apesar de ainda não estarem concluídas, as análises aqui apresentadas indicam que o comportamento da dinâmica dos elétrons em QDs ainda é alterada pela presença de SPPs mesmo em temperaturas finitas. Isso mostra que muito ainda há para ser feito nessa área. 



\section{Apêndice B - SPPs numa fenda metálica simples}

Conforme foi visto na seção 4.6, os modos de SPPs suportados por grades metálicas com diferentes valores de período são capazes de interagir de maneira diferente com cada nível do éxciton confinado no QD.

Uma pergunta plausível que pode ser feita nesse tipo de sistema é se o campo do SPP é mais importante no processo de excitação ou no processo de decaimento de éxciton.

Quando se trata do processo de excitação, é possível que os altos campos do SPP sejam responsáveis por uma saturação local do estado fundamental do éxciton e isso dê origem a um espectro de PL contendo níveis excitados.

No entanto, se os SPPs participam com mais efetividade no processo de decaimento dos éxcitons, após o pulso de luz os éxcitons se formam e a partir daí que a dinâmica de interação SPP-QD irá dominar população de estados excitados. Essa é uma outra explicação para a modificação do espectro de PL na presença de estruturas metálicas.

Com o mesmo intuito de mostrar que os efeitos apresentados durante a tese não se tratam apenas de um efeito de saturação local dos QDs, um outro conjunto de medidas foi realizado.

Nesse caso uma amostra com uma camada simples de QDs de InAs/GaAs foi excitada através de uma única fenda fabricada sobre um filme metálico de Au com 120nm de espessura.

Os modos de SPPs suportados pela fenda metálica dependem fortemente do comprimento da mesma. Por esse motivo, foram realizadas medidas de PL com fendas de diferentes comprimentos $(L=10,5,2,1 \mu \mathrm{m})$ e com mesma largura $w=100 \mathrm{~nm}$. As medidas foram realizadas num sistema de microPL com a amostra mantida a 70K. O diâmetro do feixe laser utilizado foi de $2 \mu \mathrm{m}$.

Como se pode observar na fig. 62, à medida que o valor do comprimento $L$ da fenda metálica muda, o estado excitado dos éxcitons no QD aparece mais ou menos pronunciado. Observe, por exemplo, que para a fenda com $L=2 \mu \mathrm{m}$ a razão entre os picos dos estados fundamental e primeiro excitado é praticamente a mesma e na fenda com $L=1 \mu \mathrm{m}$ 
o estado excitado praticamente não aparece, mesmo quando comparado com fendas de comprimentos maiores.

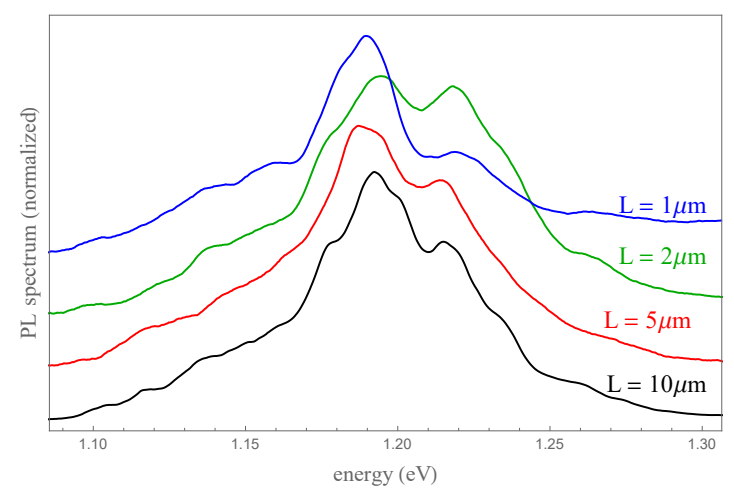

Figura 62 - Espectro de PL para uma camada de QDs a 50nm de distância de uma fenda simples fabricada num filme metálico. O comprimento $L$ da fenda está indicado. Os gráficos apresentados estão normalizados e deslocados verticalmente para facilitar a visualização.

Fonte: Elaborada pelo autor.

As medidas realizadas com essas amostras ainda precisam de uma análise mais minuciosa, por exemplo estudando como o espectro se comporta quando a distância entre os QDs e a superfície do metal muda, já que os resultados apresentados na fig. 62 são para uma distância fixa.

Além disso, à medida que as dimensões da fenda se tornam cada vez menores, quando apenas modos localizados de SPPs são suportados pelas estruturas, esses modos devem ser cada vez mais dependendes da geometria das fendas (retangular, circular etc), o que não foi levado em consideração nessa abordagem, onde apensas fendas retangulares foram empregadas. 